\title{
Intuition or logic in pathological anxiety : belief bias threat-confirmation bias and hemisphere preference
}

Citation for published version (APA):

Smeets, A. A. C. M. (2005). Intuition or logic in pathological anxiety : belief bias threat-confirmation bias and hemisphere preference. [Doctoral Thesis, Maastricht University]. Datawyse / Universitaire Pers Maastricht. https://doi.org/10.26481/dis.20051123as

Document status and date:

Published: 01/01/2005

DOI:

10.26481/dis.20051123as

Document Version:

Publisher's PDF, also known as Version of record

\section{Please check the document version of this publication:}

- A submitted manuscript is the version of the article upon submission and before peer-review. There can be important differences between the submitted version and the official published version of record.

People interested in the research are advised to contact the author for the final version of the publication, or visit the DOI to the publisher's website.

- The final author version and the galley proof are versions of the publication after peer review.

- The final published version features the final layout of the paper including the volume, issue and page numbers.

Link to publication

\footnotetext{
General rights rights.

- You may freely distribute the URL identifying the publication in the public portal. please follow below link for the End User Agreement:

www.umlib.nl/taverne-license

Take down policy

If you believe that this document breaches copyright please contact us at:

repository@maastrichtuniversity.nl

providing details and we will investigate your claim.
}

Copyright and moral rights for the publications made accessible in the public portal are retained by the authors and/or other copyright owners and it is a condition of accessing publications that users recognise and abide by the legal requirements associated with these

- Users may download and print one copy of any publication from the public portal for the purpose of private study or research.

- You may not further distribute the material or use it for any profit-making activity or commercial gain

If the publication is distributed under the terms of Article $25 \mathrm{fa}$ of the Dutch Copyright Act, indicated by the "Taverne" license above, 
INTUITION OR LOGIC IN PATHOLOGICAL ANXIETY:

BELIEF BIAS

THREAT-CONFIRMATION BIAS

AND HEMISPHERE PREFERENCE 
ISBN: 9073838517

C A.A.C.M. Smeets, Rotterdam 2005

Productie: F\&N Boekservice / Eigen Beheer 


\title{
INTUITION OR LOGIC IN PATHOLOGICAL ANXIETY: BELIEF BIAS
}

\author{
THREAT-CONFIRMATION BIAS
}

\section{AND HEMISPHERE PREFERENCE}

PROEFSCHRIFT

Ter verkrijging van de graad van doctor aan de Universiteit Maastricht, op gezag van de Rector Magnificus, Prof. Mr. G.P.M.F. Mols, volgens het besluit van het College van Decanen, in het openbaar te verdedigen op woensdag 23 november 2005 om 16.00 uur

door

Augustinus Antonius Catharina Maria Smeets 


\section{PROMOTORES}

Prof.dr. P.J. de Jong, Rijksuniversiteit Groningen

Prof.dr. M.A. van den Hout, Universiteit Utrecht

\section{BEOORDELINGSCOMMISSIE}

Prof.dr. A. Arntz (voorzitter)

Prof.dr. M. Kindt (Universiteit van Amsterdam)

Prof.dr. W. Schaeken (Universiteit Leuven, België)

Prof.dr. H. Schmidt (Erasmus Universiteit Rotterdam)

Dr. R. Wiers 


\section{CONTENTS}

CHAPTER 1 Introduction: goal-directed reasoning and righthemisphere reliance in anxiety disorders

CHAPTER 2 Belief bias and symptoms of psychopathology

CHAPTER 3 Confirmatory reasoning in panic disorder and obsessive-compulsive disorder

CHAPTER 4 Better safe than sorry: reasoning with conditionals in the context of threat

CHAPTER 5 "If you suffer from a headache, then you have a brain tumour": domain-specific reasoning 'bias' and hypochondriasis

CHAPTER 6 Panic disorder and right-hemisphere reliance

CHAPTER 7 Summary and conclusions

DANKWOORD 
$4.9+4$

$\cdots+4$ 


\section{CHAPTER 1}

\section{INTRODUCTION: \\ GOAL-DIRECTED REASONING AND \\ RIGHT-HEMISPHERE RELIANCE IN ANXIETY DISORDERS}

Adapted and translated from: Smeets, G. (1999). Als een moedervlek jeukt dan is het huidkanker: Doelrationaliteit en de instandhouding van irrationele angst. De Psycholoog, 34, 554-559*

\footnotetext{
"This article was awarded the "Publicatieprijs voor aankomende auteurs 1999", by the Dutch professional association of psychologists (Nederlands Instituut wan Psychologen, NIP)
} 


\section{UCTIVE REASONING AND ANXIETY}

ogical research has shown that people generally do not tive abilities for the purpose of logical reasoning, but rather e personal goals. Everyday rationality is goal-oriented and nt logical errors. These logical errors might explain why the of anxiety patients show such persistence, despite the fact atastrophe never materialises.

\section{Everyday reasoning errors: an example}

make regular use of e-mail will be familiar with them: eou about a new computer virus. The message often follows 'If you receive an e-mail with a certain title, don't open it! sontain a very dangerous computer virus, for which no cure ret.' At the end of the message you are asked to pass the nany people as possible. Of course you readily do so, as you sct your esteemed colleagues as well as your family and danger.

lething remarkable is happening here, something you have been aware of, for you accept unquestioningly that the id the danger is real. "Better safe than sorry", you may think, $h$ the question whether the message is in fact that safe. Those elves to making viruses are only too aware that people tend ings seriously. The best way to spread a virus is therefore to gainst a virus, with the request to pass the message on to as ossible.

; another interesting aspect to your credulity: you will never 2 warning was correct. When you receive an e-mail with the en warned against (if ever you do), you will obviously not 
open it. Just imagine, an unknown virus in the $\mathrm{PC}_{\text {, }}$ with all possible consequences. Your decision not to open the e-mail has a clear goal, namely avoiding the dangerous virus, but also an effect, which is that your opinion about the virus cannot be disproved, as this can only be done by opening the e-mail. This way a possibly unfounded belief may persist without reason. The persistence of particularly dysfunctional cognitions, such as the phobic beliefs of anxiety patients, could be explained in the same way. They believe and attach importance to their conviction and therefore they avoid the situations they are so afraid of, which in turn causes their unfounded belief to persist. This issue will be discussed in greater depth in this thesis.

\section{Rationality: theory and practice}

Piaget argues that our ability for formal-operational thinking begins at the age of fifteen (Piaget, 1972). From this age we are able to reason, we are aware of logic and we can verify hypotheses by thinking; we are able to make mental representations with new information and arrive at logical conclusions by a process of deduction; and we are even able to represent information that goes against objective reality and draw conclusions on the basis of fabrications or patent lies that despite everything fulfil the requirements of formal logic. This ability makes us by far the most intelligent species on earth. Formaloperational thinking is reserved to humanity and has been very beneficial to mankind so far: it forms the basis of philosophy and therefore the basis of science as a whole. Where would we be without our ratio?

Although this may be an attractive theory, our everyday practice tells a different story. Observation of human behaviour has taught us that in everyday life we do anything but act on logical rationality. Errors in assessing situations and in our reasoning are the order of the day; all of us fall victim to them, we let ourselves be taken for a ride by our own cognitive illusions. We misjudge our chances and logic is often miles away in our reasoning (see for 
instance: Palmarini, 1996). Despite all this, we generally function very well. There is usually sufficient time and opportunity to correct our behaviour and review our decisions. Yet one can imagine situations in which one wrong decision can have catastrophic results. Particularly in risky situations the importance of the right decision is paramount: just think of a surgeon during an operation, a judge who has to pass sentence on a defendant, or simply an everyday traffic situation.

That mistakes in our judgement do occur at times when important decisions must be taken is illustrated by research published in the prominent journal The New England Journal of Medicine by McNeil, Pauker, Sox and Tversky in 1982. One of the things the researchers did was presenting the effects of a particular treatment for lung cancer to a large group of doctors. It should be noted that this concerns a group of highly educated people who have to take decisions on the pros and cons of certain treatments on a daily basis. When the effects of the treatment were presented in terms of a chance of survival of $93 \%$ after five years, the doctors were much more inclined to recommend the treatment to their patients than when they were told that the chance of the patient dying within five years after the treatment was $7 \%$. A significant conclusion from this research is that when assessing chances the doctors allow themselves to be distracted by the perspective in which those chances are presented. When doctors are confronted with the risks of a treatment they take another stance than when they focus on the positive effects of a treatment. Apparently the fear for a possible fatal effect of the treatment leads doctors to a preference for another treatment. It is quite clear that this involves a logical error on their part: a chance of survival of $93 \%$ simply corresponds to a $7 \%$ chance of dying; a glass that is half-full is at the same time half-empty. Nevertheless, many people understand this logical error: there is a clear chance of dying as a result of the treatment. There is a real danger, and as the consequences are so far-reaching, a chance of $7 \%$ 
'feels' like a substantial risk. Our logic apparently gets clouded the moment we become aware of an existing risk. In such a case we prefer to aim for safety and try to avoid danger. Although the views we adopt in such situations are not always very rational, they usually are effective for achieving our goal, which is to avoid real dangers.

The question why people make errors in their judgement and reasoning, despite the fact that they are at the same time perfectly capable of logical reasoning, becomes particularly relevant when errors in reasoning lead to systematic dysfunctionall and maladjusted behaviour, such as in case of people who suffer from a psychological disorder. A group of people for whom the threat that is felt in specific situations is by definition in no proportion to the real, objective danger, are anxiety patients. Cognitive-psychological research has demonstrated that people who suffer from anxiety disorders display dominant danger schemas in specific content domains (e.g., Clark, 1986; Beck, Emery \& Greenberg, 1985; Clark \& Wells, 1995). These danger schemas are dysfunctional in nature: they do not correspond to objective reality and they lead to maladjusted behaviour and negative emotions. Panic patients, for instance, are convinced that palpitations and chest pains are clear indications of an imminent heart attack and obsessive-compulsive patients feel that not carrying out their compulsive actions will bring misfortune upon them (APA, 1994). The anxious beliefs of anxiety patients are irrational, but despite a profusion of disconfirming information from the outside world they stubbornly persist. Despite surviving dozens of panic attacks the panic patient remains convinced that the next attack of palpitations and dizziness will be fatal. Given the fact that the dreaded catastrophe never takes place, the question arises why, after some time, these patients do not see that their belief is mistaken. 


\section{Chapter 1}

\section{Objective}

So far a number of explanations for the persistence of the irrational cognitions of anxiety patients have been put forward that are based on disturbed information handling processes among phobics. At first, these explanations focused on disturbed perception and attention processes. Tomarken, Mineka and Cook (1989), for instance, argue that phobics overestimate the correlation between a phobogenic stimulus and an aversive event, which causes the phobic conviction to persist (i.e., "covariation bias"; see too: De Jong, Van Den Hout \& Merckelbach, 1995). In addition, Lavy, Van den Hout and Arntz (1993), among others, demonstrated that phobics selectively directed their attention towards threatening information (i.e., "attentional bias', Lavy et al., 1993). However, despite the fact that these phenomena can be very helpful in explaining why anxiety patients are so afraid, they do not offer a clear explanation for the lack of response to disconfirming information among anxiety patients.

One of the hypotheses tested in this dissertation is that invalid deductive reasoning strategies may be one of the factors that are responsible for the persistence of irrational fear. This view is based in particular on the finding that disconfirmation of the irrational cognitions of anxiety patients results in a reduction in fear. Disconfirmation lies at the heart of cognitive behaviour therapy, which is by far the most effective treatment of phobic fear (Clark \& Fairburn, 1997). During the therapy, the patient, with the help of a therapist and by means of empirical verification, learns to understand that his or her belief is mistaken and needs to be modified. This observation led to the hypothesis that anxiety patients make errors in the reasoning process when they go through the "empirical cycle' independently, which causes disconfirming information not to be processed or to be processed incorrectly. As a result, invalid conclusions are drawn and invalid beliefs are not modified. 
The present dissertation focuses globally on two kinds of reasoning errors that might contribute to the persistence of irrational fear in this way, namely 'belief bias' and 'confirmation bias'. Both reasoning errors and the paradigms to measure these phenomena will be clarified below.

\section{Belief bias}

In order to verify certain views one has to be able to infer the logical implications of new information. However, people frequently make the mistake of allowing the subjective believability of the information to lead them in this process. In cognitive psychology this logical error in their reasoning is known as belief bias (Evans, Over \& Manktelow, 1993; Newstead, Pollard, Evans \& Allen, 1992). Belief bias refers to people's tendency to judge believable information as logically valid and unbelievable information as invalid, irrespective of the actual logical status of such information (e.g., Evans, Barston \& Pollard, 1983; Revlin, Leirer, Yopp \& Yopp, 1980). In anxiety patients such a confirmative reasoning pattern could result in persistence of the phobic fear, as invalid views on reality are not falsified (De Jong et al., 1997b).

One of the ways to establish belief bias is by applying linear syllogisms (see for instance: Evans, Newstead \& Byrne, 1993). A syllogism consists of two premises and a conclusion. The subject has to consider whether the conclusion follows logically from the two premises, without taking into account the subjective believability or the level of reality of the premises and the conclusion. An example may illustrate this. Just imagine you are given the following two premises:

I. A baby is older than a toddler

II. A toddler is older than an adult

And the conclusion:

C. A baby is older than an adult 


\section{Chapter 1}

The conclusion is logically valid, as it follows logically from the two premises. Yet at the same time the conclusion is not believable. Systematic manipulation of the logical validity and the believability of the conclusion results in four possibilities (see too Table 1):

1. the conclusion is believable and valid

2. the conclusion is believable but not valid

3 . the conclusion is not believable yet valid

4. the conclusion is not believable and not valid

Belief bias occurs when a subject makes more mistakes or needs comparatively more time for his or her judgement of conclusions of type (2) and (3) than for his or her judgement of conclusions of type (1) and (4) (Sternberg, 1980).

Table 1. Examples of syllogisms with conclusions that vary in terms of believability and logical validity

\begin{tabular}{|c|c|c|c|c|}
\hline & & Believable & & Nor believable \\
\hline Valid: & So: & $\begin{array}{l}\text { An adult is older than a toddler } \\
\text { A toddler is older than a baby } \\
\text { Alt adult is older than a baby (1) }\end{array}$ & So: & $\begin{array}{l}\text { A baby is older than a toddler } \\
A \text { toddler is older than an adult } \\
\text { A baby is older than an adult ( } 3 \text { ) }\end{array}$ \\
\hline Inwalld: & So: & $\begin{array}{l}\text { A baby is older than a toddler } \\
\text { A toddler is older than an adult } \\
\text { An adult is older than a baby (2) }\end{array}$ & So: & $\begin{array}{l}\text { An adult is older than a toddler } \\
\text { A toddler is older than a baby } \\
\text { A baby is older than an adult (4) }\end{array}$ \\
\hline
\end{tabular}

Research conducted by De Jong et al. (1997b) led to the conclusion that both spider-phobics and normals show belief bias. This previous study used linear syllogisms referring to general domains (see for instance Table 1) and phobiaspecific domains (for instance (I) A spider is more dangerous than a fish. (II) A fish is more dangerous than a fly. (C) A spider is more dangerous than a fly). Although a certain level of belief bias could be observed both in normals and spider-phobics, the latter group displayed a much stronger inclination to judge believable conclusions as logically valid - and unbelievable conclusions 
as not valid. A remarkable finding was, that the increased belief bias of spider-phobics not only occurred when phobia-specific syllogisms were used, but spider-phobics also demonstrated an increased belief bias on syllogisms that were unrelated to the phobia, such as the ones listed in the table above. The finding that this group of anxiety patients demonstrated an increased general reasoning bias, suggests a predisposition and not just an effect or a symptom of the phobia. Apparently spider-phobics have greater difficulty than normals with giving up views they once adopted after receiving information that conflicts with those views. This could be a premorbid vulnerability factor that prevents them from reconsidering phobogenic beliefs. Chapter 2 describes a study which explores the tenability of the idea that a general tendency to confirm rather than to falsify personal beliefs (i.e., belief bias) is responsible for the general refractoriness of dysfunctional convictions that play a role in psychopathology. Chapter 3 describes a study that was designed to explore the role of belief bias in the maintenance of patients' anxiety complaints. We tested whether panic disordered and obsessive-compulsive patients are characterized by a relatively enhanced belief bias, and whether this bias would be restricted to the domain of concern, or would reflect a more general cognitive characteristic exerting its influence in anxiety irrelevant domains as well. Furthermore, we tested whether belief bias is related to psychopathological complaints and whether belief bias could predict treatment outcome and relapse.

\section{Threat-confirmation bias}

A second error in reasoning that may contribute to the persistence of irrational fear is threat-confirmation bias. In general, confirmation bias refers to people's tendency to selectively search for information that confirms the views they hold. The phobogenic beliefs of anxiety patients can often be reduced to conditional assumptions of the type "If $P$ then $Q$ ", with a certain 
signal (P) being the predictor of a catastrophic outcome (Q). For instance: "If $I$ feel a palpitation, it signifies an imminent heart attack", "If I blush, people will find me incompetent" or "If a brown mole is itching it is skin cancer" (e.g., Hawton, Salkovskis, Kirk \& Clark, 1989). Such assumptions have two logical implications. The rule about the mole, for instance, implies on the one hand that someone whose mole is itching must therefore have skin cancer ( $P$, therefore Q). In jargon this is called modus ponens. Yet, at the same time the rule implies that someone who does not have skin cancer may therefore not have an itching molle either (not-Q, therefore not-P); in jargon this is called modus tollens. According to Aristotelian logic the only correct way to verify the validity of the rule is by looking for potentially falsifying cases (Popper, 1959). This means that one should check whether there are eases of $P$ and not$Q$ (i.e., are there people who do have an itching mole but who nevertheless do not have skin cancer). If this criterion is met, it demonstrates that the rule is invalid and therefore the believability of the rule is reduced. Applying an illogical strategy (i.e., selectively looking for potentially verifying cases but not for potentially falsifying cases) can only contribute to the believability of dysfunctional assumptions and therefore to the persistence of irrational fear.

A suitable instrument for identifying this confirmation bias is the Wason selection task (WST; Wason, 1968). For this task the subject is given four cards and a conditional rule relating to the cards. Each card represents one incidental case, with one side of the card giving information about the antecedent (i.e., does $\mathrm{P}$ apply or does not-P apply) and the other side of the card containing information about the consequent of this specific case (does $Q$ apply or does not-Q apply). Only one side of each card is visible. The task of the subject is to decide which card(s) he or she absolutely needs to turn over to see whether the rule applies to these four cases or not. An example of a modified WST may demonstrate this. 
Box 1. Example of a modified Wason selection task (WST)

Imagine you are staying for a few days with an eldetly woman who lives in a forest. The elderly woman lives largely from nature. She often uses plants and fruits that she picks in the forest for her cooking. Today she is planning to make mushroom soup and she has asked you to pick mushrooms in the forest. You are of course terrified about any poisonous mushrooms ending up in the soup. It could cost you and the elderly woman your lives. In order for you to distinguish between the poisonous and edible mushrooms the elderly woman gives you the following rule:

\section{"If a mushroom has a brown stalk it is poisonous"}

To be on the safe side, you decide to investigate the matter of the mushrooms further. You visit a biologist who is renowned for his expertise regarding mushrooms. He takes you to his archive that contains a card catalogue of poisonous and non-poisonous mushrooms. On the one side of each card he has indicated whether a mushroom has a brown stalk or not and on the other side of the card whether the mushroom is poisonous or not. The biologist shows you the following four cards:
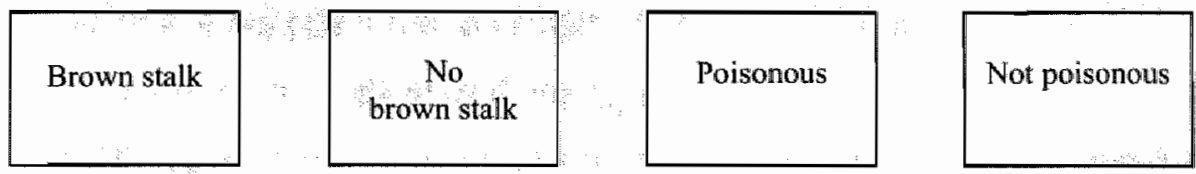

Question: Which card(s) do you absolutely need to turn over to check whether the rule of the elderly woman applies in these four cases?

The only logically correct strategy is the choice for the card 'brown stalk' to check whether this particular mushroom is indeed poisonous, and the card 'not poisonous' in order to check whether this mushroom does not have a brown stalk after all. Turning the other cards over is not necessary, for the rule does not say anything about mushrooms that do not have a brown stalk and neither does the rule exclude that a poisonous mushroom can have a stalk of a different colour.

In recent years it has become increasingly clear that people usually do not solve tasks such as the WST by following the rules of formal logic, but 


\section{Chapter 1}

that their choice of cards is specifie for certain domains and is determined by the subjective experience of the utility of the information presented on a card (e.g., Evans \& Over, 1996, Kirby, 1994; Manktelow \& Over, 1991). In a threat-related context the subjective importance of certain information strongly depends on the kind of rule, for in a context of threat either danger rules may apply, "If $P$ then danger", or safety rules, "If $P$ then safe". In threatening situations, information that signifies danger is of relatively much importance. It may be rather unpleasant to flee without cause but the consequences of making the mistake not to take a danger alert seriously on just one occasion may be much more catastrophic (one only needs to remind oneself of the example of the e-mail that potentially contained a virus). For this reason it would be unwise not to take danger alerts seriously. The opposite applies to safety rules. If one mistakenly trusts a safety rule once, this can have fatal consequences as well. A well-known example is the unguarded level crossing: if the white lights are flashing, you may well check to see whether there is indeed no train coming. In short, if we want to avoid injury we have to be alert for any information that signifies danger. Therefore we should be alert for information that confirms the danger in case of danger signals, and we should be alert for information that disproves the safety in case of safety signals. Note that verifying danger signals and falsifying safety signals is in fact a threat-confirming strategy. As said before, although it can be very useful to direct one's behaviour and information processing in this manner in case of objective danger, such a reasoning strategy could logically contribute to the persistence of irrational fear.

In an attempt to shed some light on the role of threat-confirming reasoning in the persistence of phobic fear, two lines of research employing the Wason selection task are described in Chapter 4 and Chapter 5. Chapter 4 describes three experiments in which the hypothesis is tested that reasoning in the domain of threat is goal oriented and guided by perceived utilities. More 
specifically, it is tested in Experiment 1 whether subjects relatively often select potentially verifying cards in the case of danger rules whereas they relatively often selected potentially falsifying cards in the case of safety rules. In Experiment 2 the robustness of this 'better safe than sorry strategy' is evaluated in the light of an alternative strategy that could have confounded the results of the first experiment. The third experiment explored the influence of perceived threat on the degree of danger-confirming reasoning.

Chapter 5 describes an experiment in which hypochondriacal patients and normal controls were presented with Wason selection tasks pertaining to general threats and health threats. It was tested whether threat-confirming reasoning was particularly pronounced in high anxious subjects (i.e., hypochondriacal patients) and whether this relatively strong reasoning bias was specific for the phobic domain.

\section{HEMISPHERICITY, COGNITIVE STYLES AND ANXIETY}

Reviewing the literature on psychopathology, one observes a historical dichotomization between psychological and neurobiological research lines. As McNally stated almost a decade ago, further progress in the science of the psychopathology of anxiety disorders may depend on the conjunction of neuroscience and experimental psychopathology (McNally, 1998). Yet, the relationship between cognitive and neurobiological abnormalities in anxiety disorders remains a relatively unexplored terrain.

Since the first split brain operations, a progression of labels have been used to describe the cognitive processes that are characteristic of the left hemisphere and the right hemisphere. Most researchers agree that the left hemisphere is involved in verbal, analytic and rational processes, whereas the right hemisphere sustains an imaginal, holistic and intuitive mode of information 
processing (e.g, Zenhausern, 1978; Casasanto, 2003). The idea that the two hemispheres are specialized for different modes of thought has led to the concept of hemisphericity. Hemisphericity refers to the idea that a given individual relies more on one hemisphere than the other. This differential utilization is presumed to be reflected in the individual's 'cognitive style' (e.g., Zenhausern, 1978). The idea that the left prefrontal cortex is involved in analytic and rational processes is supported by recent neuroimaging studies (i.e., PET; fMRI). Most pertinent in the context of the present thesis, it was recently found that both syllogistic reasoning and conditional reasoning specifically activate left frontal-temporal regions (Goel, Gold, Kapur \& Houle, 1997; Goel \& Dolan, 2004; Wagner, Maril, Bjork \& Schacter, 2001; Goel, Shuren, Sheesley \& Grafman, 2004; Noveck, Goel \& Smith, 2004).

Closely related to the concept of hemisphericity in terms of cognitive processes, is the idea that the left and the right cerebral hemisphere are differentially involved in the processing and regulation of emotions (e.g., Jackson, Mueller, Dolski, Dalton, Nitschke, Urry, Rosenkranz; Ryff, Singer \& Davidson, 2003). While the details are still a matter of some debate, there is growing evidence for the claim that left cortical areas are critically involved in approach behaviour and positive affect, whereas right cortical areas play a role in avoidance behaviour and negative affect (e.g., Davidson, 1992; Sutton \& Davidson, 1997; Jackson et al,, 2003). Accordingly, a relative hypoactivation of the left hemisphere and/or a hyperactivation of the right hemisphere would contribute to anxious feelings. Following this line of reasoning, several authors have proposed that certain anxiety symptoms may be related to a habitual right hemisphere overactivation (e.g., Heller, Etienne \& Miller, 1995). Chapter 6 describes a study in which panic patients are compared to normal controls with respect to hemisphere preference. The hypothesis is tested whether panic patients are characterized by an 
information processing style that points in the direetion of a relative right hemisphere overactivation.

\section{REFERENCES}

American Psychiatric Association (APA; 1994). Diagnostic and Statistical Manual of Mental Disorders. Fourth Edition (DSM-IV). Washington D.C.: APA.

Arntz, A. Rauner, M., \& Van Den Hout, M.A. (1995). "If I feel anxious, there must be danger": Ex-consequentia reasoning in inferring danger in anxiety disorders. Behaviour Research and Therapy, 33, 917-925.

Beck, A.T., Emery, G. \& Greenberg, R.L. (1985). Anxiety Disorders and Phobias: A Cognitive Perspective. New York: Basic Books.

Casasanto, D. (2003). Hemispheric specialization in prefrontal cortex: Effects of verbalizability, imageability and meaning. Journal of Neurolinguistics, 16, 361 -382 .

Clark, D.M. (1986). A cognitive approach to panic. Behaviour Research and Therapy, $24,461-470$.

Clark, M.D., \& Fairburn, C.G. (Eds.) (1997). Science and practice of cognitive behaviour therapy. Oxford: Oxford University Press.

Clark, D.M., \& Wells, A. (1995). A cognitive model of social phobia. In: Heimberg, R., Liebowitz, M.R., et al. (Eds.). Social Phobia: Diagnosis, Assessment and Treatment. New York: Guilford Press.

Cosmides, L. (1989). The logic of social exchange: Has natural selection shaped how humans reason? Studies with the Wason selection task. Cognition, 31, 187-276.

Davidson, R.J. (1992). Emotion and affective style: Hemispheric substrates. Psychological Science, 3, $39-43$

De Jong, P.J., Haenen, M-A., Schmidt, A. \& Mayer, B. (1998a). Hypochondriasis: The role of fear-confirming reasoning. Behaviour Research and Therapy. 36 , 65-74.

De Jong, P.J., Mayer, B., \& Van Den Hout, M.A. (1997a). Conditional reasoning and phobic fear: Evidence for a fear-confirming reasoning pattern. Behaviour Research and Therapy, 35, 507-516. 


\section{Chapter 1}

De Jong, P.J, Van Den Hout, M.A., \& Merckelbach, H. (1995). Covariation bias and the return of fear: Behaviour Research and Therapy, 33, 211-213.

De Jong, P.I, Weertman; A., Horselenberg, R., \& Van Den Hout, M.A. (1997b). Deductive reasoning and pathological anxiety: Evidence for a relatively strong 'belief bias' in phobic subjects. Cognitive Therapy and Research, 21, 647-662.

Evans, J.SLB.T., Barston, J.L., \& Pollard, P. (1983). On the conflict between logic and belief in syllogistic reasoning. Memory and Cognition, 1/(3), 295-306.

Evans, J.St.B.T., Newstead, S.E., \& Byme, R.M.J. (1993). Human reasoning: The psychology of deduction. Hove, UK: Psychology Press.

Evans, J.St.B.T., \& Over, D.E. (1996). Rationality in the selection task: epistemic utility versus uncertainty reduction. Psychological Review, $103,356-363$.

Evans, J.St.B.T, Over, D.E., \& Manktelow, K.I. (1993). Reasoning, decision making and rationality. Cognition, 49, 165-187.

Goel, V., \& Dolan, R.J. (2004). Differential involvement of left prefrontal cortex in inductive and deductive reasoning. Cognition, 93, B109-B121.

Goel, V., Gold, B., Kapur, S., \& Houle, S. (1997). The seats of reason: A localization study of deductive and inductive reasoning using PET (O15) blood flow technique. NeuroReport, 8, 1305-1310.

Goel, V., Shuren, J., Sheesley, L., \& Grafman, J. (2004). Asymmetrical involvement of frontal lobes in social reasoning. Brain, $127,783-790$.

Hawton, K., Salkovskis, P., Kirk, J., \& Clark, D. (1989). Cognitive therapy for psychiatric problems. Oxford: Oxford University Press:

Jackson, D.C., Mueller, C.J., Dolski, I., Dalton, K.M., Nitschke, J.B., Urry, H.L., Rosenkranz, C.D., Ryff, C.D., Singer, B.H., \& Davidson, R.J. (2003). Now you feel it, now you don"t: Frontal brain electrical asymmetry and individual differences in emotion regulation. Psychological Science, 14,612-617.

Kirby, K.N. (1994). Probabilities and utilities of fictional outcomes in Wason's fourcard selection task. Cognition, 51, 1-28.

Lavy, E., Van Den Hout, M.A., \& Arntz, A. (1993). Attentionall bias and facilitated escape: A pictoral test. Advances in Behaviour Research and Therapy, 15, 279 . 289. 
Manktelow, K.I., \& Over, D.E. (1991). Social roles and utilities in reasoning with deontic conditionals. Cognition, 39, 85-105.

McNally, R.J. (1998). Information-processing abnormalities in anxiety disorders: Implications for cognitive neuroscience. Cognition and Emotion, 12; 479-495.

McNeil, B.J., Pauker, S.G., Sox, H.C. \& Tversky, A. (1982). On the elicitation of preferences for alternative therapies. The New England Jounnal of Medicine, $306(21), 1259-1262$.

Newstead, S.E., Pollard, P., Evans, J.St.B.T., \& Allen, J. (1992). The source of belief bias in syllogistic reasoning. Cognition, 45, 257-284.

Noveck, I.A., Goel, V., \& Smith, K.W. (2004). The neural basis of conditional reasoning with arbitrary content. Cortex, 40, 613-622.

Palmarini, M.P. (1996). Onvermijdelijke illusies: Hoe beredeneringsfouten ons denken beheersen. Utrecht: Het Spectrum.

Piaget, J. (1972). Intellectual evolution from adolescence to adulthood. Human Development, 15(1), 1-12.

Popper, K.R. (1959). The logic of scientific discovery. London: Hutchinson

Revlin, R., Leirer, V., Yopp, H., \& Yopp, R. (1980). The belief-bias effect in formal reasoning: The influence of knowledge in logic. Memory and Cognition, $8(6)$, 584-592.

Smeets, G., De Jong, P.J., \& Mayer, B. (2000). If you suffer from a headache, then you have a brain tumour: Domain-specific reasoning 'bias' and hypochondriasis. Behaviour Research and Therapy, 38, 763 - 776.

Smeets, G., De Jong, P.J., \& Mayer, B. (2004). Better safe than sorry: Reasoning with conditionals in the context of threar. Submitted for publication.

Sutton, S. K., \& Davidson, R.J. (1997). Prefrontal brain asymmetry: A Biological substrate of the behavioral approach and inhibition systems. Psychological Science, 8, 204-210.

Sternberg, R.J. (1980). Representation and process in linear syllogistic reasoning. Journal of Experimental Psychology: General, 109, 119-159.

Tomarken, A.J., Mineka, S., \& Cook, M. (1989). Fear-relevant selective associations and covariation bias. Journal of Abnormal Psychology, 98, 381-394. 


\section{Chapter 1}

Wagner, A.D., Maril, A., Bjork, R.A., \& Schacter, D.L. (2001). Prefrontal contributions to executive control: fMRI evidence for functional distinctions within lateral prefrontal cortex. Newrolmage, $14,1337-1347$.

Wason, P.C. (1968). Reasoning about a rule. Quarterly Journal of Experimental Psychology, 20, 273-281. 


\section{CHAPTER 2}

\section{BELIEF BIAS AND SYMPTOMS OF PSYCHOPATHOLOGY}

Adapted from: Smeets, G. \& de Jong, P. J. (2005). Belief bias and symptoms of psychopathology in a non-clinical sample. Cognitive Therapy and Research, 29, 377-386. 


\begin{abstract}
This study explores the tenability of the idea that a general tendency to confirm rather than to falsify personal beliefs (i.e., belief bias) is responsible for the general refractoriness of dysfunctional convictions that play a role in psychopathology. Therefore, we investigated the relationship between a generally enhanced belief bias and the severity of self-reported psychopathological symptoms in a non-clinical sample. Participants $(n=200)$ solved a series of linear syllogisms concerning neutral themes (de Jong, Weertman, Horselenberg \& Van den Hout, 1997). They were asked to judge the syllogisms' logical validity, without taking the bellievability of the syllogisms into account. Participants performed relatively poor (i.e., more errors and longer response latencies) when there was a mismatch between the logical validity and believability of the syllogisms (belief bias). However, there was no linear association between the severity of the general belief bias and the severity of psychopathological complaints. Thus, the present study lends no support to the idea that a generally enhanced tendency to confirm rather than to falsify prior beliefs is a diathesis for the development of psychopathology.
\end{abstract}




\section{INTRODUCTION}

To explain the persistence of phobic fear, cognitive approaches focus on the role of dysfunctional beliefs in the generation of problematic appraisals that are typical for the anxiety disorders (McNally, 2001). The central viewpoint in these so called appraisal models is that dysfunctional beliefs provide the causal basis for various kinds of catastrophic misappraisals, for example in panic disorder (Clark, 1986), social-phobia (Clark \& Wells, 1995), obsessivecompulsive disorder (Salkovskis, 1999), generallized anxiety disorder (Wells \& Carter, 1999), and posttraumatic stress disorder (Ehlers \& Clark, 2000). According to these theories, due to an underlying dysfunctional belief, the person misinterprets a harmless stimulus as a harbinger of imminent catastrophe. For example, a panic patient who has the conviction that heart palpitations signify impending cardiac arrest, might get a panic attack merely by drawing the wrong conclusions when becoming aware of some harmless interoceptive cues (e.g., Clark, 1986). Treatment studies confirm the importance of beliefs in the generation of irrational fear by demonstrating that anxiety complaints disappear by taking the edge off the underlying belief (e.g., Arntz; 2003).

If beliefs, indeed, play such a prominent role in the aetiology of anxiety disorders, it is important to know what factors consolidate or weaken beliefs, and which mechanisms might play a role in causing the negative emotions. One important question that needs to be answered in this context, is why dysfunctional beliefs persist in the face of disconfirming evidence. Why do panic patients hold to the conviction that the next attack of palpitations and dizzyness will be fatal, despite many dozens of panic attacks that turned out to be harmless?

Recently, it has been proposed that common reasoning patterns might be one of the factors that play a role in the refractoriness of phobogenic 


\section{Chapter 2}

beliefs in the face of falsifying information (e.g., de Jong, Weertman, Horselenberg \& Van den Hout, 1997; de Jong, Haenen, Schmidt \& Mayer, 1998. Smeets, de Jong \& Mayer, 2000). One common reasoning pattern that may immunize against the refutation of dysfunctional beliefs is known as belief bias. Belief bias refers to the tendency to endorse information that is in line with the personal view of the world and to reject information that contrasts this view, irrespective of the informations' logical status (e.g., Evans, Over \& Manktelow, 1993; Newstead, Pollard, Evans \& Allen, 1992). Evans argued that in everyday life some degree of belief bias might be considered functional. Note in this respect that everyday reasoning serves individuals' decision making, which is aimed at the achievement of personal goals rather than of arriving at logically valid conclusions. For example, in potentially dangerous situations, when capacities are bounded and time is limited, it seems adaptive to rely on prior beliefs and act on plausible conclusions, rather than to pause and consider whether those conclusions meet the standards of formal logic. However, if the perceived threat is based on dysfunctional pathogenic convictions, the same strategy might become counterproductive. In that case, jumping to a conclusion would hinder the falsification of the underlying argument. In other words, belief bias logically immunizes against refutation of a (somehow acquired) phobogenic view.

Recent research provided evidence to suggest that belief bias might not only play a role in the maintenance of psychopathological complaints, but may also relate to the acquisition of such complaints. That is, it has been demonstrated that phobic individuals are characterized by a generally enhanced belief bias (de Jong et al., 1997). More specifically, phobic individuals were found to be characterized by an enhanced belief bias that was not restricted to the domain of their specific phobic concerns, but was also evident in the syllogisms concerning neutral themes (e.g., the size of trees compared to plants). The absence of domain-specifity of the enhanced belief 
bias raises the interesting possibility that belief bias reflects a trait-like information processing bias that acts as a diathesis in the development of the disorder. Note that a relatively strong belief bias will impede the correction of erroneous and potentially pathogenic convictions, which in turn may render people liable to pathological anxiety (cf. de Jong et al., 1997).

If belief bias, indeed, plays a role in the persistence of dysfunctional convictions in general, it would make people not only vulnerable for the acquisition of anxiety complaints but also for other types of psychopathology. In other words, the relationship between belief bias and psychopathology should not be restricted to anxiety complaints. In addition, if enhanced belief bias is indeed a causal agent and not the consequence of an invalidating disorder (e.g., anxiety disorders may promote a general sense of insecurity, and the use of confirmatory reasoning strategies may reflect a way to cope with uncertainty), the relationship between belief bias and psychopathological symptoms should also be evident in the preclinical range. Therefore, the present study tested whether in non-clinical subjects belief bias is associated with scores on some major self-report instruments in the area of psychopathology.

\section{Present Experiment}

In the last two decades, a vast number of studies have demonstrated that the influence of belief bias on syllogistic reasoning tasks is a robust phenomenon in human reasoning (see Evans, Newstead \& Byrne, 1993; chapter 8, for an overview). Typically, a syllogism consists of two propositions and a conclusion. In most studies concerning belief bias, categorical syllogisms were used, for example (Evans, Barston \& Pollard, 1983; Evans, Handley \& Harper, 2001):

No addictive things are inexpensive 


\section{Chapter 2}

Some cigarettes are inexpensive

Therefore, some addictive things are not eigarettes

As a rule, participants find categorical syllogisms very difficult to solve. Even highly educated subjects make many mistakes in judging the logical validity of categorical syllogisms (Evans et al., 1983). Since some patients may have limited educational experience, categorical syllogisms do not seem suitable for this group. Therefore, de Jong et al. (1997) explored whether belief bias effects could be found when using the more easy to solve linear syllogisms (e.g., An adult is older than an adolescent, an adolescent is older than a toddler; Therefore, an adolescent is older than a toddler). Indeed, the authors found strong effects of prior beliefs on reasoning performance in a group of normal subjects. The authors concluded that linear syllogisms seem suitable to index belief bias (de Jong et al., 1997; Experiment 1).

The reasoning task that was used in the present study was a computerized version of the task used by de Jong et al. (1997). The task consisted of four different linear syllogisms concerning neutral themes, referring to the age of toddlers, the size of houses etc.. For each of the syllogisms, there were four different types of which the conclusions systematically varied in logical validity and believability. Belief bias would be reflected by a relatively poor performance (i.e., many errors; long latencies) if the conclusions were in line with subjects' prior beliefs but logically invalid or when the conclusion was contrary to subjects' prior beliefs but logically valid. More specifically, belief bias would be reflected in an interaction effect between the believability and the logical validity of the syllogisms' conclusions. To the extent that belief bias does play a role in the aetiology of psychopathological complaints, the strength of this interaction effect should be positively correlated with the scores on self reported measures of psychopathological complaints. 


\section{METHOD}

\section{Participants}

A total of 200 undergraduate students (157 women) from the University of Maastricht participated in the present study. Participants received a small financial remuneration (Euro 5,-) for their participation. Mean age was 19.5 years (range $=18$ to 38 years; $S D=2.1$ ). Participants who indicated that they were familiar with syllogistic reasoning tasks, were excluded from participation.

\section{Reasoning task}

To index belief bias, the linear syllogistic reasoning task was programmed in MEL professional version $2.0 \mathrm{~d}$, for IBM-compatible computers (Schneider, 1989). The task was adapted from de Jong et al. (1997; Experiment 1) and consisted of four different linear syllogisms concerning neutral themes. For each of the four syllogisms, there were four different types of which the conclusions systematically varied in logical validity and believability. That is, for each of the 4 syllogisms, there were two versions with a conclusion in line with subjects' prior view of the world, one of which was logically valid (believable and valid; Type 1), and one of which was invalid (believable but invalid; Type 2). Furthermore, there were two versions with a conclusion opposite to the subjects" prior view of the world, again one of which was logiaclly valid (unbelievable but valid; Type 3 ), and one which was logically invalid (unbelievable and invalid; Type 4). To control for task recoding effects ${ }^{1}$, each syllogism was presented twice, once with the premises in the

\footnotetext{
' Standard order is $A>B, B>C \rightarrow A>C$. In this order, the first mentioned item ( $A$ ) is always bigger/ smaller/ faster efc. than the last mentioned item (C). If one is aware of this fact, one does not necessarily have to use deductive strategies to solve the syllogism.
} 
standard order (i.e, $\mathrm{A}>\mathrm{B}, \mathrm{B}>\mathrm{C}$ ) and once with the premises in reversed order (i.e., $B>C, A>B$ ). Thus, in total there was a pool of 4 X 4 X 2 (32) syllogisms. All subjects were exposed to the same set of 32 syllogisms. Syllogisms were presented in fixed random order. Specific examples of syllogism types are presented in Table 1. The program recorded the subjects' decisions (valid or invalid) as well as their response latencies (in milliseconds) on a trial by trial basis.

Table 1. Examples of syllogisms with conclusions varying in logical validity and believability

\begin{tabular}{|c|c|c|}
\hline & Believable conctusion & Nor believable conclusion \\
\hline \multirow{4}{*}{ Valid conolusion } & An adult is older than an adolescent & A toddler is older than an adolescent \\
\hline & An adolescent is older than a toddler & An adolescent is older than an adult \\
\hline & $\begin{array}{c}\text { C: An adwh is older than a toddler } \\
\text { (Type I) }\end{array}$ & $\begin{array}{c}\text { C: A woddler is older than an adult } \\
\text { (Type 3) }\end{array}$ \\
\hline & $\because \quad: \quad \cdots$ & \\
\hline & A toddler is older than an adolescent & An adult is older than an adolescent \\
\hline Invalid conclusion & $\begin{array}{l}\text { C: An adwh is older than a toddler" } \\
\text { (Type 2) }\end{array}$ & $\begin{array}{c}\text { C: A toddler is older than an adul" } \\
\text { (Type 4) }\end{array}$ \\
\hline
\end{tabular}

\section{Self reported measures of psychopathological complaints}

As a multi-dimensional index of psychopathological complaints the Symptom Checklist was administered (SCL-90; Derogatis, Lipman \& Covi, 1973; Arrindell \& Ettema, 1986). The SCL-90 is a 90 item self report questionnaire, which consists of the following subscales: Anxiety, Agoraphobia, Depression, Somatisation, Feelings of Insufficiency, Sensitivity, Hostility, Sleep. (alpha's of subscales $>0.72$; alpha of anxiety scale $=0.88$; alpha total score $>0.95$; Arrindell \& Ettema, 1986).

Self reported anxiety levels were measured using the State-Trait Anxiety Inventory, (STAl-trait; DY-2; Spielberger, Gorsuch \& Lushene, 1970; Van der Ploeg, Defares, \& Spielberger, 1980) and the Anxiety Sensitivity Index (ASI; Reiss, Peterson, Gursky \& McNally 1986). 


\section{Procedure}

Participants were tested in small groups ( $5-7$ persons). The participant was seated in front of a 14-inch monitor on which the syllogisms and the instructions were presented. Participants were instructed to decide as quickly as possible whether or not the conclusion was correct (i.e., logically valid). It was emphasized that they should not take the reality basis of the premises (i.e., believability), nor the correctness of the conclusions into account, but only to decide whether or not the given conclusion was logically valid given the two premises. Before the experiment proper, subjects received two example items to get familiarized with the reasoning task: one item with a conclusion that was believable and valid (i.e., A toddler is younger than an adolescent $\backslash$ An adolescent is younger than an adult $\| \mathrm{A}$ toddler is younger than an adult) and one one item with a conclusion that was unbelievable but valid (i.e., An adult is younger than an adolescent $\backslash$ An adolescent is younger than a toddler $\backslash$ An adult is younger than a toddler). After each example item, the subject was given feedback about the correctness of the decision, along with a standard explanation about the validity of the conclusion.

Preceding every single stimulus presentation the sentence "pay attention!' appeared on the screen to alert the subject for the next syllogism. By pushing the button 'valid' or 'invalid', the subject indicated wheter he or she considered the presented syllogism valid or not. Immediately after the subject had pushed one of the two buttons, the syllogism dissapeared from the screen. Every next stimulus presentation appeared after a 2000 milliseconds time interval. During the experiment, subjects did not receive feedback about their performance. 


\section{Chapter 2}

\section{Data reduction and analysis}

Reaction times were normalized using a square root transformation. To test the interaction effect between logical validity and believability of the syllogisms conclusions, the reaction time data as well as the number of logical errors were subjected to a 2 (believable / unbelievable) X 2 (valid / invalid) analysis of variance (ANOVA), both factors being within-subjects. In the analysis of reaction times, only correct answers were included.

Separate belief bias indices (BBI) were computed based on the reaction times (BBI ${ }_{\mathrm{RT}}$ ) and the number of logical errors (BBI ER). The following formula was used BBI ${ }_{R T}=($ Type $2+$ Type 3$) /($ Type $1+$ Type 4$)$, and BBI $\mathrm{ER}=[($ Type $2+$ Type $3+1) /($ Type $1+$ Type $4+1)]$. From this formula it follows, that a stronger belief bias is reflected in a higher BBI-score. On the other hand, a perfectly logical reasoning style (i.e., no belief bias) would yield a BBI-score of about 1.

Before testing the relationship between belief bias and symptoms of psychopathology, all questionnaire scores were subjected to a factor analysis in order to reduce the number of variables. One factor, accounting for $59.3 \%$ of the variance was clearly the most important and all subscales loaded on it. A composite score was generated by standardizing each subscale by converting into Z-scores, and then averaging across the measures (see Rosenthal \& Rosnow, 1991 for this procedure).

To test the relationship between belief bias and symptoms of psychopathology, Pearson correlations were computed between both BBI scores and the composite scores of psychopathological complaints.

\section{RESULTS}

Mean reaction times and percentages of logical errors for the four different types of syllogisms are presented in Table 2. 


\section{Reaction times}

The restriction to correct answers resulted in the exclusion of one subject for this analysis, who gave only wrong answers on Type 2 syllogisms. Analysis of variance (ANOVA) revealed no main effect of believability, $F(1,198)=$

Table 2 Mean reaction times (ms) and percentage of logical errors

\begin{tabular}{|c|c|c|c|}
\hline & Believable & & Not believoble \\
\hline & & Reaction times & \\
\hline Valid & $8310(2160)$ & & $9340(2430)$ \\
\hline \multirow[t]{2}{*}{ Invalid } & $10140(2640)$ & & $9160(2610)$ \\
\hline & & Errors & \\
\hline Valid & $6.7 \%$ & & $11.9 \%$ \\
\hline Invalid & $10.7 \%$ & & $7.6 \%$ \\
\hline
\end{tabular}

$.62, p=.80$. Yet, in accordance with previous research there was a main effect of validity, $F(1,198)=100.70, p<.001$, indicating that participants were generally faster on valid syllogisms as compared to invalid syllogisms. Most pertinent to our hypothesis, a significant interaction was found between believability and validity, $F(1,198)=118.24, p<.001$. That is, in line with our hypothesis, subjects' reaction times on trials with valid and invalid syllogisms were differentially affected by the believability of the syllogisms" conlusions (Figure 1).

Subsequent $t$ tests indicated that on trials with believable syllogisms, subjects were significantly faster when syllogisms were valid than when they were not valid $[t(198)=9.63, p<.001]$. The opposite pattern occured on trials with unbelievable syllogisms. In these cases, subjects were significantly faster when syllogisms were not valid than when they were valid $[t(198)=$ $8.14, p<.001]$. 


\section{Logical errors}

An ANOVA revealed no main effect of believability, $F(1,199)=2.35, p>.1$, nor any main effeet of validity, $F(1,199)=04, p>.8$. However, as for the reaction times, a significant interaction was found between believability and validity, $F(1,199)=30.74, p<.001$, indicating that in line with our hypothesis, the number of logical errors was differentially affected by the believability of the syllogisms' conclusion (Figure 2).

Figure 1. Mean reaction times after square root normalization $\sqrt{ } \mathrm{RT}$ (ms) on valid and invalid syllogisms as a function of believability.

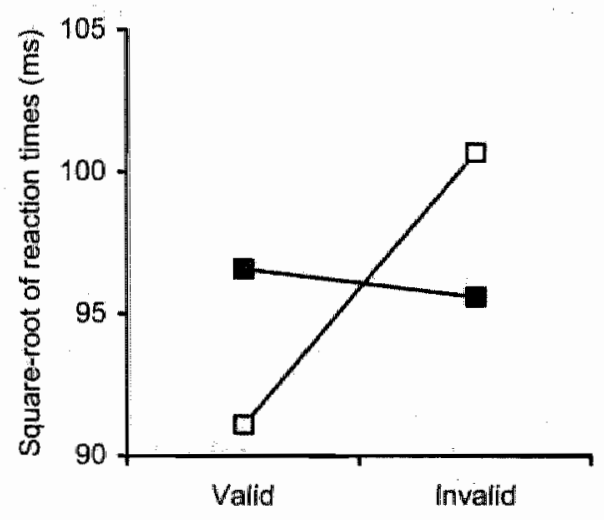

$-\square-$ Believable

$\rightarrow$ Not believable

Figure 2. Mean percentage of logical errors on valid and invalid syllogisms as a function of believability.

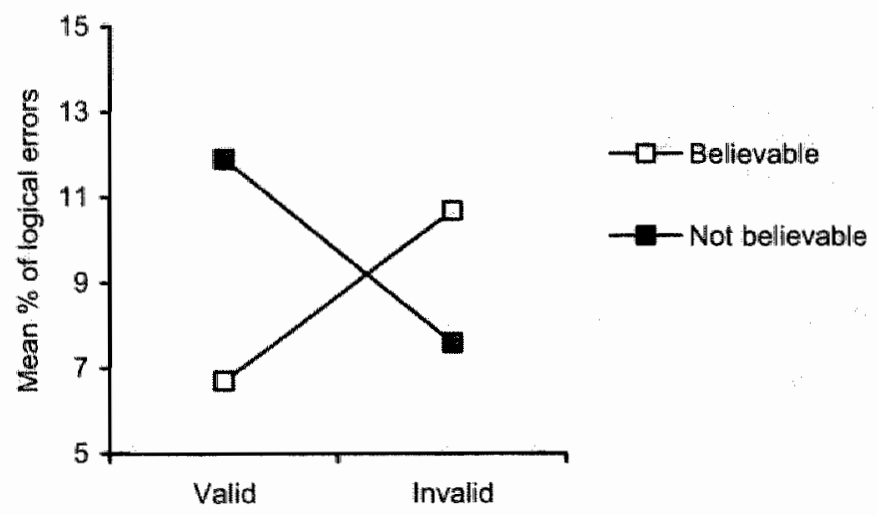


Again, subsequent $t$ test indicated that; on trials with believable syllogisms, subjects made significantly less logical errors when the syllogisms were valid than they were not valid $[t(199)=5.17, p<.001]$. On the other hand, on syllogisms with unbelievable conclusions, subjects made significantly less logical errors when syllogisms were not valid then when they were valid, $[r(199)=2.9, p<.005]$.

\section{Belief bias and psychopathological symptoms}

Mean scores, standard deviations, and ranges for all separate questionnaires as well as for the composite score of psychopathological complaints are presented in Table 3. $\mathrm{BBI}_{\mathrm{RT}}$ could be computed for 199 subjects, since one subject had a missing value on reaction times (see: Reaction times). Mean $\mathrm{BBI}_{\mathrm{RT}}$ was 1.06 (Range $=0.87$ to $1.32 ; S D=.08$;). $\mathrm{BBI}$ ER $_{\text {could be computed }}$ for 200 subjects. Mean $B B I_{E R}$ was 1.69 (Range $=0$ to $7 ; S D=1.24$ )

Table 3. Means, range and standard deviations for the SCL-90, ASI, STAI and composite score for these questionnaires

\begin{tabular}{lcc}
\hline & Mean (SD) & Range \\
\hline SCL-90 & $129.3(35.5)$ & $90-292$ \\
ASI & $25.8(8.1)$ & $16-92$ \\
STALLD2 & $36.6(9.7)$ & $21-71$ \\
Composite & $0(.76)$ & $-.84-3.67$ \\
Psychopathology & & \\
\hline
\end{tabular}

Note. SCL-90 = Symptom Checklist; ASI = Anxiety Sensitivity Index; STAI-DY2 = Trait-version of the State-Trait Anxiety Inventory 
Table 4. Pearson correlations between psychopathology-scores and bellef bias indices:

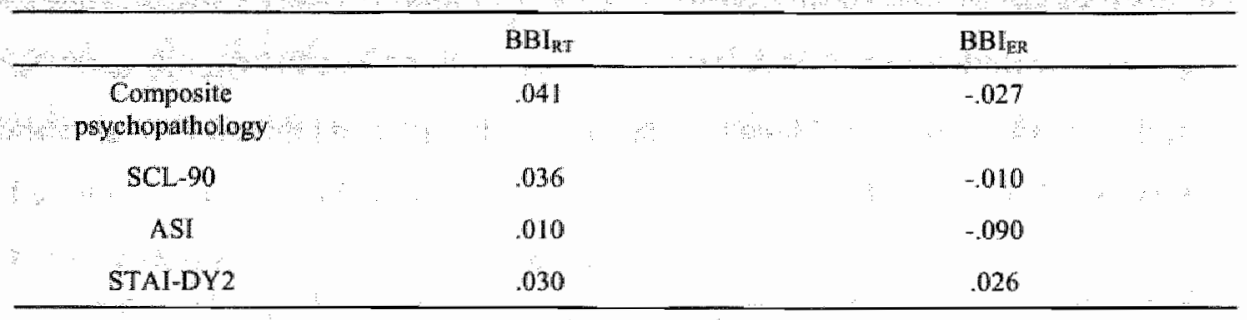

Note. None of the correlations reached significance at .05 level, one tailed. SCL-90= Symptom Checklist; ASI = Anxiety Sensitivity Index; STAI-DY2 = Trait-version of the State-Trait Anxiety Inventory

Pearson correlations between BBI-indices and psychopathology-scores are presented in Table 4. cores on the anxiety questionnaires ASI and STAIDY2. As can be seen in this Table neither the $\mathrm{BBI}_{\mathrm{RT}}$ nor the $\mathrm{BBI}$ ER correlated significantly with the composite score of psychopathological symptoms. Also, no specific correlation emerged between belief bias indices and the $\mathrm{s}$

\section{DISCUSSION}

In line with previous research using categorical rather than linear syllogisms (e.g., Evans et al., 1993), the results of the present study showed that people are generally inclined to judge believable conlusions as valid, and unbelievable conclusions as invalid, irrespective of the actual logical status of the conclusions (belief bias). That is, in the case of believable conclusions, participants showed both longer response latencies and more logical errors on invalid conclusions as compared to valid conclusions. The opposite pattern occurred in the case of conlusions that were not believable. Here, participants showed longer response latencies and more logical errors on valid conclusions as compared to invalid conclusions. The finding that latencies as well as error 
rates were relatively large when the syllogism did not match with the subjects' prior beliefs is in line with the idea that reasoning processes may (reciprocally) affect prior beliefs in a way that is likely to maintain existing beliefs.

Previous research showed that phobic subjects display an enhanced belief bias which is not specific for the domain of their phobia (de Jong et al,, 1997). This absence of domain specifity suggests that a generally enhanced belief bias might be a predisposing factor in the development of pathogenic concerns. However, in the present study no correlation was evident between the level of belief bias and the severity of psychopathological complaints, nor was there any correlation between belief bias and anxiety sensitivity or trait anxiety. From this, it can be concluded that the level of belief bias is not directly associated with psychopathological complaints in normal subjects. Thus, the present data lend no support to the idea that a generally enhanced belief bias might act as a diathesis that renders people vulnerable to the development of pathogenic convictions (e.g., de Jong et al., 1997).

Several testable explanations can be put forward to explain the absence of a relationship between belief bias and the level of psychopathological complaints. First although participants" belief bias showed a considerable range, it might still have been too restricted to detect the alleged relationship between belief bias and psychopathological symptoms. Relatedly, participants in the present study were all undergraduate university students who are likely to have relatively high abstract reasoning capacities. Indeed, the response latencies as well as the standard deviations on neutral syllogisms in a group of participants with low or moderate educational level reported by de Jong et al. (1997; Experiment 2) were considerably higher (i.e., up to $20 \%$ ) than participants' performance in the present study. Hence it can not be ruled out that the present study might have lacked sufficient sensitivity to detect the 
hypothesized relationship between enhanced belief bias and relatively intense psychopathological symptoms.

Second, it should be acknowledged that in the present set-up we could not control for the presence (nor for the intensity) of particular personal experiences that are crucial for the development of particular dysfunctional convictions. Yet, it might be the joint influence of such particular experiences and an enhanced belief bias that eventually facilitates the generation of relatively stable dysfunctional beliefs. One way to circumvent this problem might be to investigate the influence of belief bias in a laboratory setting that allows to control for the relevant experiences. For example, one could assess individualls" UCS-expectancies in the context of a differential aversive conditioning paradigm (e.g., Öhman, Erixon \& Lofberg, 1975). If belief bias indeed plays an essential role in the acquisition and maintainance of dysfunctional convictions, one would expect that subjects with a relatively high belief bias show a relatively steep acquisition curve and a relatively strong resistance to subsequent extinction of aversive UCS-expectancies. A third explanation for the present findings is that the generally enhanced belief bias that de Jong and his colleagues found in spider phobics (de Jong et al., 1997) should be interpreted as a consequence rather than as a cause of the phobic complaints. There are at least two theories that support the view that reasoning errors result from, rather than be the cause of anxiety. First, anxiety might generate a general sense of insecurity and stress, which results in a relatively strong perception of time pressure. As a result, scanning patterns become chaotic and subjects may leap into inappropriate conclusions (e.g., Keinan, 1987). Another line of research shows that in high anxious subjects working memory capacity is reduced which affects attention and the temporary storage and manipulation of information (e.g., Eysenck; 1985; MacLeod \& Donnellan, 1993; Tohill \& Holyoak, 2000). According to this view, the performance deficits (e.g., reasoning errors) in high anxious subjects 
are the result of a restriction in working memory capacity. If, indeed, the previously found enhanced belief bias in phobic individuals should be considered as a consequence rather than a cause of the anxiety complaints, this would be at odds with the idea that enhanced belief bias is a premorbid characteristic. Meanwhile, such a view does not rule out the possibility that there is a reciprocal relationship between anxiety complaints and confirmatory reasoning patterns. That is, such a view is not necessarily inconsistent with the idea that belief bias still adds to the maintenance or intensification of the anxiety complaints.

To conclude, the present results provide no support for the idea that a relatively enhanced belief bias put people at risk for the development of psychopathological complaints. Meanwhile, there is circumstantial evidence that the enhanced belief bias which was previously found in phobic individuals was the result rather than a cause of the anxiety disorder. However, since there are several testable explanations for the absence of a relationship between belief bias and the severity of psychopathological symptoms in the present study, it seems premature to completely dismiss the idea that belief bias might play a role in the persistence of psychopathological complaints. Finally, even if future studies would further question the role of enhanced belief bias in the development of psychopathology, it remains clear that once pathogenic concerns are present, (ordinary) belief bias (as well as other confirmatory reasoning patterns) logically act in a way that hinders the realistic evaluation of critical situations, thereby sustaining irrational concerns.

\section{REFERENCES}

Arntz, A. (2003). Cognitive therapy versus applied relaxation as treatment of generalized anxiety disorder. Behaviour Research and Therapy , 41, 633-646. 
Arrinde11, W. A., \& Ettema, J. H.M. SCL-90 (1986). Handleiding bij een multidimensionele psychopathologie-indicator. Lisse, The Netherlands: Swets and Zeillinger

Clark, D.M. (1986). A cognitive approach to panic Behaviour Research and Therapy, $24,461-470$.

Clark, D.M., \& Wells, A. (1995). A cognitive model of social phobia. In R.G. Heimberg, M.R. Liebowitz, D.A. Hope, \& F.R. Schneier (Eds.), Social phobia. New York: Guilford Press. 69 - 93.

de Jong, P.ll., Haenen, M-A., Schmidt, A., \& Mayer, B. (1998). Hypochondriasis: The role of fear-confirming reasoning. Behaviour Research and Therapy, 36, 6574.

de Jong, P.J., Weertman, A., Horselenberg, R., \& Van den Hout, M.A. (1997). Deductive reasoning and pathological anxiety: Evidence for a relatively strong "bellef bias" in phobic subjects. Cognitive Therapy and Research, 21, 647 662.

Derogatis, L.R., Lipman, R.S., \& Covi, L. (1973). SCL-90: An outpatient psychiatric rating scale. Preliminary report. Psychopharmacology Bulletin, 9, 13-27.

Ehlers, A., \& Clark, D.M. (2000). A cognitive model of posttraumatic stress disorder. Behaviour Research and Therapy, 37,809-829.

Eysenck, M.W. (1985). Anxiety and cognitive task performance. Personality and Individual Differences, 6,579-586.

Evans, J. St. B. T., Barston, J.L., \& Pollard, P. (1983). On the conflict between logic and belief in syllogistic reasoning. Memory and Cognition, 11,295-306.

Evans, J. St. B. T., Newstead, S.E., B Byrne, R.M.J. (1993). Human reasoning: The psychology of dedwction. Hove, UK: Lawrence Erlbaum Associates Ltd.

Evans, J. St. B. T., Handley, S.J., \& Harper, C. (2001). Necessity, possibility and belief: A study of syllogistic reasoning. Quarterly Joumal of Experimental Psychology: Human-Experimental-Psychology, 54A, 935-958.

Evans, J. St. B. T., Over, D.E., \& Manktelow, K.I. (1993). Reasoning, decision making and rationality. Cognition, 49, $164-187$. 
Huey, D. (2000). The relationship bteween everyday reasoning and mood-dependent reasoning. Poster presented at the 30th Congress of the European Association for Behavioural and Cognitive Therapies. Granada: Spain

Keinan, G. (1987). Decision making under stress: Scanning of alternatives under physical threat. Acta Psychologica, 64, $219-228$.

MacLeod, C., \& Donellan, A.M. (1993). Individual differences in anxiety and the restriction of working memory capacity. Personality and Individual Differences, $15,163-173$.

McNally, R.J. (2001). On the scientific status of cognitive appraisal models of anxiety disorder. Behoviour Research and Therapy, 39,513-521.

Newstead, S.E., Pollard, P., Evans, J.St.B.T., \& Allen, J. (1992). The source of belief bias in syllogistic reasoning. Cognition, 45, 257-284.

Öhman, A., Erixon, G., \& Lofberg, I. (1975). Phobias and preparedness: Phobic versus neutral pictures as conditioned stimuli for human autonomic responses. Journal of Abnormal Psychology, 84, 41 - 45.

Reiss, S., Peterson, R. A., Gursky, D. M., \& McNally, R.J. (1986). Anxiety sensitivity, anxiety frequency and the predictions of fearfulness. Behaviour Research and Therapy, 24, $1-8$.

Rosental, R. \& Rosnow, R.L. (1991). Essentials of behavioral research: Methods and data analysis (2nd ed.). New York: McGraw-Hill

Salkovskis, P.M. (1999). Understanding and treating obsessive-conpulsive disorder. Behaviour Research and Therapy, 37, S29-S52.

Spielberger, C.D., Gorsuch, R.L., \& Lushene, R.E. (1970). Manual for the state- trait anxiety inventory (self evaluation questionnaire). Palo Alto CA: Consulting Psychologists Press

Schneider, W. (1989). Enhancing a standard experimental delivery system (MEL) for advanced psychological experimentation. Behavior Research Methods, Instruments and Computers, 21, 240-244.

Smeets, G., De Jong, P.I., \& Mayer, B. (2000). If you suffer from a headache, then you have a brain tumour: Domain-specific reasoning 'bias' and hypochondriasis._Behaviour Research and Therapy, 38, $763-776$. 
Tohill, J.M. \& Holyoak, K.J. (2000). The impact of anxiety on analogical reasoning. Thinking and Reasoning, 6, $27-40$.

Van der Ploeg, H.M, Defares, P.B., \& Spielberger, C.D. (1980). Handleiding bij de Zelfbeoordelings Vragenlijst (ZBV): Een Nederlandse bewerking van de Spielberger State-Trait Anxiety Inventory (STAI-DY). Lisse: Swets \& Zeitlinger.

Wells, A., \& Carter, K. (1999). Preliminary tests of a cognitive model of generalized anxiety disorder. Behaviour Research and Therapy, 37, 585 - 594. 


\section{CHAPTER 3}

\section{CONFIRMATORY REASONING IN OBSESSIVE-COMPULSIVE AND PANIC DISORDER}

Adapted from: Smeets, G. \& de Jong, P. J. (submitted). Confirmatory reasoning in obsessive-compulsive and panic disorder: Belief bias over the course of treatment. 


\title{
46 Chapter 3
}

\begin{abstract}
The present study was designed to explore the role of belief bias in the maintenance of patients' anxiety complaints. We tested whether (i) anxiety patients are characterized by a relatively strong belief bias; (ii) enhanced belief bias is sensitive to cognitive behavioural treatment; (iii) residual belief bias is related to relapse. OCD $(n=25)$ and PD patients $(n=36)$, and normal controls $(n=20)$ were presented with a series of linear syllogisms concerning neutral, OCD-relevant, and PD-relevant themes. The computerized reasoning task was administered both before and after treatment. Self-report measures of patients' complaints (FQ- main phobia; FQ; SCL-90) were administered before and after treatment, as well as at six months follow-up. No evidence emerged for a generally enhanced belief bias at pre treatment in panic disordered or obsessive-compulsive patients. Domain-specific belief bias occurred in PD patients but not in OCD patients. In PD patients, domain-specific belief bias at pre-treatment predicted treatment outcome. Overall, there were no significant differences between belief bias before and after treatment. Post-treatment domain-specific belief bias predicted the return of self reported complaints in OCD patients but not in PD patients. The results pinpoint the potential value of belief bias in predicting treatment outcome and relapse. More research is necessary to critically test the causal properties of belief bias in the maintenance of pathological anxiety.
\end{abstract}




\section{INTRODUCTION}

Cognitive theories of psychopathology propose that dysfunctional beliefs provide the causal basis for the catastrophic misappraisals that are typical for anxiety disorders (Beck, 1976). According to these theories, due to an underlying belief, the anxiety patient over-estimates the dangerousness of the situation and misinterprets harmless stimuli as forerunners of oncoming catastrophe (e.g., McNally, 2001). Several studies have shown, that each anxiety disorder is associated with one or more specific negative beliefs that cause people to draw erroneous conclusions that are characteristic for the various disorders (e.g., Clark, 1986; Clark \& Wells, 1995; Salkovskis, 1999; Ehlers \& Clark, 2000). For example, an obsessive-compulsive patient who believes that not preventing a disaster is as bad as making it happen, might engage in neutralizing compulsive behaviours like washing or ritualizing, merely by drawing the wrong conclusions after having a (normal) intrusive thought about the possibility of causing harm to someone (e.g., Salkovskis, 1999). In a similar vein, panic patients who believe that palpitations signify impending cardiac arrest might get a panic attack, merely by misinterpreting some harmless interoceptive cues (e.g., Clark, 1986). Typically, anxiety disorders are very persistent in the absence of treatment (APA, 1994).

Given the fact that the anxiogenic beliefs are mistaken, the question arises why such beliefs are so persistent. For therapeutic purposes, particular attention has been paid to the factors that prevent anxiety patients from changing their negative beliefs about the dangers they fear (e.g., Clark, 1999). By definition, anxiety patients engage in safety-seeking behaviours that hamper disconfirmation of their irrational beliefs (APA, 1994; Salkovskis, Clark, Hackmann, Wells, \& Gelder, 1999). However, although safety-seeking behaviours may play an important role in the persistence of complaints, it provides no satisfying explanation for the observation that dysfunctional 
beliefs also persist when incompatible evidence is available. For example, why does a panic patient hold on to his conviction that every next attack of dizziness and palpitations will be fatal, even after experiencing dozens of panic attacks that turned out to be harmless? In other words, a crucial question that remains is why dysfunctional beliefs persist despite the fact that the feared outcomes do never happen. Satisfying answers to questions like these may provide a valuable contribution to the understanding of the maintenance of anxiety disorders and the development of effective treatments.

One mechanism that may play a fairly direct role in patients' failure to correct their dysfunctional beliefs is their deductive reasoning style. Correcting erroneous beliefs requires the ability to accurately deduce the logical implications of empirical evidence for certain beliefs. In general, people are characterized by a bias in deductive reasoning that acts in a way to confirm rather than to falsify prior beliefs (i.e., "belief bias"; Evans, Over \& Manktelow, 1993). That is, belief bias is demonstrated in a general tendency to endorse conclusions which are a priori believable as valid and those which are unbelievable as invalid, regardless of their actual logical status. This interference of prior beliefs has been shown to be at least partly automatic in the sense that it is unintentional and involuntary. Even if participants are instructed to ignore the concrete content of the reasoning problem and to only judge the logical validity of the presented conclusions (e.g., the mouse is larger than the cat; the cat is larger than the elephant; therefore, the mouse is larger than the elephant) participants are typically slower and make more mistakes when there is a mismatch between validity and believability relative to problems in which there is a match between believability and validity of the conclusion (e.g., de Jong, Weertman, Horselenberg, \& Van den Hout 1997; Smeets \& de Jong, 2005).

By now there is considerable evidence that some degree of belief bias is characteristic of human reasoning (see supra). In everyday life, some degree 
of belief bias can be considered as functional. In potentially dangerous situations for example, it seems adaptive to rely on prior beliefs and to act on quick and dirty conclusions, rather than to pause and consider the logical validity of those conclusions. However, if the perceived threat is based on pathogenic convictions, the same strategy might become counterproductive. In that case, jumping to a conclusion would hinder the falsification of the underlying argument and logically immunize against the refutation of anxiogenic views.

Earlier research in the context of spider phobia (de Jong et al., 1997) provided preliminary evidence to suggest that a possible enhanced belief bias in relation to psychopathology may take two forms. First, enhanced belief bias may be evident in the domain of disorder-related concerns that are relevant for the patient. Second, a strong belief bias might (also) be a general cognitive characteristic of individuals suffering from psychopathological complaints, exerting its influence in complaint-irrelevant domains as well.

If enhanced belief bias is restricted to the domain of concerns this would be consistent with the idea that the incorrigibility of anxiogenic beliefs may not itself result from a reasoning abnormality, but represents a normal manifestation of tenacity for important and strongly held beliefs (cf. Garety \& Hemsley, 1997). Pertinent to the issue of causality of domain-specific belief bias, it would be important to know whether (residual) belief bias after successful therapy is associated with patients' prognosis (cf. de Jong et al., 1997). To the degree that enhanced belief bias is more than an epiphenomenon of psychopathology, post-treatment (residual) belief bias may be a predictor of relapse.

When patients' belief bias is generally enhanced this would raise the possibility that this reasoning bias reflects a trait-like information processing bias that acts as a diathesis in the development of psychopathological disorders in general (cf. Arntz et al., 1995). Note that a relatively strong belief 


\section{Chapter 3}

bias will impede the correction of somehow acquired erroneous and potentially pathogenic convictions, which in turn may render people liable to psychopathology (cf. de Jong et al., 1997; Smeets \& de Jong, 2005). That is, if a person tend to endorse idiosyncratic, dysfunctional beliefs (e.g., due to particular learning experiences), the presence of an enhanced belief bias might prevent participants from giving up such beliefs (e.g., "I am worthless") in the face of logically incompatible data. In other words, generally enhanced belief bias would immunize against refutation of all kinds of pathogenic views. Thus, enhanced belief bias would logically serve to maintain dysfunctional convictions in general.

The focus of the present study is to examine whether treatment seeking individuals suffering from invalidating anxiety disorders exhibit an enhanced belief bias. Therefore, we measured domain-specific and general belief bias before and after treatment in obsessive-compulsive and panic disordered patients as well as in a group of normal controls. If indeed belief bias plays a role in the development and/or maintenance of anxiety disorders, individuals suffering from obsessive-compulsive disorder or panic disorder should display enhanced levels of belief bias compared to individuals without complaints. Moreover, if belief bias is a general premorbid characteristic that contributes to the development of dysfunctional beliefs, enhanced belief bias in anxiety patients should not only be present in the domain of their concerns, but in the neutral domain as well. Second, if there is a direct and causal association between enhanced belief bias and anxiety disorders, belief bias should diminish after successful treatment. Finally, if enhanced belief bias is more than an epiphenomenon of psychopathology, successfully treated patients who nevertheless show a post-treatment bias, should be more vulnerable to relapse than patients who do not display such post-treatment bias. 


\section{METHOD}

\section{Participants}

Twenty-five patients with obsessive-compulsive disorder (16 women) and thirty-six patients with panic disorder ( 30 women), were recruited among individuals seeking treatment at the community mental health care centre in Maastricht, the Netherlands. All patients met DSM-IV criteria for obsessivecompulsive disorder (OCD) or panic-disorder (PD) with or without agoraphobia, as assessed with the Structural Clinical Interview for DSM-IV (SCID; First, Spitzer, Gibbon \& Williams, 1995). The mean age in the OCDgroup was 30.5 years $(S D=9.3)$ and 34.2 years $(S D=9.9)$ in de PD-group. Mean educational level on a scale ranging from 1 ('no education') to 11 ('university degree') was $8.0(S D=1.9)$ in the $O C D$-group and $6.9(S D=2.1)$ in the PD-group. Six participants (24\%) in the OCD-group and twelve patients (33\%) in the PD-group dropped out during treatment. Thirteen individuals (1 OCD and $12 \mathrm{PD}$ ) did not participate in one or more of the follow-up assessments due to refusal or procedural errors. From the initial group, 18 OCD patients and 12 PD patients completed all assessments at pre-treatment, post-treatment, and follow-up.

Twenty healthy control participants (14 women) were recruited through advertisements in local newspapers. They received a small financial remuneration for their participation in the study. Controls were included after extensive screening on (a history of) any DSM-IV axis-I disorder. Their mean age was 36.1 years $(S D=14.2)$ and their mean educational level was 8.0 ( $S D$ $=2.3$ ) . There were no significant differences between the thee groups of participants with respect to gender $\left(\chi^{2}=3.1, p=.21\right)$, age $(F(2,78)=1.6, p=$ $.21)$, or educational level $(F(2,78)=2.6, p=.08)$, although there was a tendency that the educational level of the PD group was lower than that of the other groups. 


\section{Procedure and assessment}

All participants signed informed consent and were tested individually. OCDpatients received protocolized cognitive therapy with an average of 18 sessions (cf. van Oppen \& Arntz, 1994). Panic patients received either protocolized cognitive behaviour therapy (cf. Clark, Salkovskis, Hackmann, Middleton, Anastasiades \& Gelder, 1994) or protocolized interpersonal psychotherapy (IPT; Weissman \& Markowitz, 1998) with an average of 16 sessions. Patients were tested before treatment $(\mathrm{T} 1=\mathrm{Pre})$, immediately after treatment (Post), and at six months follow-up (FU). Control participants were tested only once (Tl).

\section{Self reported measures of psychopathology}

To index treatment effects, the Fear Questionnaire (FQ; Marks \& Mathews, 1979) and the Symptom Checklist (SCL-90; Derogatis; Lipman \& Covi, 1973; Arrindell \& Ettema, 1986) were administered. The FQ is a frequently used measure in anxiety research, measuring fear and avoidance symptoms. The SCL-90 is a widely used multidimensional index of psychopathological complaints. Both questionnaires have acceptable psychometric properties (Marks \& Mathews, 1979; Arrindell \& Ettema, 1986).

\section{Reasoning task}

The reasoning task that was used in the present study was an adapted version of the computerized task used by de Jong et al. (1997; see also Smeets \& de Jong, 2005). The task consisted of three sets of four different linear syllogisms. The three sets concerned neutral themes (e.g., a mouse is larger than an elephant), OCD-relevant themes (e.g., preventing errors is more important than having fun), and panic disorder-relevant themes (e.g., palpitations are more dangerous than a mosquito bite; see Appendix I and II). 
The disorder-relevant themes were developed in collaboration with an experienced therapist. They were based on the most frequently reported concerns relevant for each disorder. Panic relevant themes included palpitations, dizziness, gasping, and pain on the chest. Obsessive-compulsive themes included dirtiness, being careful, preventing mistakes, and checking.

For each of the syllogisms, there were four different types of which the conclusions systematically varied in logical validity and believability. That is, for each of the syllogisms, there were two versions with a conclusion in line with participants" prior view of the world, one of which was logically valid (believable and valid; Type 1), and one of which was invalid (believable but invalid; Type 2). Furthermore, there were two versions with a conclusion opposite to the participants ${ }^{3}$ prior view of the world, again one of which was logically valid (unbelievable but valid; Type 3), and one which was logically invalid (unbelievable and invalid; Type 4). Belief bias would be reflected by a relatively poor performance (i.e., many errors; long latencies) if the conclusions were in line with participants' prior beliefs but logically invalid or when the conclusion was contrary to participants' prior beliefs but logically valid. More specifically, belief bias would be reflected in an interaction effect between the believability and the logical validity of the syllogisms' conclusions.

To control for task order effects, each syllogism was presented twice, once with the premises in the standard order (i.e., $\mathrm{A}>\mathrm{B}, \mathrm{B}>\mathrm{C}$ ) and once with the premises in reversed order (i.e., $B>C, A>B$ ). Thus in total there was a pool of 3 (Domains) X 4 (Themes) $\times 4$ (Types) $\times 2$ (Order) $=96$ syl logisms. Specific examples of syllogism types are presented in Appendix II.

All participants were exposed to the same pool of 96 syll.ogisms. Syllogisms were presented in fixed random order. The total pool of syllogisms as well as the order in which the syllogisms were presented was the same at each assessment. To prevent that fatigue would influence the responses as the 


\section{Chapter 3}

reasoning task progressed, participants had to take a rest period for at least two minutes after the first and the second set of 32 syllogisms.

\section{Procedure of the assessment}

In a sound attenuated room, the participant was seated in front of a 14-inch monitor on which the syllogisms and the standard instructions were presented. Participants were instructed to decide as quickly as possible whether or not the conclusion was correct (i.e., logically valid) given the two premises. It was emphasized that the reality basis (i.e., believability) of the premises and the conclusions should not be taken into account. To get familiarized with the reasoning task, participants received four example syllogisms. After the first two examples, the participants received feedback about the correctness of their decision, along with a standard explanation about the validity of the pertinent conclusion. After the third and fourth example, the participants received feedback about the correctness of their decision without explanation. While the feedback and explanation were presented, the particular syllogism remained on the screen. After the example syllogisms, the instructions for the reasoning task were summarized. The participant could start the actual reasoning task by pushing the space bar whenever he or she was ready.

Preceding every single stimulus presentation the sentence "Pay attention!" appeared on the screen to alert the participant for the next syllogism. The participant indicated whether he or she considered the syllogism valid or not by pushing either the "valid' or the 'not valid' button. The syllogism disappeared from the screen immediately after the participant had pushed one of the two buttons. Every next stimulus presentation appeared after a 2000 milliseconds interval. The program recorded the participants" decisions (valid or invalid) as well as their response latencies (in milliseconds) on a trial by trial basis. During the experiment, the participants received no feedback about their performance. 
After the first and the second set of 32 syllogisms, the computer paused and displayed the text "This was the first (second) set of syllogisms. Please take a break for at least two minutes. Whenever you are ready, you may push the space bar to continue". During the rest period, the computer did not respond for two minutes.

\section{Data-reduction and analysis}

Reaction times on the reasoning task were normalized using square root transformation (cf. Smeets \& de Jong, 2005). As mentioned before, belief bias would be reflected in a significant interaction effect between the logical validity and the believability of the syllogisms. To test this interaction effect at $\mathrm{T} 1$ and to test whether belief bias was domain-specific and varied in strength (and/or domain) across the three groups, the response latencies as well as the number of logical errors at T1 were subjected to a 3 (Group) X 2 (Believability) $\mathrm{X} 2$ (Validity) MANOVA on the three domains (Neutral, OCD-specific, and PD-specific), with the last two factors being within subjects factors. The analysis of reaction times was restricted to those trials on which the participant gave a correct response. To retain optimal statistical power, all participants who completed the assessments at $\mathrm{T} 1$ were included in the analysis testing belief bias at $\mathrm{Tl}$.

To index the interaction between believability and validity, a belief bias index (BBI) was computed for each the three domains (i.e., neutral, OCDspecific, PD-specific). Separate indices were computed for the reaction times (BBI-rt) and the number of logical errors (BBI-er). To express the relative performance on syllogisms with 'mismatching conclusions' (i.e., believable but invalid [Type 2]; not believable but valid [Type 3]) as compared to syllogisms with 'matching conclusions'(i.e., believable and valid [Type 1]; not believable and not valid [Type 4]), while controlling for between subject variability, the following formulas were used (cf. Smeets \& de Jong, 2005): 


\section{Chapter 3}

BBI-rt $=[($ Type $2+$ Type 3$) /($ Type $1+$ Type 4$)]-1$, and BBI-er $=[($ Type 2 + Type $3+1$ ) / (Type $1+$ Type $4+1)]-1$. From these formulas it follows, that stronger belief bias is reflected in a higher BBI-score. Meanwhile, a perfectly logical reasoning style (i.e., no belief bias) would yield a BBI-score of about zero.

Before testing the relationship between belief bias and self-reported levels of anxiety and general psychopathology, composite scores were calculated for belief bias to reduce the number of variables. Within each domain (neutral, OCD, and PD) and across the assessments (TI, Post and FU), BBI-er and BBI-rt scores were combined after converting them into Zscores $(\mathrm{BBI}=\mathrm{Z}$-BBI-rt + Z-BBI-er; see Rosenthal \& Rosnow, 1991 for this procedure).

To test the relationship between pre-treatment belief bias and self reported levels of anxiety and general psychopathology, Pearson correlations were calculated between composite scores of pre-treatment BBI and pretreatment scores on the Fear-Questionnaire (FQ) and the Symptom Checklist (SCL-90).

To check for effectiveness of treatment (i.e., manipulation-check), a 2 Group (OCD vs. PD) X 2 Time (pre vs. post) MANOVA was performed on the Fear Questionnaire and the SCL-90 data. To test whether belief bias in both patient groups was reduced after treatment and to see whether such a reduction would be specific for the domain of concerns, BBI-scores were subjected to 2 Group (OCD, PD) X 2 Time (pre-treatment, post-treatment) MANOVAs with the last factor being a within subjects factor.

To test whether pre-treatment levels of belief bias would predict treatment outcome, Pearson correlations were calculated between composite scores of pre-treatment belief bias and the reduction of self-reported anxiety and psychopathological scores symptoms from pre- to post treatment and from pre-treatment to follow-up $\left(\Delta F Q_{\text {pre - posit }} ; \triangle \mathrm{FQ}_{\text {pre - fu }} ; \Delta S C L-90\right.$ pre - post; 
$\Delta S C L-90_{\text {pre -fiu; }}$ note that higher difference scores indicate larger treatment effects). To test whether changes in belief bias levels were associated with the reduction of complaints, Pearson correlations were computed between changes in belief bias $\left(\triangle B B I_{\text {pre - posi }}\right)$ and changes on the Fear Questionnaire $\left(\Delta F Q_{\text {pre - post }}\right)$ and the Symptom Checklist $\left(\Delta S C L-90_{\text {pre - post }}\right)$. To test whether the level of residual belief bias (i.e., post-treatment bellief bias) could predict relapse, Pearson correlations were computed between composite scores of post-treatment BBI and changes on the Fear Questionnaire and the Symptom Checklist, from post treatment to 6 months follow up $\left(\Delta F Q_{\mathrm{fu}-\text { posi }} ; \triangle \mathrm{SCL}-90_{\text {fu }}\right.$ - post).

\section{RESULTS}

\section{Belief bias and psychopathology at TI}

Mean scores and standard deviations on the Fear Questionnaire and the SCL90 for the three groups at T1 (pre-treatment) are presented in Table 1. At T1, the three groups differed significantly with respect to their self-reported levels of anxiety and general psychopathology (FQ: $F(2,80)=32.1, p<.001$; SCL90: $F(2,80)=26.2, p<.001$ ). Post-hoc t-tests revealed that panic disordered patients did not differ from obsessive-compulsive patients with respect to their level of general psychopathology (SCL-90: $t(59)=-0.9, p=.16)$, although they reported significantly more anxiety-complaints (FQ: $t(59)=3.3, p<$ .005). Inspection of Table 1 reveals that this difference mainly reflects the relatively high scores on the agoraphobia subscale of the Fear Questionnaire in the PD-group. With respect to the severity of the main phobic complaints, obsessive-compulsive patients did not differ from panic disordered patients (FQ-main phobia: $t(59)=0.8, p=.45$ ). 


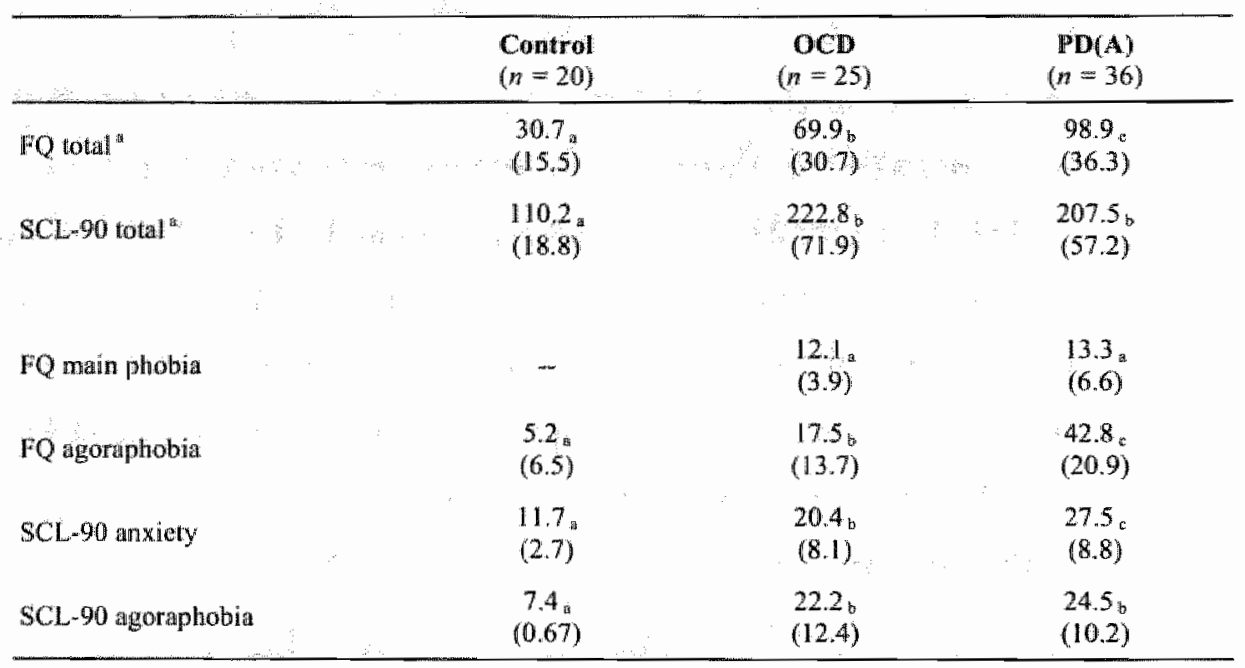

Note. Means in the same row that do not share subscripts differ at $p<.05$ in the Tukey honestly significant difference comparison.

Response latencies. Means and standard deviations of the response latencies ( $\mathrm{Vms}$ ) of the three groups on the syllogistic reasoning task at $T 1$ are presented in Table 2. Because the analysis was restricted to correct answers and some participants produced only incorrect answers on one or more syllogism types, the response latencies of 16 controls, 31 panic disordered and 20 obsessive-compulsive patients could be analyzed. The 3 (Group) X 2 (Believability) X 2 (Validity) MANOVA on the three domains revealed a significant main effect of Validity $(F(3,62)=31.0, p<.001)$. In accordance with previous research, subjects responded significantly slower on syllogisms with non-valid conclusions than on syllogisms with valid conclusions. The Validity $\mathrm{X}$ Group interaction did not reach significance $(F(6,122)=1.8, p=$ .11), so the effect of Validity was similar for all three groups. Univariate analysis revealed that the main effect of validity was present in all three domains (all $F$ 's $(1,64)>10, p$ 's $<.01$ ). Again, this effect was similar for each group, since there were no significant Validity $\mathrm{X}$ Group interactions (all $F^{\text {N }} \mathrm{s}$ $\left.(2,64)<2.6, p^{\prime} s>.05\right)$. 
Table 2. Means and standard deviations (SD) of the reaction times (Vms) on the syllogistic reasoning task for controls and anxiety patients at T1.

\begin{tabular}{|c|c|c|c|c|c|c|c|}
\hline & & \multicolumn{2}{|c|}{$\begin{array}{l}\text { Control } \\
(n=16)\end{array}$} & \multicolumn{2}{|c|}{$\begin{array}{c}\text { OCD } \\
(n=20)\end{array}$} & \multicolumn{2}{|c|}{$\begin{array}{c}\text { PD } \\
(n=31)\end{array}$} \\
\hline & & believable & $\begin{array}{c}\text { Not } \\
\text { believable }\end{array}$ & believable & $\begin{array}{c}\text { Noi } \\
\text { believable }\end{array}$ & bellevabile & $\begin{array}{c}\text { Not } \\
\text { believable }\end{array}$ \\
\hline \multirow{2}{*}{ Neutral } & Valid & $\begin{array}{c}83.7 \\
(15.4)\end{array}$ & $\begin{array}{c}85.4 \\
(17.3)\end{array}$ & $\begin{array}{c}87.9 \\
(14.9)\end{array}$ & $\begin{array}{c}90.9 \\
(14.5)\end{array}$ & $\begin{array}{c}91.1 \\
(10.8)\end{array}$ & $\begin{array}{c}93.2 \\
(1.2)\end{array}$ \\
\hline & Not valid & $\begin{array}{c}94.0 \\
(16.6)\end{array}$ & $\begin{array}{c}89.3 \\
(16.6)\end{array}$ & $\begin{array}{c}97.3 \\
(16.2)\end{array}$ & $\begin{array}{c}93.0 \\
(17.7)\end{array}$ & $\begin{array}{c}96.4 \\
(14.4)\end{array}$ & $\begin{array}{c}94.9 \\
(12.7)\end{array}$ \\
\hline \multirow{2}{*}{$O C$} & Valid & $\begin{array}{c}91.5 \\
(18.0)\end{array}$ & $\begin{array}{c}89.7 \\
(17.7)\end{array}$ & $\begin{array}{c}97.7 \\
(14.9)\end{array}$ & $\begin{array}{c}96.5 \\
(14.1)\end{array}$ & $\begin{array}{l}101.8 \\
(11.0)\end{array}$ & $\begin{array}{l}100.1 \\
(12.6)\end{array}$ \\
\hline & Not valid & $\begin{array}{c}93.8 \\
(17.0)\end{array}$ & $\begin{array}{c}93.0 \\
(18.7)\end{array}$ & $\begin{array}{l}101,2 \\
(16,3)\end{array}$ & $\begin{array}{l}100.0 \\
(15.1)\end{array}$ & $\begin{array}{l}101.7 \\
(12.7)\end{array}$ & $\begin{array}{r}102.7 \\
(12.1)\end{array}$ \\
\hline \multirow{2}{*}{ Panic } & Valid. & $\begin{array}{c}90.9 \\
(18.2)\end{array}$ & $\begin{array}{c}94.6 \\
(19.0)\end{array}$ & $\begin{array}{c}98.5 \\
(17.0)\end{array}$ & $\begin{array}{c}97.0 \\
(13.7)\end{array}$ & $\begin{array}{c}98.4 \\
(11.5)\end{array}$ & $\begin{array}{l}103.0 \\
(13.4)\end{array}$ \\
\hline & Not valid & $\begin{array}{c}94.8 \\
(17.5)\end{array}$ & $\begin{array}{c}95.9 \\
(16.7)\end{array}$ & $\begin{array}{l}103.6 \\
(17.2)\end{array}$ & $\begin{array}{l}102.4 \\
(17.4)\end{array}$ & $\begin{array}{l}103.3 \\
(12.9)\end{array}$ & $\begin{array}{l}102.3 \\
(12.7)\end{array}$ \\
\hline
\end{tabular}

Note. Neutral $=$ syllogisms within the neutral domain; $O C=$ syllogisms within the obsessive-compulsive domain; Panic = syllogisms within the panic domain.

Pertinent to our hypothesis, there was a significant interaction between Believability and Validity $(F(3,62)=3.6, p<.05)$. Overall, participants responded significantly slower when there was a mismatch between the believability and the logical validity relative to syllogisms with matching believability and validity (i.e., belief bias). There was no Group X Believability X Validity interaction, so belief bias was generally not enhanced in any of the three groups of participants $F(6,122)=1.0, p=.43$ ). Univariate analyses revealed that belief bias was evident only in the neutral domain $(F(1,64)=10.2, p<.005)$ but did not reach significance in the domain of obsessive-compulsive concerns $(F(1,64)=1.0, p=.32)$, whereas there was a trend for belief bias in de domain of panic concerns $(F(1,64)=3.1, p=.08)$. There were no significant Group X Believability X Validity interactions (All 
F's $(2,64)<1.5, p$ 's $>2)$. Thus, within the themes the groups did not differ with regard to the belief bias effects.

Logical errors. Means and standard deviations of error rates on the syllogistic reasoning task are presented in Table 3 . The 3 (Group) $X 2$ (Believability) $\times 2$ (Validity) MANOVA on the three domains revealed a significant main effect of Believability $(F(3,76)=3.5, p<.05)$. Overall, participants made significantly more errors when the syllogisms were not believable, relative to believable syllogisms. This effect appeared to be similar in the three groups, since the Group X Believability interaction did not reach significance $(F(6,150)=1.6, p=.15)$. Univariate analyses revealed that the effect of Believability was only evident in the neutral domain $(F(1,78)=7.7$, $p<, 01)$, and not in the domain of obsessive-compulsive concerns $(F(1,78)=$ $1.0, p=.33)$, nor in the domain of panic concerns $(F(1,78)=0.2, p=.66)$. This domain-specificity was similar for each group, since there were no significant Believability X Group interactions (all $F$ 's $(2,78)<2.0, p$ 's $>$ .14).

Consistent with the analyses of the response latencies and most pertinent to our hypothesis, the 3 (Group) X 2 (Believability) X 2 (Validity) MANOVA on the three domains revealed a strong interaction effect between the Believability and the Validity of the syllogisms (i.e., belief bias; $F(3,76)=$ $7.5, p<.001)$. In general, participants made significantly more errors when syllogisms contained a mismatch between the logical validity and believability relative to syllogisms with matching validity and believability. Again there was no indication that this belief bias effect was generally enhanced in anxiety disordered patients, since there was no Group $X$ Believability X Validity interaction $(F(6,150)=0.6, p=.77)$. In the univariate analyses, it turned out that belief bias was present in the neutral domain $(F(1,78)=22.5, p<.001)$ as well as in the domain of panic concerns $(F(1,78)$ $=13.3, p<.001$ ), but not in the domain of obsessive-compulsive concerns 
$(F(1,78)=1.5, p=.23)$. There were no significant Group X Believability $\mathrm{X}$ Validity interactions within the domains (all $F$ 's $(2,78)<.9, p$ 's $>.4$ ).

Table 3. Error rates (\%) and standard deviations (SD) on the syllogistic reasoning task for controls and anxiety patients at $\mathrm{Tl}$.

\begin{tabular}{|c|c|c|c|c|c|c|c|}
\hline & & \multicolumn{2}{|c|}{$\begin{array}{l}\text { Controd } \\
(n=20)\end{array}$} & \multicolumn{2}{|c|}{$\begin{array}{c}\text { OCD } \\
(n=25)\end{array}$} & \multicolumn{2}{|c|}{$\begin{array}{c}\text { PD } \\
(n=36)\end{array}$} \\
\hline & & believabtle & $\begin{array}{c}\text { not } \\
\text { believable }\end{array}$ & believable & $\begin{array}{c}\text { not } \\
\text { believable }\end{array}$ & believable & $\begin{array}{c}\text { not } \\
\text { believable }\end{array}$ \\
\hline \multirow{2}{*}{ Neutral } & Valid & $\begin{array}{l}8 \% \\
(10)\end{array}$ & $\begin{array}{l}34 \% \\
(36)\end{array}$ & $\begin{array}{l}4 \% \\
(6)\end{array}$ & $\begin{array}{l}28 \% \\
(35)\end{array}$ & $\begin{array}{l}14 \% \\
(19)\end{array}$ & $\begin{array}{l}28 \% \\
(31)\end{array}$ \\
\hline & Not valid & $\begin{array}{l}30 \% \\
(31)\end{array}$ & $\begin{array}{l}19 \% \\
(23)\end{array}$ & $\begin{array}{l}20 \% \\
(30)\end{array}$ & $\begin{array}{l}13 \% \\
(23)\end{array}$ & $\begin{array}{l}33 \% \\
(31)\end{array}$ & $\begin{array}{l}18 \% \\
(19)\end{array}$ \\
\hline \multirow{2}{*}{ OC } & Valid & $\begin{array}{l}29 \% \\
(34)\end{array}$ & $\begin{array}{l}23 \% \\
(29)\end{array}$ & $\begin{array}{l}19 \% \\
(23)\end{array}$ & $\begin{array}{l}21 \% \\
(24)\end{array}$ & $\begin{array}{l}23 \% \\
(23)\end{array}$ & $\begin{array}{l}29 \% \\
(28)\end{array}$ \\
\hline & Not valid & $\begin{array}{l}26 \% \\
(26)\end{array}$ & $\begin{array}{l}24 \% \\
(26)\end{array}$ & $\begin{array}{l}20 \% \\
(24)\end{array}$ & $\begin{array}{l}14 \% \\
(19)\end{array}$ & $\begin{array}{l}26 \% \\
(26)\end{array}$ & $\begin{array}{l}24 \% \\
(23)\end{array}$ \\
\hline \multirow{2}{*}{ Panic } & Valid & $\begin{array}{l}18 \% \\
(26)\end{array}$ & $\begin{array}{l}29 \% \\
(35)\end{array}$ & $\begin{array}{l}8 \% \\
(15)\end{array}$ & $\begin{array}{l}24 \% \\
(34)\end{array}$ & $\begin{array}{l}19 \% \\
(21)\end{array}$ & $\begin{array}{l}33 \% \\
(31)\end{array}$ \\
\hline & Not valid & $\begin{array}{l}30 \% \\
(36)\end{array}$ & $\begin{array}{l}18 \% \\
(20)\end{array}$ & $\begin{array}{l}23 \% \\
(32)\end{array}$ & $\begin{array}{l}10 \% \\
(21)\end{array}$ & $\begin{array}{l}30 \% \\
(29)\end{array}$ & $\begin{array}{l}19 \% \\
(18)\end{array}$ \\
\hline
\end{tabular}

Note. Neutral $=$ syllogisms within the neutral domain; $O C=$ syllogisms within the obsessive-compulsive domain; Panic $=$ syllogisms within the panic domain.

Domain-specificity. Means of the response latencies ( $V_{\mathrm{ms}}$ ) and number of logical errors for each group of participants at T1 are depicted in Figures 1 (Neutral domain), 2 (OCD-themes), and 3 (Panic-themes). Post-hoc 2 (Believability) $\times 2$ (Validity) MANOVAs on the response latencies in the three domains for each group of participants revealed that normal subjects displayed belief bias on syllogisms in the neutral domain $(F(1,15)=4.7, p<$ $.05)$, but not in the domain of obsessive-compulsive concerns $(F(1,15)=0.2$, $p>.6)$ nor in the domain of panic concerns $(F(1,15)=0.8, p>.3)$. For the obsessive-compulsive patients, belief bias did not reach significance in the neutral domain $(F(1,19)=3.2, p=.09)$ nor in any of the disorder relevant 


\section{Chapter 3}

domains (Both $F$ 's $(1,19)<0.1, p$ 's $>9$ ). Panic disordered patients only displayed significant belief bias in the domain of panic concerns $(F(1,30)=$ $7.9, p=.009)$. They displayed no belief bias in the neutral domain $(\mathrm{F}(1,30)=$ $2.7, p>1)$ nor in the obsessive-compulsive domain $(F(1,30)=2.0, p>.15)$

With respect to the logical errors a similar 2 (Believability) $X 2$ (Validity) MANOVAs on the number of logical errors in the three domains for each group of participants revealed that normal subjects displayed belief bias on syllogisms in the neutral domain $(F(1,19)=7.9, p<.05)$, but not in the domain of obsessive-compulsive concerns $(F(1,19)=0.1, p>.7)$ nor in the domain of panic concerns $(F(1,19)=2.5, p>.1)$. In the obsessivecompulsive patients, belief bias became evident in the neutral domain $(F(1,24)=6.6, p<.05)$ and in the domain of panic concerns $(F(1,24)=5.2, p$ $<.05)$, but not in the obsessive-compulsive domain $(\mathrm{F}(1,24)=2.1, p>.15)$. The panic disordered patients displayed the same pattern as the obsessivecompulsive patients, with significant belief bias on the neutral domain $(F(1,35)=8.6, p<.01)$ as well as on the panic domain $(F(1,35)=6.8, p<$ $.05)$, but not on the obsessive-compulsive domain $(F(1,35)=2.7, p>.1)$. 
Figure 1. Means of the response latencies ( $\mathrm{Jms}$ ) and number of logical errors for controls, obsessive-compulsive patients (OCD) and panic disorder patients (PD) on syllogisms concerning neutral themes at $\mathrm{T} 1$.

Neutral themes: Response latencies

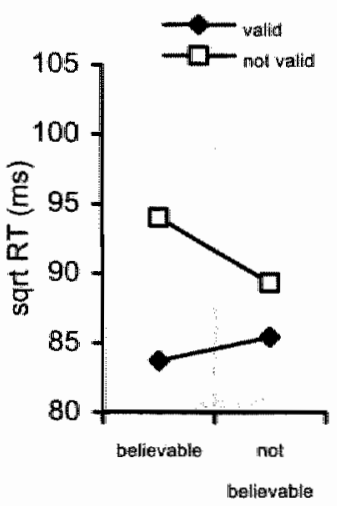

Controls*

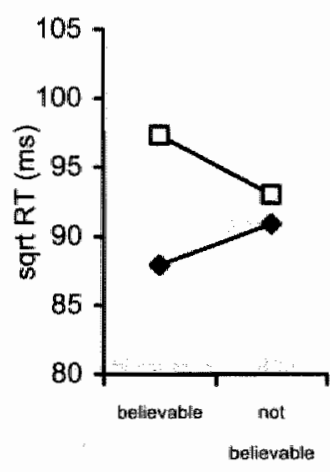

OCD

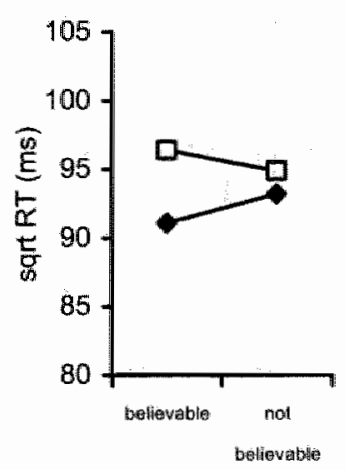

PD

Neutral themes: Logical errors

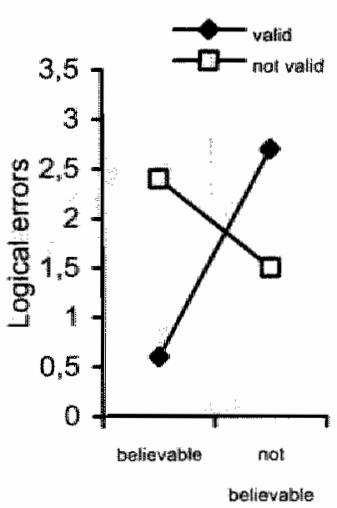

Controls*

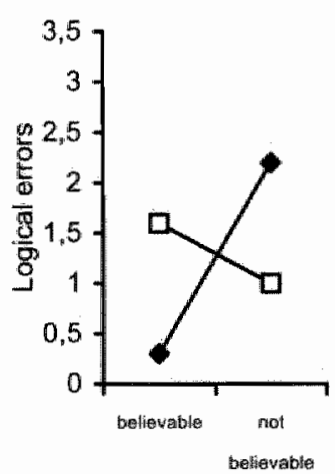

OCD*

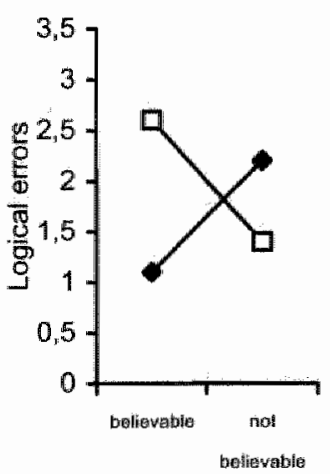

$\mathrm{PD}^{*}$

Note. ${ }^{*}$ Significant interaction (i.e., belief bias; $p<.05$ ) 
64 Chapter 3

Figure 2. Means of the response latencies $(\mathrm{Jms})$ and number of logical errors for controls, obsessive-compulsive patients (OCD) and panic disorder patients (PD) on syllogisms concerning neutral themes at $\mathrm{T} 1$.

$O C D$ themes: Response latencies

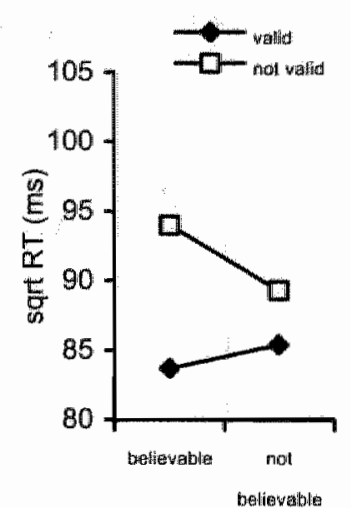

Contrals*

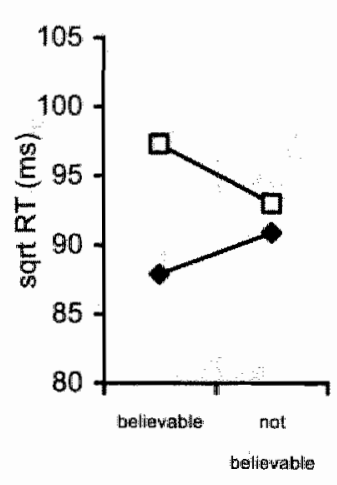

OCD

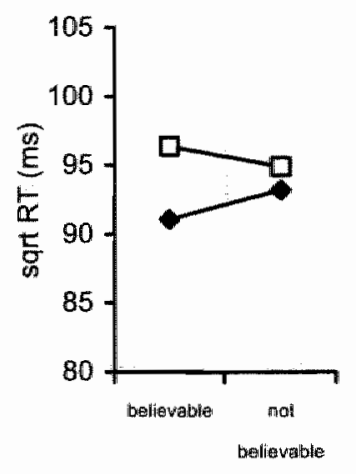

PD

OCD themes: Logical errors
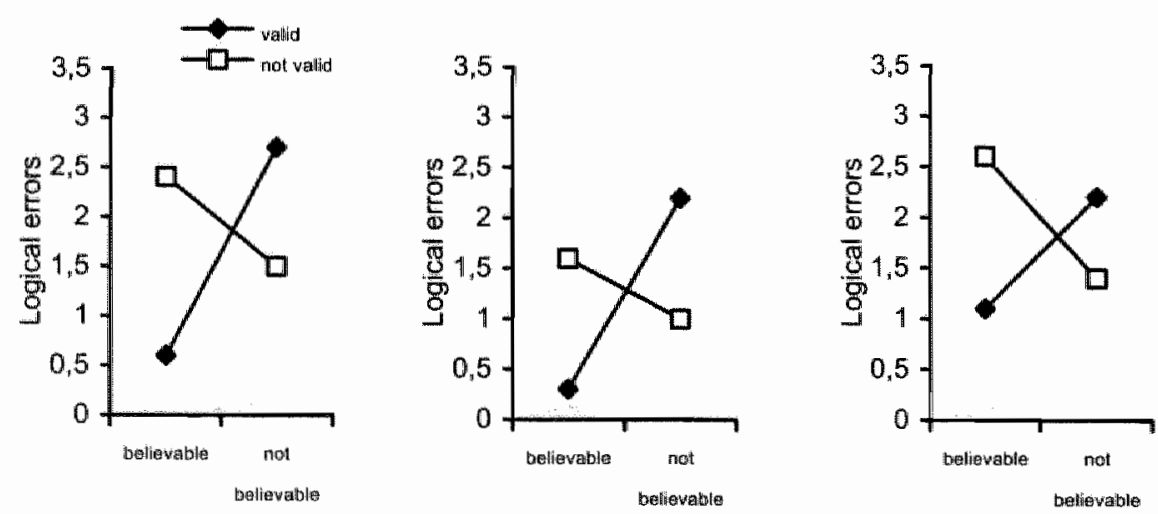

Controls $^{*}$

OCD*

PD*

Note. ${ }^{*}$ Significant interaction (i.e., belief bias; $p<.05$ ) 
Figure 3. Means of the response latencies ( $\mathrm{Vms}$ ) and number of logical errors for controls, obsessive-compulsive patients (OCD) and panic disorder patients (PD) on syllogisms concerning neutral themes at $\mathrm{T} 1$.

Panic themes: Response latencies

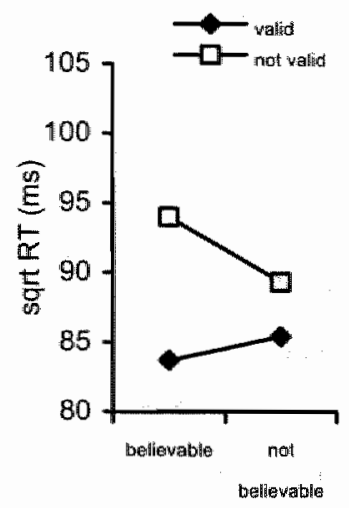

Contrals ${ }^{\star}$

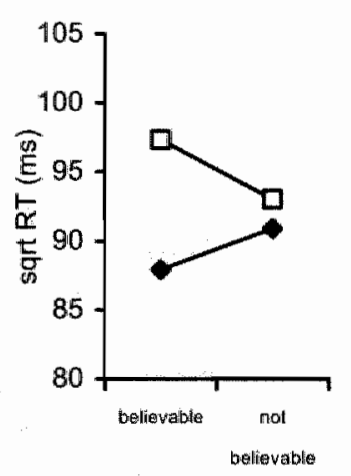

$O C D$

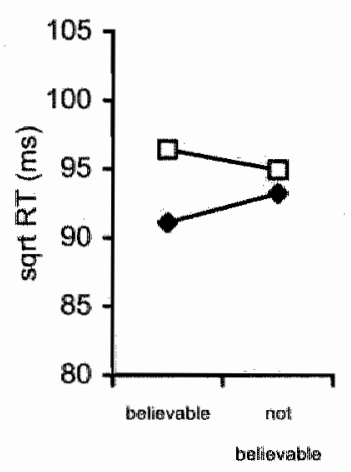

PD

Panic themes: Logical errors
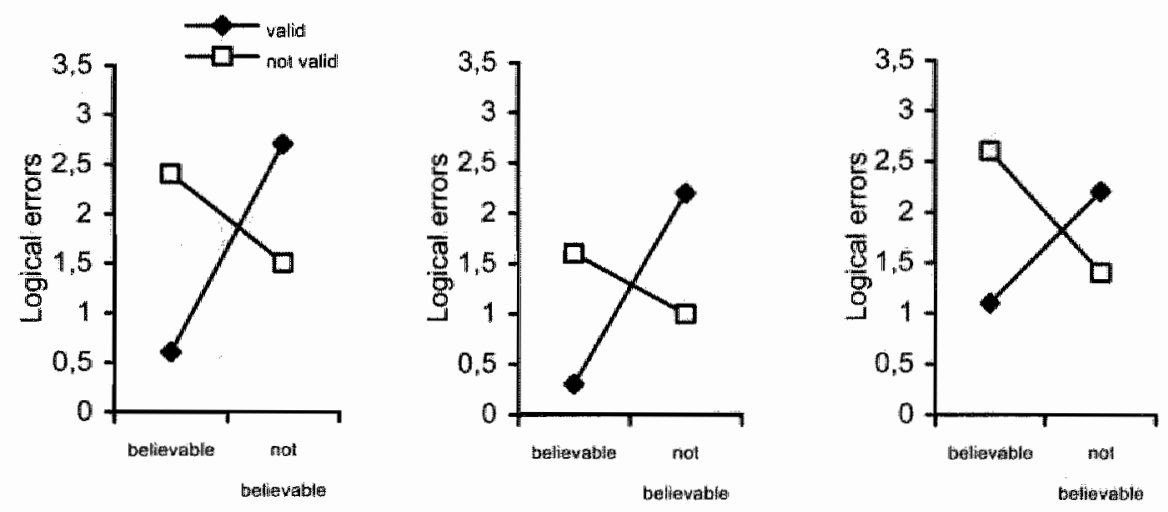

Contrals*

OCD*

PD*

Note. * Significant interaction (i.e., belief bias; $p<.05$ ) 


\section{Belief bias and treatment outcome}

Treatment effects as measured with FQ and SCL-90 are depicted in Table 4. The 2 Group (OCD vs. PD) X 2 Time (pre vs. post) MANOVA on the selfreport measures of anxiety (FQ) and general psychopathology (SCL-90) revealed a significant main effect of Tíme $(F(2,27)=7.7, p<.01)$. There was no interaction between Group and Time $(F(2,27)=2.0, p=.15)$, indicating that treatment-effects were similar for both groups of patients.

Table 4. Means and standard deviations (SD) for obsessive-compulsive and panic disordered patients on the Fear Questionnaire and the Symptom Checklist at pretreatment (Pre), post-treatment (Post) and follow-up (FU).

\begin{tabular}{|c|c|c|c|c|c|c|}
\hline & & $\begin{array}{c}\text { OCD } \\
(n=18)\end{array}$ & & & $\begin{array}{c}\text { PD } \\
(n=12)\end{array}$ & \\
\hline & Pre: & Past & Fu & Pre & Post & $\mathrm{FU}$ \\
\hline $\mathrm{FQ}$ total & $\begin{array}{l}65.6 a \\
(30.8)\end{array}$ & $\begin{array}{l}55.7 \mathrm{~b} \\
(30.7)\end{array}$ & $\begin{array}{l}56.9 \mathrm{~b} \\
(32.7)\end{array}$ & $\begin{array}{l}93.5 \mathrm{a} \\
(39.5)\end{array}$ & $\begin{array}{l}77.6 \mathrm{~b} \\
(37.3)\end{array}$ & $\begin{array}{l}51.8 \mathrm{a} \\
(31.9)\end{array}$ \\
\hline SCL-90 total & $\begin{array}{c}215.7 \text { a } \\
(70.6)\end{array}$ & $\begin{array}{c}180.3 \mathrm{~b} \\
(60.4)\end{array}$ & $\begin{array}{c}171.8 \mathrm{~b} \\
(57.5)\end{array}$ & $\begin{array}{l}187.6 \mathrm{a} \\
(49.5)\end{array}$ & $\begin{array}{l}173.3 b \\
(54.1)\end{array}$ & $\begin{array}{l}130.1 \mathrm{c} \\
(29.8)\end{array}$ \\
\hline FQmain phobita & $\begin{array}{l}13.3 \mathrm{a} \\
(2.6)\end{array}$ & $\begin{array}{l}10.3 \mathrm{~b} \\
(3.6)\end{array}$ & $\begin{array}{l}8.1 \mathrm{c} \\
(3.8)\end{array}$ & $\begin{array}{l}11.6 \mathrm{a} \\
(2.7)\end{array}$ & $\begin{array}{l}8.5 b \\
(5.3)\end{array}$ & $\begin{array}{l}5.1 \mathrm{c} \\
(3.6)\end{array}$ \\
\hline FQ-agoraphobia & $\begin{array}{l}16.4 \mathrm{a} \\
(13.7)\end{array}$ & $\begin{array}{l}14.5 \mathrm{a} \\
(13.4)\end{array}$ & $\begin{array}{l}14.8 \mathrm{a} \\
(13.4)\end{array}$ & $\begin{array}{l}39.3 \mathrm{a} \\
(23.9)\end{array}$ & $\begin{array}{l}28.8 \mathrm{~b} \\
(17.5)\end{array}$ & $\begin{array}{l}19.0 \mathrm{c} \\
(12.5)\end{array}$ \\
\hline SCL -90 anxiety & $\begin{array}{l}20.1 \mathrm{a} \\
(7.8)\end{array}$ & $\begin{array}{c}16.4 b \\
(7.4)\end{array}$ & $\begin{array}{c}14.3 \mathrm{~b} \\
(6.8)\end{array}$ & $\begin{array}{c}27.1 \mathrm{a} \\
(9.7)\end{array}$ & $\begin{array}{c}22.7 \mathrm{~b} \\
(9.9)\end{array}$ & $\begin{array}{l}15.4 c \\
(3.2)\end{array}$ \\
\hline $\begin{array}{l}\text { SCL-90 } \\
\text { agarapliobia }\end{array}$ & $\begin{array}{l}21.0 \mathrm{a} \\
(11.6)\end{array}$ & $\begin{array}{l}16.2 \mathrm{~b} \\
(8.5)\end{array}$ & $\begin{array}{l}14.9 \mathrm{~b} \\
(6.7)\end{array}$ & $\begin{array}{c}19.5 a \\
(6.9)\end{array}$ & $\begin{array}{l}16.4 \mathrm{~b} \\
(6.1)\end{array}$ & $\begin{array}{l}12.2 \mathrm{c} \\
(4.1)\end{array}$ \\
\hline
\end{tabular}

Note. Means within groups in the same row that do not share subscripts differ at $p<$ .05 in the Helmert within-subjects contrasts comparison. 
Univariate tests revealed that the treatment effect was evident in each of the self-report measures (FQ: $F(1,28)=15.5, p<.005$, SCL-90: $F(1,28)=7.7, p$ $<.05)$. Again there were no interactions between Group and Time ( $p^{\prime} s>2$ ). From this, it can be concluded that treatment resulted in a significant reduction of self-reported anxiety and psychopathological symptoms for both groups of patients.

Means and standard deviations for the response latencies and the error rates on the syllogistic reasoning task before and after treatment are presented in Table 5 and Table 6 respectively. Mean BBI-rt and BBI-er scores before and after treatment are depicted in Figure 4 . Because the analysis was restricted to correct answers and some participants produced only incorrect answers on one or more syllogism types, the response latencies of 11 panic disordered and 16 obsessive-compulsive patients could be analysed. The 2 (Group) X 2 (Time) MANOVA on BBI-rt for the three domains revealed no main effect of Time $F(3,23)=0.6, p=.65)$. Overall, BBI-rt was not influenced by effective treatment. There was no Time $X$ Group interaction $(F(3,23)=1.4, p=.27$ ). The 2 (Group) X 2 (Time) MANOVA on BBI-er for the three domains revealed no main effect of Time $(F(3,26)=0.9, p=.46)$. Consistent with the analysis on BBI-rt, overall, BBI-er was not influenced by effective treatment. Again, there was no Time X Group interaction $(F(3,26)=$ $0.5, p=.7)$. 
Table 5. Means and standard deviations (SD) of the reaction times $(\sqrt{\mathrm{ms}})$ on the syllogistic reasoning task for obsessive-compulsive and panic disordered patients, before (Pre) and after treatment (Post).

\begin{tabular}{|c|c|c|c|c|c|c|c|c|c|}
\hline & & \multicolumn{4}{|c|}{$\begin{array}{c}\text { OCD } \\
(n=16)\end{array}$} & \multicolumn{4}{|c|}{$\begin{array}{c}\mathbf{P D} \\
(n=11)\end{array}$} \\
\hline & & \multicolumn{2}{|c|}{ Pre } & \multicolumn{2}{|c|}{ Post: } & \multicolumn{2}{|c|}{ Pre } & \multicolumn{2}{|c|}{ Post } \\
\hline & & $\mathrm{Bel}$. & N-bel. & Bel. & N-bel. & Bel. & N-bel. & Bel. & N-bel. \\
\hline \multirow{2}{*}{ Neutral } & Valid & $\begin{array}{r}85.1 \\
(14.1)\end{array}$ & $\begin{array}{c}91.0 \\
(14.7)\end{array}$ & $\begin{array}{c}80.0 \\
(13.7)\end{array}$ & $\begin{array}{r}81.6 \\
(15.5)\end{array}$ & $\begin{array}{l}92.4 \\
(9.0)\end{array}$ & $\begin{array}{l}97.1 \\
(9.7)\end{array}$ & $\begin{array}{c}85.9 \\
(11.6)\end{array}$ & $\begin{array}{r}93.1 \\
(11.9)\end{array}$ \\
\hline & N-valid & $\begin{array}{c}96.8 \\
(16.5)\end{array}$ & $\begin{array}{c}90.0 \\
(15.9)\end{array}$ & $\begin{array}{c}85.5 \\
(16.6)\end{array}$ & $\begin{array}{c}81.9 \\
(11.9)\end{array}$ & $\begin{array}{l}100.3 \\
(11.1)\end{array}$ & $\begin{array}{c}97.6 \\
(10.4)\end{array}$ & $\begin{array}{c}93.6 \\
(11.6)\end{array}$ & $\begin{array}{c}90.4 \\
(10.9)\end{array}$ \\
\hline \multirow{2}{*}{$O C$} & Valid & $\begin{array}{c}97.5 \\
(16.2)\end{array}$ & $\begin{array}{c}95.7 \\
(13.8)\end{array}$ & $\begin{array}{c}87.7 \\
(17.1)\end{array}$ & $\begin{array}{c}88.3 \\
(17.2)\end{array}$ & $\begin{array}{l}107.1 \\
(6.6)\end{array}$ & $\begin{array}{l}101.8 \\
(11.9)\end{array}$ & $\begin{array}{l}100.8 \\
(12.6)\end{array}$ & $\begin{array}{c}94.7 \\
(10.2)\end{array}$ \\
\hline & N-valid & $\begin{array}{l}101.0 \\
(17.1)\end{array}$ & $\begin{array}{c}98.7 \\
(15.1)\end{array}$ & $\begin{array}{c}91.6 \\
(20.6)\end{array}$ & $\begin{array}{c}93.5 \\
(16.4)\end{array}$ & $\begin{array}{r}104.8 \\
(11.6)\end{array}$ & $\begin{array}{l}104.7 \\
(12.8)\end{array}$ & $\begin{array}{l}104.0 \\
(11.3)\end{array}$ & $\begin{array}{c}102.8 \\
(10.7)\end{array}$ \\
\hline \multirow{2}{*}{ Panic } & Valid & $\begin{array}{c}97.6 \\
(17.3)\end{array}$ & $\begin{array}{c}96.6 \\
(14.1)\end{array}$ & $\begin{array}{c}86.1 \\
(15.9)\end{array}$ & $\begin{array}{c}90.0 \\
(18.4)\end{array}$ & $\begin{array}{c}99.2 \\
(10.0)\end{array}$ & $\begin{array}{l}106.4 \\
(11.3)\end{array}$ & $\begin{array}{l}94.5 \\
(9.1)\end{array}$ & $\begin{array}{r}103.6 \\
(10.8)\end{array}$ \\
\hline & N-walid & $\begin{array}{r}102.9 \\
(17.8)\end{array}$ & $\begin{array}{c}99.6 \\
(15.6)\end{array}$ & $\begin{array}{c}91.2 \\
(16.3)\end{array}$ & $\begin{array}{c}88.8 \\
(15.8)\end{array}$ & $\begin{array}{l}105.6 \\
(10.0)\end{array}$ & $\begin{array}{l}104.7 \\
(8.2)\end{array}$ & $\begin{array}{l}103.9 \\
(12.5)\end{array}$ & $\begin{array}{l}103.6 \\
(12.5)\end{array}$ \\
\hline
\end{tabular}

Note. Neutral $=$ syllogisms within the neutral domain; $O C=$ syllogisms within the obsessive-compulsive domain; Panic = syllogisms within the panic domain. 
Figure 4. Mean belief bias indices (BBI_rt and BBI_er) for OCD-patients (left panel) and PD-patients (right panel) on the syllogistic reasoning task before (Pre) and after treatment (Post).

QPre DPost
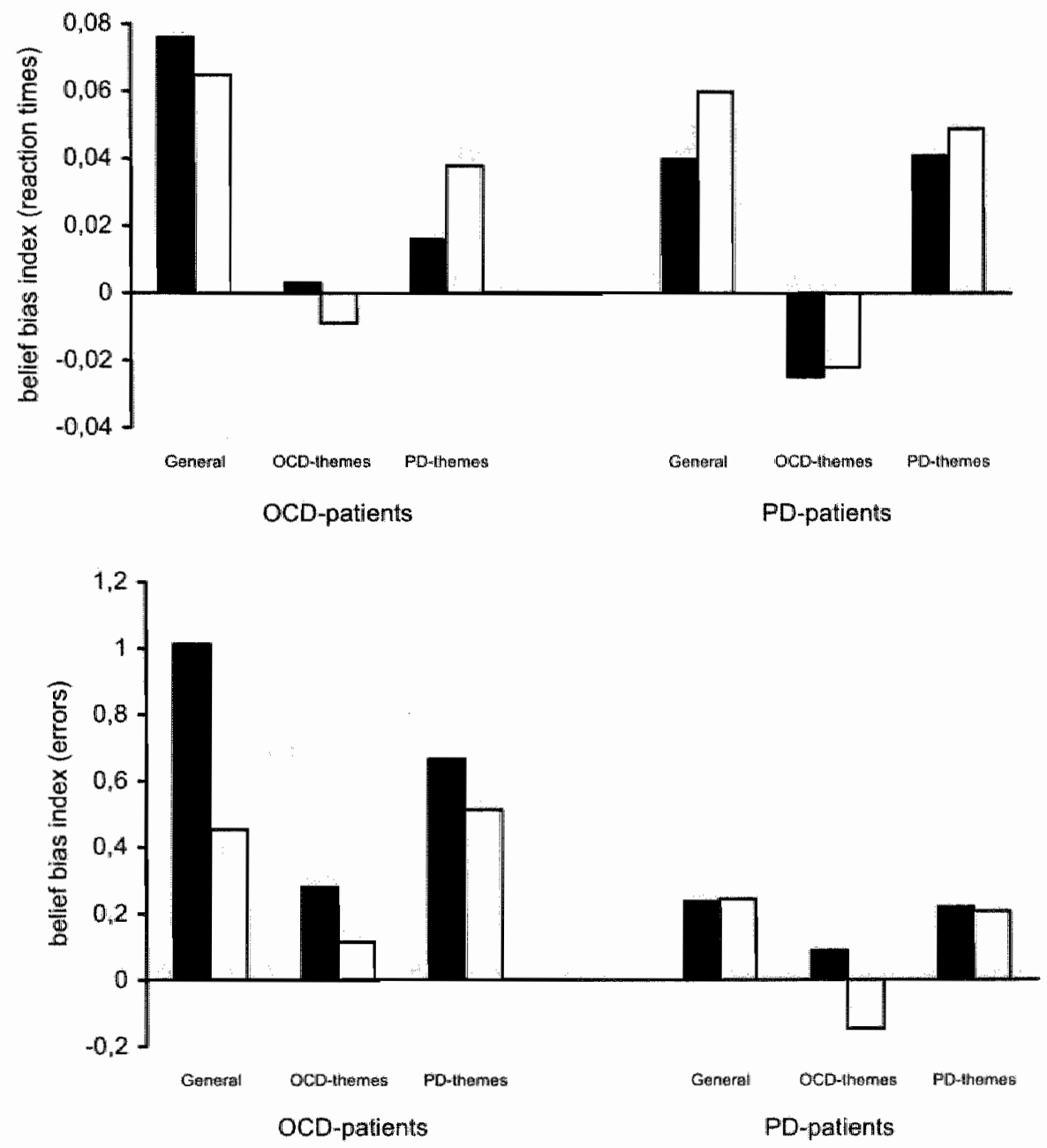
Table 6. Error rates (\%) and standard deviations (SD) on the syllogistic reasoning task for obsessive-compulsive and panic disordered patients, before (Pre) and after treatment (Post).

\begin{tabular}{|c|c|c|c|c|c|c|c|c|c|}
\hline & & \multicolumn{4}{|c|}{$\begin{array}{c}\text { OCD } \\
(n=18)\end{array}$} & \multicolumn{4}{|c|}{$\begin{array}{c}\mathbf{P D} \\
(n=12)\end{array}$} \\
\hline & & \multicolumn{2}{|c|}{ Pre } & \multicolumn{2}{|c|}{ Post } & \multicolumn{2}{|c|}{ Pre } & \multicolumn{2}{|c|}{ Post } \\
\hline & & Bel. & N-betl. & Bel. & $\mathrm{N}$-bel. & Bel. & N-bel. & $\mathrm{Bel}$ & $\mathrm{N}$-bel. \\
\hline \multirow{2}{*}{ Neutral } & Valid & $\begin{array}{l}4 \% \\
(6)\end{array}$ & $\begin{array}{l}18 \% \\
(31)\end{array}$ & $\begin{array}{l}4 \% \\
(10)\end{array}$ & $\begin{array}{l}15 \% \\
(30)\end{array}$ & $\begin{array}{l}20 \% \\
(20)\end{array}$ & $\begin{array}{l}21 \% \\
(15)\end{array}$ & $\begin{array}{l}10 \% \\
(21)\end{array}$ & $\begin{array}{l}13 \% \\
(14)\end{array}$ \\
\hline & N-valid & $\begin{array}{l}18 \% \\
(26)\end{array}$ & $\begin{array}{l}5 \% \\
(10)\end{array}$ & $\begin{array}{l}16 \% \\
(23)\end{array}$ & $\begin{array}{l}10 \% \\
(21)\end{array}$ & $\begin{array}{l}24 \% \\
(21)\end{array}$ & $\begin{array}{l}23 \% \\
(28)\end{array}$ & $\begin{array}{l}10 \% \\
\text { (1.1) }\end{array}$ & $\begin{array}{l}16 \% \\
(29)\end{array}$ \\
\hline \multirow{2}{*}{ OC } & Valid & $\begin{array}{l}14 \% \\
(23)\end{array}$ & $\begin{array}{l}18 \% \\
(24)\end{array}$ & $\begin{array}{l}9 \% \\
(15)\end{array}$ & $\begin{array}{l}13 \% \\
(21)\end{array}$ & $\begin{array}{l}23 \% \\
(15)\end{array}$ & $\begin{array}{l}23 \% \\
(19)\end{array}$ & $\begin{array}{l}25 \% \\
(26)\end{array}$ & $\begin{array}{l}16 \% \\
(19)\end{array}$ \\
\hline & N-valid & $\begin{array}{l}18 \% \\
(24)\end{array}$ & $\begin{array}{l}10 \% \\
(14)\end{array}$ & $\begin{array}{l}11 \% \\
(20)\end{array}$ & $\begin{array}{l}10 \% \\
(18)\end{array}$ & $\begin{array}{l}23 \% \\
(21)\end{array}$ & $\begin{array}{l}19 \% \\
(18)\end{array}$ & $\begin{array}{l}16 \% \\
(16)\end{array}$ & $\begin{array}{l}25 \% \\
(25)\end{array}$ \\
\hline \multirow{2}{*}{ Panic } & Valid & $\begin{array}{l}5 \% \\
\text { (11) }\end{array}$ & $\begin{array}{l}14 \% \\
(26)\end{array}$ & $\begin{array}{l}3 \% \\
(5)\end{array}$ & $\begin{array}{l}16 \% \\
(31)\end{array}$ & $\begin{array}{l}25 \% \\
(25)\end{array}$ & $\begin{array}{l}29 \% \\
(21)\end{array}$ & $\begin{array}{l}21 \% \\
(31)\end{array}$ & $\begin{array}{l}18 \% \\
(24)\end{array}$ \\
\hline & N-walid & $\begin{array}{l}19 \% \\
(31)\end{array}$ & $\begin{array}{l}6 \% \\
09)\end{array}$ & $\begin{array}{l}15 \% \\
(26)\end{array}$ & $\begin{array}{l}8 \% \\
\text { (13) }\end{array}$ & $\begin{array}{l}18 \% \\
(19)\end{array}$ & $\begin{array}{l}20 \% \\
(21)\end{array}$ & $\begin{array}{l}16 \% \\
(15)\end{array}$ & $\begin{array}{l}23 \% \\
(31)\end{array}$ \\
\hline
\end{tabular}

Note. Neutral $=$ syllogisms within the neutral domain; $\mathrm{OC}=$ syllogisms within the obsessive-compulsive domain; Panic = syllogisms within the panic domain.

In Table 7, Pearson correlations are presented between pre-treatment belief bias composite scores and treatment effects as measured with the Fear Questionnaire (FQ) and the Symptom Checklist (SCL-90). In the panic disordered group, significant and strong positive correlations were found between panic-specific belief bias on the one hand, and treatment effects $\left(\triangle F Q_{\text {pre - post }} ; \Delta F Q_{\text {pre }- \text { fus }} \Delta \mathrm{SCL}-90_{\text {pre - post; }}, \Delta S C L-90_{\text {pre - fu }}\right.$ ) on the other hand (all $r$ 's $>0.50$; all $p$ 's $<.05$ ), indicating that higher levels of pre-treatment domain-specific belief bias predict better treatment outcome. In the obsessivecompulsive group, none of the correlations reached significance, indicating that there was no association between pre-treatment belief bias and treatment outcome in this group. 
Table 7. Correlation between pre-treatment belief bias and treatment effect.

\begin{tabular}{|c|c|c|c|c|}
\hline \multirow[b]{2}{*}{$($ Pre - post $) /($ Pre-FU $)$} & \multicolumn{2}{|c|}{ BBI neutral domain } & \multicolumn{2}{|c|}{ BBI specific domain } \\
\hline & $\begin{array}{c}\text { OCD } \\
(n=16)\end{array}$ & $\begin{array}{c}\text { PD } \\
(n=12)\end{array}$ & $\begin{array}{c}\text { OCD } \\
\left(n n^{\prime \prime}=18\right)\end{array}$ & $\begin{array}{c}\text { PD } \\
(n=12)\end{array}$ \\
\hline$\triangle F Q$ & $0.01 / 0.04$ & $0.40 / 0.09$ & $-0.01 / 0.32$ & $0.71 * / 0.83 * *$ \\
\hline$\triangle S C L-90$ & $-0.15 /-0.07$ & $0.10 /-0.03$ & $-.16 / 0.17$ & $0.51 * / 0.62 *$ \\
\hline
\end{tabular}

* Correlation is significant at the 0.05 level (two-tailed)

** Correlation is significant at the 0.01 level (two-tailed)

Pearson correlations between changes in belief bias composite scores $\left(\triangle B B I_{\text {pre - post }}\right)$ and treatment effects as measured with Fear Questionnaire $\left(\Delta F Q_{\text {pre - posi }}\right)$ and the Symptom Checklist $\left(\triangle S C L-90_{\text {pre - posi }}\right)$ are presented in Table 8. In general, there was no association between overall treatment effects and changes in belief bias levels. None of the correlations reached significance.

Table 8. Correlation between changes in belief bias and treatment effect.

\begin{tabular}{|c|c|c|c|c|}
\hline \multirow{2}{*}{$\begin{array}{l}\text { (Pre - post) } \\
\text { (Pre - post) }\end{array}$} & \multicolumn{2}{|c|}{$\triangle B B I$ neutral domain } & \multicolumn{2}{|c|}{$\triangle B B I$ specific domain } \\
\hline & $\begin{array}{c}\text { OCD } \\
(n=16)\end{array}$ & $\begin{array}{c}\text { PD } \\
(n=11)\end{array}$ & $\begin{array}{c}\text { OCD } \\
(n=18)\end{array}$ & $\begin{array}{c}\text { PD } \\
(n=11)\end{array}$ \\
\hline$\triangle \mathrm{FQ}$ & 0.07 & 0.06 & -10.20 & 0.20 \\
\hline$\triangle S C L-90$ & -0.45 & -0.17 & -.41 & -0.08 \\
\hline
\end{tabular}

Note. None of the correllations reached significance.

\section{Post-treatment belief bias and relapse}

Pearson correlations between composite scores of post-treatment belief bias and relapse as measured with the Fear Questionnaire $\left(\Delta F Q_{\text {post }}\right.$ fu $)$ and the Symptom Checklist ( $\triangle \mathrm{SCL}-90_{\text {post }-\mathrm{fu}}$ ) are presented in Table 9. A significant negative correlation was found in the obsessive-compulsive group between post-treatment OCD-specific belief bias on the one hand, and the SCL-90 post-fu difference score on the other hand $(r=.49, p<.05)$ This correlation 
indicates that a higher level of OCD-specific belief bias at post-treatment was associated with greater relapse in general psychopathology in obsessivecompulsive patients.

Table 9. Correlations between post-treatment belief bias and relapse.

\begin{tabular}{|c|c|c|c|c|}
\hline \multirow[b]{2}{*}{$($ Post - FU) } & \multicolumn{2}{|c|}{ BBI neutral domain } & \multicolumn{2}{|c|}{ BBI specific domaim } \\
\hline & $\underset{(n=17)}{O C D}$ & $\begin{array}{c}\text { PD } \\
(n=11)\end{array}$ & $\begin{array}{c}\operatorname{OCD} \\
(n=18)\end{array}$ & $\begin{array}{c}\mathbf{P D} \\
(n=\| 1)\end{array}$ \\
\hline$\triangle \mathrm{PQ}$ & 0.41 & -0.22 & -0.29 & 0.36 \\
\hline$\triangle \$ S C-90$ & -0.38 & -0.35 & $-.49^{*}$ & 0.02 \\
\hline
\end{tabular}

* Correlation is significant at the 0.05 level (two-tailed)

\section{DISCUSSION}

The results of the present study demonstrate that participants generally make significantly more errors and display significantly longer response latencies on those syllogisms that have a mismatching believability and logical validity. All groups of participants demonstrated belief bias in the sense that they tend to endorse conclusions which are a priori believable as logically valid and those which are unbelievable as invalid, regardless of the actual logical status of the conclusions (cf. Evans, Over \& Manktelow, 1993). The finding that response latencies as well as error rates were relatively large when syllogisms did not match with the subjects' prior beliefs, is in line with the idea that reasoning processes may reciprocally affect prior beliefs in a way that is likely to maintain existing beliefs.

In contrast to our predictions the present data lend no support for the idea that belief bias is generally enhanced in panic disordered or obsessivecompulsive patients. In previous research, it was found that spider phobic individuals are characterized by an enhanced belief bias that was not restricted to the domain of their specific phobic concerns, but which was also present in 
syllogisms concerning neutral themes (de Jong et al., 1997). It was argued that such a general reasoning bias would impede the correction of erroneous convictions that are potentially pathogenic, which in turn would make people vulnerable for the acquisition of pathological anxiety. The present data do not support the idea that panic disordered or obsessive-compulsive patients are characterized by such a trait-like reasoning bias that could have acted as a diathesis in the development of their disorder. With respect to the role of enhanced belief bias in the development of psychopathology, the present finding is consistent with the results of previous study in a non-clinical sample (Smeets \& de Jong, 2005). In an attempt to shed some more light on the relationship between belief bias and psychopathology, Smeets and de Jong (2005) argued that if belief bias is indeed a causal agent in the acquisition of psychopathology (cf. de Jong et al, 1997), the relationship between belief bias and psychopathological symptoms should also be present in the preclinicall range. However, in contrast to this prediction no evidence emerged to support the presence of such a linear association between belief bias and the severity of self-reported psychopathological complaints. The present study cast further doubt on the idea that belief bias might be a predisposing factor in the development of psychopathology. Meanwhile, it remains clear that once pathogenic concerns are present, common belief bias logically hinders the realistic evaluation of critical situations, thereby sustaining such irrational concerns.

The present finding that obsessive-compulsive and panic disordered patients do not generally differ from normal controls with respect to their reasoning strategies fits to the findings reported by Pélissier and $O^{\prime} \mathrm{Connor}$ (2002). Using a series of reasoning tasks concerning neutral themes, these authors tested whether obsessive-compulsive and generalized anxiety disordered patients differed from non-anxious controls with respect to inductive and deductive reasoning patterns. Although the experimental 


\section{Chapter 3}

paradigms used by Pélissier and O'Connor did not focus directly on the influence of subjective believability of the premises and conclusions in their deductive reasoning tasks, they also failed to find evidence to sustain the idea that clinical groups differ from normal controls with respect to their ability to make correct deductions. Furthermore, these authors found no differences between the three groups concerning their ratings of the plausibility of a conclusion that was based on a given premise. Together, these earlier findings led Pélissier and $O^{\prime}$ Connor (2002) to conclude that there are no fundamental differenees in deductive reasoning between anxiety patients and non-anxious controls.

With respect to the domain-specificity of the reasoning bias, we found that normal subjects display belief bias in the neutral domain, but not in any of the disorder specific domains. This effect was independent of whether belief bias was operationalized in terms of response latencies or in terms of logical errors. In contrast to normal controls and in line with our hypothesis, panic disordered patients typically displayed belief bias in the domain of panic-related concerns. Panic patients displayed no belief bias in de obsessive-compulsive domain. In the neutral domain, they did display a significant belief bias but only in terms of the number of logical errors. No domain-specific belief bias could be demonstrated in the obsessivecompulsive group. Meanwhile, obsessive-compulsive patients did show belief bias in the neutral domain (in terms of error rates). One explanation for the present failure to find a domain-specific belief bias in obsessive-compulsive patients could be that the syllogistic reasoning task lacked sufficient sensitivity within the obsessive-compulsive domain. Obviously, the presence of strong prior beliefs is a prerequisite for belief bias to occur. Yet, compared to panic disorder or specific phobias, the core beliefs of obsessive-compulsive disorders are much more heterogeneous (Foa \& Kozak, 1995). In the present study, belief bias was measured using four different beliefs within each 
domain. It might well have been the case that the four syllogisms within the obsessive-compulsive domain did not consistently match to the core beliefs of the obsessive-compulsive individuals who were tested in the present study. So by and large, the present results support the idea that belief bias represents a manifestation of personally relevant beliefs.

Within the panic disordered group, it was found that pre-treatment levels of panic specific belief bias predict treatment outcome for up to $50 \%$ at post-treatment. At follow-up, even $69 \%$ of treatment effect could be predicted by the level of pre-treatment panic specific belief bias. In contrast to what one might expect, it was found that higher levels of belief bias predict better treatment outcome. No such association was found for obsessive-compulsive patients. Note however that this might be due to a lack of sensitivity of the reasoning task within the obsessive-compulsive domain (see supra). One explanation for the present finding that panic patients with higher levels of domain-specific belief bias take more profit from treatment could be that a treatment which focuses on the correction of dysfunctional beliefs, although not tailored to undermine belief bias itself, might be more effective in those cases where cognitive factors such as belief bias play a significant role in the maintenance of the complaints as compared to cases in which such cognitive factors play a less important role.

Although treatment resulted in a significant decrease in the levels of self reported anxiety and general psychopathology in both patient groups, we found no association between treatment effects and changes in the level of belief bias in any of the three domains (neither with respect to changes in the response latencies, nor in the percentage of logical errors on target syllogisms). These findings suggest that belief bias is not influenced by effective treatment. In its turn, this pattern of results refutes the idea that (domain-specific) belief bias is an epiphenomenon of psychopathological complaints (e.g., Smeets \& de Jong, 2005). In addition, it shows that the 
presence of complaint-specific belief bias is neither sufficient for the persistence of anxiety complaints nor for the persistence of psychopathology in general.

The present study found some support for the idea that higher levels of belief bias at post treatment predict relapse. In the obsessive-compulsive group, a significant association was found between post-treatment domainspecific belief bias and relapse in the level of general psychopathological complaints. However, no such association between belief bias and relapse was found in panic disordered patients. Inspection of the treatment effects revealed that only one panic patient relapsed between post treatment to follow up, whereas half of the obsessive-compulsive patients displayed at least some relapse. It is very likely therefore, that the failure to find an association between residual belief bias and the return of complaints within the panic disordered group was due to the fact that there was no substantial return of complaints in this group (i.e., restriction of range). Given the fact that the level of belief bias did not systematically change through effective treatment in any of the groups, and that domain-specific belief bias was present at least in de PD-group before treatment, the present findings clearly show that a high level of belief bias in itself is not a sufficient cause for anxiety symptoms to return. If, however, symptoms do return, as was the case in some patients within the obsessive-compulsive group, the level of domain-specific belief bias that remains after effective treatment was found to be predictive of relapse. Taken together, it can be concluded that, although belief bias in itself is not sufficient for anxiety complaints to arise, it might play a vital role in the persistence and the return of such complaints.

The finding that belief bias in anxiety disordered patients is domainspecific and not generally enhanced, addls to the idea that belief bias reflects a normal manifestation of personally held beliefs. That is, one could argue that anxiety patients do not display reasoning abnormalities in general, but merely 
display abnormalities with respect to the specific content of their personal beliefs, which in turn results in domain-specific belief bias as a common consequence of endorsing those beliefs. The finding that domain-specific belief bias was not affected by the reduction of dysfunctional beliefs (i.e., effective treatment) appears somewhat contrasting to this viewpoint. Several explanations can be put forward to explain these apparently contrasting findings. One possibility could be that the dysfunctional beliefs on which treatment was aimed in the present sample did not systematically match to the beliefs that were used to construct the disorder-specific syllogisms for the present study, leaving the domain-specific belief bias level unaffected. Another possibility could be that although dysfunctional beliefs diminish through treatment (e.g., Arntz, 2002), they might still exist on a low or even non-conscious level when the clinical symptoms of the disorder have disappeared (e.g., Wilson, Lindsey \& Schooler, 2000). Note that the syllogistic reasoning task can be seen as an indirect measure of the influence of idiosyncratic beliefs on subjects' reasoning strategies and behaviour. Accordingly, it might well be that the present reasoning task more closely reflects automatically activated beliefs rather than more deliberate, reflexive beliefs (cf. Strack \& Deutsch, 2004). There is evidence that automatic beliefs are relatively resistant to (therapy-induced) change (e.g., Teachman \& Woody, 2003; Huijding \& de Jong, in preparation) which may explain the apparent absence of systematic treatment effects on patients' belief bias. It might well be that residual automatic dysfunctional beliefs play a role in the return of the original explicit (dysfunctional) beliefs, and therefore of the return of complaints (e.g., Wilson et al., 2000).

Future research should be aimed at the specific role of reasoning errors in the persistence and return of psychopathology. It should be acknowledged that, although in itself not being a sufficient cause, (domain-specific) reasoning bias might be a prerequisite for various kinds of psychopathology to 


\section{Chapter 3}

occur. One way to test this hypothesis is to investigate whether a reduction of (domain-specific) reasoning bias would also result in a reduction of anxiety complaints. Another target for future research would be to further test the predictive validity of individuals' level of domain-specific belief bias for treatment success and relapse.

Although at present spectacular results are achieved by giving cognitive behaviour therapy for anxiety disorders, more knowledge about dysfunctional reasoning patterns that specifically contribute to the persistence of irrational fears could result in further refinement of the available interventions. In particular with a view to the long-term effects of treatment and the transfer of treatment effects beyond the domain of training, it might be very useful to put more emphasis on teaching (reasoning) skills that can be applied to deal with dysfunctional beliefs in addition to challenging its particular content. Although the modification of dysfunctional cognitive processes is implicitly addressed in CBT, it is currently not a specific objective of the intervention.

In sum, the present study demonstrated that in general, normal controls as well as panic disordered and obsessive-compulsive patients display a belief bias. Secondly, we found that belief bias is not generally enhanced in anxiety patients. Thirdly, it was demonstrated that panic disordered patients display a domain-specific belief bias, whereas this could not be demonstrated in obsessive-compulsive patients. Fourthly, the level of domain-specific belief bias before treatment strongly predicts treatment outcome in panic disordered patients at post treatment as well as at follow up. Fifthly, belief bias levels are not influenced by effective treatment. Sixthly, the level of belief bias that remains after effective treatment can predict relapse. The results pinpoint the potential value of belief bias in predicting treatment outcome and relapse. More research is necessary to critically test the causal properties of belief bias in the maintenance of pathological anxiety. Therefore, we are currently testing 
whether treatment that is aimed at reducing domain-specific belief bias results in a reduction of pathological anxiety.

\section{REFERENCES}

American Psychiatric Association. (1994). Diagnostic and statistical mamual of mental disorders ( $4^{\text {th }}$ ed.). Washington, $\mathrm{DC}$ : Author.

Arntz, A. (2002). Cognitive therapy versus interoceptive exposure as treatment of panic disorder without agoraphobia. Behaviour, Research and Therapy" 40, $325-341$.

Arntz, A., Rauner, M., \& van den Hout, M.A. (1995). 'If I feel anxious, there must be danger': Ex-consequentia reasoning in inferring danger in anxiety disorders. Behawiour Research and Therapy, 33, 917-925.

Arrindell, W. A., \& Ettema, J. H.M., SCL-90 (1986). Handleiding bij een multidimensionele psychopathologie-indicator. Lisse, The Netherlands: Swets and Zeitlinger.

Beck, A.T. (1976). Cognitive therapy and the emotional disorders. New York: Meridan

Clark, D.M. (1986). A cognitive approach to panic. Behaviour Research and Therapy, $24,461-470$.

Clark, D.M. (1999). Anxiety disorders: Why they persist and how to treat them. Behaviour Research and Therapy, 37, S5-S27.

Clark, D.M. \& Wells, A. (1995). A cognitive model of social phobia. In R.G. Heimberg, M.R. Liebowitz, D.A. Hope \& F.R. Schneier, Social phobia. New York: Guilford Press. pp 69-93.

Clark, D.M., Salkovskis, P.M., Hackmann, A., Middleton, H. Anastasiades, P., \& Gelder, M. (1994). A comparison of cognitive therapy, applied relaxation and imipramine in the treatment of panic disorder. British Journal of Psychiarry, 165, 759-769.

Clark, D.M., Salkovskis, P.M., Hackmann, A., \& Middleton, H. (1994). Cognitive therapy for panic: Reply. British Journal of Psychiatry, 165, 557-559. 
de Jong, P.J., Weertman, A., Horselenberg, R., \& Van den Hout, M.A. (1997). Deductive reasoning and pathological anxiety: Evidence for a relatively strong "belief bias" in phobic subjects. Cognitive Therapy and Research, 21, 647 662.

Derogatis, L.R., Lipman, R.S., \& Covi, L. (1973). SCL-90: An outpatient psychiatric rating scale. Preliminary report. Psychopharmacology Bulletin, 9, 13-27.

Ehlers, A., \& Clark., D.M. (2000). A cognitive model of posttraumatic stress disorder. Behcriour Research and Therapy, 38, 319-345.

Evans, J. St. B. T., Over, D.E., \& Manktelow, K.I. (1993). Reasoning, decision making and rationality. Cognition, 49, $164-187$.

Foa, E.B., \& Kozak, M.J. (1995). DSM-IV field trial: Obsessive-compulsive disorder. American Journal of Psychiatry, 152, 90-96

Garrety, P.A., \& Hemsley, D.R. (1997). Delusions: Investigations into the psychology of delusional reasoning. Hove: Psychology Press Ltd.

Huijding, J., \& de Jong, P.J. (2005). The change of automatic and self-peported spider phobia-related affective associations over the course of treatment and the prediction of relapse. Manuscript in preparation.

Marks, I. M. \& Mathews, A. M. (1979). Brief standard self-rating for phobic patients. Behaviour Research and Therapy, 17, 263-267.

McNally, R.J. (2001). On the scientific status of cognitive appraisal models of anxiety disorder, Behaviour Research and Therapy, 39, 513-521.

Pélissier, M.C., \& O'Connor, K.P. (2002). Deductive and inductive reasoning in obsessive-compulsive disorder. British Journal of Clinical Psychology, 41, 1527.

Rosental, R. \& Rosnow, R.L. (1991). Essentials of behavioral research: Methods and data analysis (2nd ed.). New York: McGraw-Hill.

Salkovskis, P.M., Clark, D.M., Hackmann, A., Wells, A., \& Gelder, (1999). An experimental investigation of the role of safety-seeking behaviours in the maintenance of panic disorder with agoraphobia. Behaviour Research and Therapy, 37, 539-574. 
Salkovskis, P.M. (1999). Understanding and treating obsessive-compulsive disorder. Behaviour Research and Therapy, 37, \$29-S52.

Smeets, G., \& de Jong, P.J. (2005). Belief bias and symptoms of psychopathology in a non-clinical sample. Cognitive Therapy and Research, 29, 377-386.

Strack, F., \& Deutsch, R. (2004). Reflective and impulsive determinants of social behaviour. Personality and Social Psychology Review, 8, 220-247.

Teachman, B. A., \& Woody, S. R. (2003). Automatic processing in spider phobia: Implicit fear associations over the course of treatment. Journal of Abnormal Psychology, 112, 100-109.

van Oppen, P., \& Arntz, A. (1994). Cognitive therapy for obsessive-compulsive disorder. Behaviour Research and Therapy。32, 79-87.

Weissman, M.M., \& Markowitz, J.C. (1998). An overview of interpersonal psychotherapy. In: J.C. Markowitz (Ed.). Interpersonal Psychotherapy. Washington DC: American Psychiatric Association. pp 1-33.

Wilson, T.D., Lindsey, S., \& Schooler, T.Y. (2000). A model of dual attitudes. Psychological Review, 107, 101-126. 


\section{Chapter 3}

\section{APPENDIX I}

Examples of Syllogisms with Conclusions varying in Logical Validity and Believability

\begin{tabular}{|c|c|c|}
\hline & Bellevable onehwsion & Nor believable conclusion \\
\hline Falid ronchusion & $\begin{array}{l}\text { An adwlt is older than an adolescent } \\
\text { An adolescent is older than a toddler } \\
\text { C. An adult is oldew than a roddler } \\
\text { (Type 1) }\end{array}$ & $\begin{array}{l}\text { A toddler is older than an adolescent } \\
\text { An adolescent is older than an adult } \\
C: A \text { toddler is older than an adult } \\
\text { (Type } 3 \text { ) }\end{array}$ \\
\hline moalid conclusion & $\begin{array}{l}\text { A toddler is older than an adolescent } \\
\text { An adolescent is older than an adult } \\
\text { C: An adult is older than or rodder } \\
\text { (Type } 2 \text { ) }\end{array}$ & $\begin{array}{l}\text { An adult is older than an adolescent } \\
\text { An adolescent is older than a toddler } \\
\text { C. A toddter is older than an adwl } \\
\text { (Type 4) }\end{array}$ \\
\hline
\end{tabular}




\section{APPENDIX II}

Syllogism Contents used in the Present Experiment*

Neutral themes:

Castle $>$ house $>$ caravan (bigger)

Airplane $>$ car $>$ bicycle (faster)

Tree $>$ bush $>$ plant (bigger)

Elephant $>$ dog $>$ mouse (bigger)

Panic themes:

Palpitations $>$ a wasp's sting $>$ a mosquito bite (more dangerous)

Dizziness $>$ hearing an ambulance $>$ sniffing a flower (scarier)

Gasping > a dark cellar > a romantic movie (scarier)

Pain on the chest $>$ broken leg $>$ cold (more dangerous)

Obsessive-compulsive themes:

Dirtiness $>$ smoking $>$ sports (more dangerous)

Being careful $>$ being learned $>$ being nice (more dangerous)

Preventing mistakes $>$ relaxing $>$ having fun (more dangerous)

Checking $>$ being creative $>$ acting quickly (more dangerous)

* Note: Syllogisms varied systematically in believability and validity, in the same way as the examples in Appendix I. 


\section{CHAPTER 4}

\section{BETTER SAFE THAN SORRY: REASONING WITH CONDITIONALS IN THE CONTEXT OF THREAT}

Adapted from: Smeets, G., de Jong, P.J., \& Mayer, B. (submitted). Better safe than sorry: Reasoning with conditionals in the context of threat. 


\title{
86 Chapter 4
}

\begin{abstract}
To explore human reasoning in the context of threat we carried out three experiments. In Experiment 1, female undergraduates $(n=40)$ were presented with Wason selection tasks pertaining to threatening situations. The selection tasks contained safety rules (if $p$ then safe) and danger rules (if $p$ then danger). Participants relatively often selected potentially falsifying cards in case of safety rules whereas they relatively often selected potentially verifying cards in case of danger rules. In experiment $2(n=48)$, we systematically varied the type of rule (safe/danger) and the absence/presence of a negation in the consequent (i.e., if $p$ then safe/if $p$ then no danger/if $p$ then not safe/if $p$ then danger) to disentangle the relative contributions of a danger-confirming strategy and matching bias. Again, subjects displayed a danger-confirming strategy. Meanwhile, no evidence for matching bias emerged. In Experiment 3 $(n=60)$, we explored the influence of perceived threat on the degree of danger-confirming reasoning. For this purpose we created a high-threatening and a low-threatening version of the WST. In both conditions subjects displayed a danger-confirming strategy. No effect of threat intensity emerged. The preference of confirmatory reasoning in the domain of threat may have clinical significance. If such a reasoning strategy is also present in the realm of irrational threats (e.g., phobias), this may serve to maintain individuals, fearful concerns.
\end{abstract}




\section{INTRODUCTION}

To explain the persistence of phobic fear despite the availability of information that can disconfirm that the feared cues are dangerous, several mechanisms have been put forward. For instance, several authors have demonstrated that anxiety disordered patients are characterized by an attentional bias toward threat-related information (e.g., Mathews \& MacLeod, 1985; Lavy, Van den Hout, \& Arntz, 1993). It has been suggested that such a processing bias reflects an increased focus on danger and threat stimuli, which, in turn, is likely to perpetuate phobic fear (e.g., Mineka \& Sutton, 1992). In addition, several studies have demonstrated that phobic subjects tend to overestimate the covariation between phobia-relevant stimuli and aversive outcomes (e.g., Tomarken, Mineka, \& Cook, 1989; de Jong, Merckelbach, Arntz, \& Nijman, 1992). Such a judgmental bias logically serves to maintain or enhance phobic fear and it has been shown that a residual covariation bias is related to the return of fear after successful treatment (de Jong, van den Hout, \& Merckelbach, 1995).

A third factor that may be related to the persistence of fear is subjects' reasoning pattern. That is, the disconfirmation of phobic cognitions (e.g., "if 1 feel a heartbeat, then I will get a heart attack"; "If I blush, then they will think that I am incompetent") requires that subjects select relevant information from the environment and subsequently deduce the logical implications of empirical evidence for a certain cognition. Unfortunately, subjects' reasoning performance has received minimal attention in experimental research on fears and phobias. Thus, the role of reasoning performance in the maintenance of irrational fears is largely unknown.

Meanwhile, there is a growing body of evidence from more fundamental reasoning research which converges to the conclusion that, in general, subjects' reasoning performance is strongly affected by pragmatic 
factors (e.g., Cheng \& Holyoak, 1985). In line with this, a series of studies employing the Wason selection task (Wason, 1968) showed that human reasoning performance differs across contents and contexts (for a review see e.g., Evans, Newstead, \& Byrne, 1993). In other words, it appears that reasoning strategies are domain-specific. Most of these studies used deontic conditionals (e.g., social contract rules; obligations/permissions) and provided evidence to suggest that subjects' responses are guided by their utility judgments (e.g., Manktelow \& Over, 1991; Kirby, 1994). That is, reasoning performance is typically not guided by formal logical rules, but by the importance that subjects attach to certain information.

If subjects' responses are, indeed, guided by their utility judgments, the influence of perceived utilities may not be restricted to reasoning with deontic conditionals, but may also be evident in other domains of vital importance, for instance life-threatening situations. Most relevant to the context of fears and phobias, it would be interesting to see whether reasoning performance in the domain of threat is also affected by perceived utilities. To explore this issue, we carried out three experimental studies. In line with previous studies concerning the influence of pragmatic factors on reasoning performance, we used the Wason selection task as the experimental technique. As compared to the syllogistic reasoning task (e.g., Smeets \& de Jong, 2005a, 2005b), the Wason selection task requires an active search of information. That is, in the syllogistic reasoning task all information that is required to solve the problem is explicitly presented, whereas in the Wason selection task the subjects have to actively search and select information that could be relevant to solve the problem. Note that the latter method is more in keeping with real life where people not only passively respond to information, but also actively search for relevant information. 


\section{EXPERIMENT 1}

To investigate the influence of perceived utilities on subjects' responses in the context of threat, we presented subjects with Wason selection tasks pertaining to potentially dangerous situations. Intuitively it seems reasonable to argue that perceived utility is systematically linked to subjective dangerousness and probability of aversive outcome. Note that any information that prevents the individual from harm in threatening situations is of vital importance.

In the domain of threat there are two different types of (indicative) rules: "If there is a certain signal then there is danger" (danger rule) and "If there is a certain signal then there is no danger" (safety rule). In potentially dangerous situations it is adaptive to rely on verifying information concerning danger rules, whereas it seems preferable to search for falsifying information in case of safety rules. An example of both types of rules may clarify this point.

An example of a danger rule could be "If the alarmbell rings, then there is a fire". In this case, it is adaptive to take the rule very seriously, even if the bell sometimes rings in the absence of a fire. That is, although it is very uncomfortable to flee for nothing on some occasions, only one time ignoring the bell may be fatal. Thus, one's interests are better served knowing whether the bell rings when there really is a fire, in which case both the antecedent and the consequent of the rule would be true (true antecedent [TA]; true consequent $[\mathrm{TC}]$ ). Whether the bell sometimes rings [TA] in the absence of a fire (false consequent $[\mathrm{FC}]$ ) would be less important to know.

An example of a safety rule could be "If the mushrooms have brown stems, then they are not poisonous". In this instance, it is adaptive to check whether it is, indeed, safe when the signal is present (are there perhaps any mushrooms that violate this rule?). In other words, it would be adaptive to 
search for possible falsifying information: mushrooms with brown stems [TA] that are nevertheless poisonous [FC].

Thus, if people, indeed, rely on utility judgments, a verifying strategy would be evident for danger rules, resulting in relatively more TC selections. Meanwhile, a falsifying strategy would be evident for safety rules, resulting in relatively more FC selections. To investigate this issue, subjects were presented with two Wason selection tasks referring to threatening contexts. One task contained a danger rule ("if $p$ then danger"), and one a safety rule ("if p then no danger").

\section{METHOD}

\section{Participants}

Participants were 40 female undergraduate students. They participated voluntarily and received a small financial renumeration. Mean age was 22.3 years $($ range $=20-26$ years $)$.

\section{Materials and Assessment}

All participants were presented with 2 selection task problems: one task containing a danger rule ("if p then danger"), and one task containing a safety rule ("if $p$ then no danger"). Each selection task consisted of a context story, a rule, and 4 cards (TA, FA, TC, FC). Participants were instructed to mark only those card(s) they definitely needed to turn over to check whether or not the rule is true for these four cases.

To control for task irrelevant pecularities of any individual context, we constructed several selection tasks (see Table 1 and the Appendix). More specifically, we designed 4 (context stories) $\times 2$ (danger/safe) selection tasks, which allowed for 12 different sets of 2 selection tasks (for each participant, a particular context appeared only once). The order of the type of rule (danger 
vs. safe) for each set as well as the order of the four cards for each problem were randomized.

Table 1 . Conditional danger (safety) rules employed in experiment 1

If the indians have blue stripehs on their face, then they are (not) aggressive.

If the monkeys are screaming, then there are (no) bears mearby.

If the mushrooms have brown stems, then they are (nof) poisonous.

If you stroke a dog when it is barking, then the dog will (not) bite.

To evaluate the threatening characteristics of the context stories, participants were asked to rate the situations' dangerousness (e.g., the dangerousness of biting dogs; the dangerousness of attacking indians), by means of $100 \mathrm{~mm}$ Visual Analogue Scales (VASs) ranging from 0 ('not dangerous at all') to 100 ('very dangerous'). To evaluate the probability of the rules, participants were asked to indicate the likelihood that the threatening stimulus would do any harm (e.g., the likelihood that the dog will bite; the likelihood that the indians will attack) by means of a VAS ranging from 0 ('not likely at all') to 100 ('very likely").

\section{Procedure}

Participants were tested in small groups (range $=2-6$ participants). Before the experiment proper, the experimenter explained the task by means of a sample item. Following this, participants received a booklet containing a written instruction, an example of the Wason selection task, and 2 selection task problems (each on a separate sheet).

After participants had completed the selection task problems, the stories and rules were presented for a second time. Participants were asked to rate the situations' dangerousness and the likelihood that the threatening stimulus would do any harm on $100 \mathrm{~mm}$ Visual Analogue Scales. 


\section{Data Reduction and Analysis}

Following the procedure of Platt and Griggs (1993), "logical' sumscores were calculated for both types of tasks. The final analysis was restricted to the TC (-1) and FC (1) selections (cf. de Jong, Mayer \& van den Hout, 1997), as only these cards differentiate between a verifying strategy (TC cards) and a falsifying strategy ( $\mathrm{FC}$ cards). Note that turning over TA cards is appropriate for both verifying and falsifying safety/danger rules, whereas turning FA cards is neither appropriate for verifying nor for falsifying safety/danger rules. To test the hypothesis that participants would tend to search for disconfirming information (FC cards) in case of safety rules and for verifying information (TC cards) in case of danger rules, sumscores of both types of tasks were subjected to a paired t-test.

To investigate the alleged dangerousness of the selection tasks' contexts and to determine whether the perceived threat was independent of the type of rule which was used (safe/danger), we computed subjective utility indices. That is, the dangerousness ratings were multiplied by the probability ratings. These indices were subjected to a paired $t$-test.

Finally, we tested the alternative explanation that the different responses to safety and danger rules are the result of differences with respect to the rules' probability. It has been suggested that participants might consider safety rules (e.g., "if the dog is barking, it will not bite') as less probable than danger rules (e.g., "if the dog is barking, it will bite'). If so, this would stimulate a fallsificationistic strategy in the case of safety rules (FC selections) and a verificationistic strategy in the case of danger rules (TC selections). Note that this would eventually result in a similar response pattern as would be predicted by a threat confirming strategy. To test whether or not the responses with respect to safety and danger rules could be confounded by 
differential levels of the rules' probability ratings, the probability ratings for danger and safety rules were subjected to a t-test.

\section{RESULTS}

\section{Manipulation check}

The threat indices confirmed that the threat stories reflected threatening situations. Mean threat ratings were $80.1(S D=18.4)$ and $84.2(S D=19.8)$ for the threat stories with safety and danger rules, respectively. Mean probability ratings were $46.5(S D=26.4)$ for the safety rules and $56.4(S D=26.5)$ for the danger rules. Probability ratings did not significantly differ between safety rules and danger rules: $r(38)=1.18 ; p=.24$. The subjective utility indices (threat $x$ probability) appeared to be independent of the type of rule that was used $[t(39)<1]$, mean scores being 4021 and 4730 for the threat stories with safety rules and danger rules, respectively.

\section{Card selection}

The paired t-test revealed that the overall sumscores concerning the safety rules were significantly larger than the sumscores concerning the danger rules $[t(39)=-2.3, p=.025]$, means being 0.1 and -0.4 , respectively. Thus, in line with our predictions, participants relatively often selected potentially verifying information in the case of danger rules, whereas they relatively often selected potentially falsifying information in case of safety rules.

\section{DISCUSSION}

The present results are consistent with the hypothesis that subjects display a different reasoning strategy in case of safety rules than in case of danger rules. The differential response pattern with respect to safety and danger rules could not be explained by differential levels of the rules' probability. In line with 


\section{Chapter 4}

our predictions, the pattern of results strongly suggests that reasoning performance in the domain of threat is also guided by perceived utilities. More speeifically, it appears that reasoning is goal sensitive and guided by a threat detection algorithm. In the context of threat, subjects' primary goal would be to prevent that any harm would occur to them. In this kind of situations it would be adaptive to rely on verifying information concerning danger rules, but on falsifying information concerning safety rules (i.e., threat detection algorithm). In line with this, subjects relatively often adopted a disconfirmatory strategy (FC selections) for safety rules and a verificationistic strategy (TC selections) for danger rules. Taken together, the present pattern of results supports the idea that subjects' reasoning with (indicative) danger/safety rules is goal sensitive.

Although the results of Experiment 1 are consistent with the idea that reasoning in the context of threat is guided by perceived utilities, an alternative explanation is possible. That is, it can not be ruled out that these results are (partly) due to 'matching bias'. Matching bias (Evans \& Lynch, 1973) refers to the selection of those cards which represent the information that matches with the rule, irrespective of the logical requirements. Thus, given the rule "if $p$ then $q$ ", matching bias would result in the selection of the cards representing the $p$ - and the $q$-instance. In logical terms speaking, these card-selections represent respectively, the true antecedent (TA) and the true consequent (TC) of the rule. However, if a rule is formulated as 'if $p$ then not $q^{\prime}$, subjects still tend to select the cards representing $p$ and $q$ instances (e.g., Griggs \& Cox, 1983). It is important to note, that in the latter example the card representing $q$ represents in logical terms the false consequent (FC; i.e., NOT-[not-q]).

Note also that in Experiment 1, danger rules were changed in safety rules by negating their consequents. For example, the danger rule "if the mushrooms have brown stems, then they are poisonous" was changed in a 
safety rule by adding 'not' to the consequent ("if the mushrooms have brown stems, then they are not poisonous"). The matching bias hypothesis predicts that subjects would select the cards representing 'brown stems' and 'poisonous' for both rules. Yet; in case of danger rules such a strategy would result in the selection of TC cases, whereas the same strategy would result in the selection of FC cards in case of safety rules. Thus, matching bias and the hypothesis that subjects are prone to a danger-confirming reasoning strategy predict the same pattern of results. Although the influence of matching bias has been found to be mainly restricted to more abstract versions of Wason selection tasks (e.g., Griggs \& Cox, 1983) and versions using implicit negative cases (Evans, Clibbens \& Rood, 1996), it cannot be excluded that matching bias contributed partly to subjects' card selections in the danger and safety rules used in Experiment 1. To replicate the findings of experiment 1 and to disentangle the relative contributions of matching bias and a dangerconfirming reasoning (threat detection) strategy, we carried out a second experiment.

\section{EXPERIMENT 2}

In this study, we systematically varied the type of rule (danger vs. safety) and the absence/presence of a negation in the consequent. More specifically, subjects were presented with four types of selection tasks pertaining to threatening situations. Two types of selection tasks contained a danger rule; one with a negation (e.g., "if the mushroom has a brown stem, then it is not edible") and one without (e.g., "if the mushroom has a brown stem, then it is poisonous"). The other two types of selection tasks contained safety rules; again, one with a negation (e.g., "if the mushroom has a brown stem, then it is not poisonous") and one without a negation (e.g., "if the mushroom has a brown stem, then it is edible"). 
In the present design the matching bias hypothesis and the threat detection bypothesis lead to different predictions. That is, if subjects" performance is predominantly guided by a matching bias, they should relatively often select $\mathrm{FC}$ cases for rules containing a negation, and $\mathrm{TC}$ cases for rules without a negation, irrespective of the fact whether the rule is a safety or a danger rule. If, on the other hand, subjects' performance is mainly carried by a danger-confirming reasoning strategy, they would relatively frequently select $\mathrm{FC}$ cases for safety rules, and TC cases for danger rules, irrespective of the fact whether the rule does or does not contain a negation.

\section{METHOD}

Participants

Participants were 48 undergraduate students ( 34 women). They participated voluntarily and received a small financial renumeration. Mean age was 22.2 years (range $=19-28$ years).

\section{Materials and Assessment}

All participants were presented with a set of 8 selection task problems. As in Experiment 1, each selection task consisted of a context story, a rule, and 4 "cards". There were 4 different types of selection tasks which all referred to threatening contexts. Four tasks contained a danger rule; two with a negation (e.g., "if $p$ then not safe") and two without a negation (e.g., "if $p$ then danger"). The other four tasks contained a safety rule; again, two with a negation (e.g., "if p then no danger") and two without a negation (e.g., "if $p$ then safe"). As in Experiment 1, participants were instructed to mark only those card(s) they definitely needed to turn over to check whether or not the rule is true for these four cards. 
We designed several versions for each type of task. More specifically, we designed 8 (context) $\times 2$ (safe/danger) $\times 2$ (with/without negation) selection tasks concerning threatening situations (see also Table 2). To control for task irrelevant peculiarities of any individual selection task, we composed 16 different sets of 8 selection tasks. Each set contained two tasks of each of the 4 different types of selection tasks (i.e., safety rule with and without negation, danger rule with and without negation). For each set, a particular context appeared only once. The order of types of tasks for each set and the order of the four cards for each problem were randomized. By and large, the experimental procedure was identical to that of Experiment 1.

Table 2. Examples of conditional rules used in experiment 2

Without negation

Danger rules If the mushrooms home brown stems, then they ane poisonows

If the indians have blue stripes on their faces, then they are aggressine

Safety rules If the mushrooms have brown stems, then Wey are edible

Wh indians have blue stripes on their faces, when they are peaceful
With negation

If the mushroows have brown starns: then they are not edible

If the indians wave blue stripes on their faces, they are mot peaceful

If the mushrookn have brown stems, when they are not porsonews

If the indians wowe blue suripes on their faces, then they are not aggressive

\section{Data Reduction and Analysis}

First, mean logical sumscores were calculated for each type of task (i.e., TC $=$ $-1, \mathrm{FC}=1$; cf. Experiment 1). Mean sumscores were subjected to a 2 Rule (safety vs. danger) $\mathrm{x} 2$ Negation (with vs. without) ANOVA with both factors being within subjects factors. Matching bias would result in a main effect of Negation, whereas a danger-confirming reasoning strategy would result in a main effect of Rule. 


\section{RESULTS AND DISCUSSION}

A 2 Rule (safety vs. danger) $\times 2$ Negation (with vs. without) ANOVA revealed a main effect of Rule $[F(1,47)=9.5, p=.003]$, indicating that sumscores were generally higher for safety than for danger rules, means being 0.1 and -0.2 , respectively. This effect appeared to be independent of the presence/absence of a negation in the rules. That is, there was no significant interaction between the factors Rule and Negation: $F(1,47)=0.3$. Finally, no main effect of Negation emerged: $F(1,47)=1.5, p>.2$. Thus, no evidence emerged to sustain the idea that in the current 'threat tasks' subjects' card selection was affected by a matching bias. These findings are in line with the observation that the use of rules with specific content and the formulation of explicit negations on the cards removes the matching bias effect (Evans, Clibbens \& Rood, 1996).

Although the results of the above experiments demonstrate that reasoning with conditionals in the context of threat is goal-directed, it is not clear whether this strategy represents an all or nothing phenomenon or whether there is a (linear) dose - response relationship between the level of perceived threat and the use of a 'better safe than sorry' reasoning strategy. To investigate this issue we carried out a third experiment.

\section{EXPERIMENT 3}

To further explore the influence of the level of perceived utility on subjects' reasoning strategy on Wason selection tasks in the domain of threat, we designed a high-threat and a low-threat condition. To this purpose, we manipulated the context stories that accompanied the conditional rules. It was hypothesized that a more threatening context would result in a stronger threat confirming strategy. Thus, subjects in the high threat condition would display 
a generally stronger threat confirming reasoning strategy as compared to subjects in the low threat condition.

\section{METHOD}

\section{Participants}

Participants were 60 undergraduate students ( 30 women). They participated voluntary. Mean age was 22.2 years (range $18-41$ years). Participants were randomly assigned to either the high threat or the low threat condition. In both conditions there were 15 men and 15 women. Mean age was 22.7 years in the high threat condition (range $18-41$ years) and 21.6 years in the low threat condition (range $19-25$ years; $t(58)=-1.3 ; p=.2$ ).

\section{Materials and Assessment}

Participants were presented with a set of 4 selection task problems. As in Experiment 1, each selection task consisted of a context story, a rule and four "cards". Two tasks contained a danger rule (e.g., "if p than danger"), and two

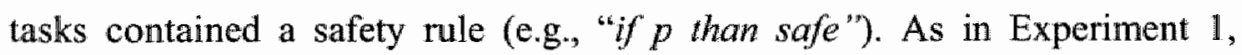
participants were instructed to mark only those card(s) they definitely needed to turn over to check whether or not the rule is true for these four cards.

In order to create the two experimental conditions, we designed two different context stories for every rule (i.e., high threat story / low threat story; See also Table 3 and the Appendix). In the high threat condition, the context story emphasized the dangerousness of the context, for example by referring to the possibility of severe physical injury or to a life-threatening situation. In the low-threat condition, the context story described a situation in which there was no risk for any (severe) physical injury, but which was nevertheless threatening in the sense that the subject could get a fright. 
Table 3. Example of a 'low threat' and a 'high threat'context story accompanying danger and safety rules.

Low threat

Imagine you got a new job in a factory. You have to operate the machine that presses feathers together before they are stuffed into pilows. Your task is easy, but you have to watch out that your hand doesn't get trapped. in the machine, because those feathers can sting. A colleague points you to a lamp on the machine and says:

"If the lamp is on, the machine is (not) going to press"
High threat

Imagine you got a new job in a factory. You have to operate the machine that presses steel. Your task is easy, but you have to watch out that your hand doesn"t get trapped in the machine, because it would shatter your hand. A colleague points you to a lamp on the machine and says:

"If the lamp is on, the machine is (not) going to press"

To control for task irrelevant pecularities of any individual selection task, we composed 6 different sets of 4 selection tasks for each condition. For each set a particular context appeared only once. The order of types of tasks for each set and the order of the four cards appeared in the same fixed random order for both conditions.

As in Experiment 1, the stories and rules were presented for a second time to evaluate the believability as well as the threatening properties of the rules by means of $100 \mathrm{~mm}$ visual analogue scales (VAS; see Experiment 1). In Experiment 1, participants were asked to indicate the likelihood that the threatening situation would do any harm. It could be argued however, that such 'probability ratings' are in fact ratings of subjective credibility, since the participants did not have any information about the probabilities concerning the presented rules. For this reason we decided to ask the participants in the present experiment to rate the credibility instead of the probability of the rules.

In contrast to Experiment 1, participants were asked to evaluate the threat that emanates from the antecedent part of the rule (e.g., the threatening properties of a barking dog), instead of the threat that emanates from the 
"worst case scenario' (e.g., the threatening properties of a biting dog; c.f. Experiment 1). Note that in fact, the antecedent part of both a safety rule as well as a danger rule contains the threat-signal. Since we were interested in the effect of the threat manipulation on the perceived threat when the threat signal was present, it seemed most accurate to restrict the evaluation of perceived threat to the antecedent parts of the rules. By and large, the experimental procedure was identical to that of Experiment 1 and Experiment 2.

\section{Data reduction and analysis}

To check whether the threat manipulation was successful, threat-scores were subjected to a 2 Condition (high threat vs. low threat) X 2 Rule (safety vs. danger) ANOVA with the last factor being within subjects. A significant manipulation effect would result in a main effect of Condition. Meanwhile we expected the perceived threat to be independent of the type of rule used (safety / danger), so that no main effect of Rule would emerge.

To test whether or not differential levels of the rules' believability ratings could have confounded the selection pattern with respect to safety and danger rules, the believability ratings for danger and safety rules were subjected to a 2 Condition (high threat vs. low threat) X 2 Rule (safety vs. danger) ANOVA, with the last factor being within subjects. If safety rules were indeed significantly less believable as compared to danger rules, this would result in a main effect of Rule.

Mean logical sumscores were calculated for each type of task (i.e., TC $=$ $-1, F C=1$; cf. Experiment 1). Mean sumscores were subjected to a 2 Condition (high threat vs. low threat) X 2 Rule (safety vs. danger) ANOVA, with the last factor being within subjects. A main effect of Rule would signify threat confirming reasoning. Most pertinent to our hypothesis, the presence of 
a generally stronger threat confirming reasoning bias in the high threat condition, would result in a interaction effect of Condition and Rule.

\section{RESULTS}

\section{Threat manipulation, believability}

Participants ratings pertaining to the threatening properties of the context stories as well as the ratings pertaining to the believability of the rules are presented in Table 4. For the threat-ratings, a 2 Condition (high threat vs. low threat) $X 2$ Rule (safety vs, danger) ANOVA revealed a main effect of Condition $[F(1,58)=6.1 ; p=0.02]$. As can be seen in Table 4, this indicates, that subjects generally perceived the antecedent parts of the rules more threatening in the high than in the low threat condition. The perceived threat was independent of the type of rule that was used (safety / danger), since there was no main effect of Rule: $F(1,58)=0.07 ; p=0.79$. Finally, there was no Condition X Rule interaction: $F(1,58)=0.86 ; p=0.36$. All in all it seems reasonable to conclude that the threat manipulation was successful.

A 2 Condition (high threat vs. low threat) X 2 Rule (safety vs. danger) ANOVA pertaining to the believability ratings of the rules revealed a main effect of condition: $F(1,58)=4.46 ; p=.039$. This finding indicates that the rules in the high threat condition were rated as being significantly more credible than the rules in the low threat condition. There was no main effect of Rule $[F(1,58)=0.99 ; p=32]$ and no Condition X Rule interaction $[F(1,58)=$ $0.01 ; p=.91]$. Thus, the perceived credibility of the rules was not systematically affected by the type of rule (safety/danger).

\section{Card selection}

Mean sumscores for the high and the low threat condition are shown in Figure 1. A 2 Condition (high threat vs. low threat) X 2 Rule (safety vs. 
Table 4. Means and standard deviations of participants' ratings of the threatening properties of the context stories and the believability of the rules as a function of condition (high threat / low threat).

\begin{tabular}{|c|c|c|c|c|}
\hline & \multicolumn{2}{|c|}{ High threat } & \multicolumn{2}{|c|}{ Low threat } \\
\hline & Danger & Safe & Danger & Safe \\
\hline Threat & $51(20)$ & $48(20)$ & $37(19)$ & $39(22)$ \\
\hline Believability & $54(18)$ & $51(22)$ & $47(15)$ & $43(19)$ \\
\hline
\end{tabular}

danger) ANOVA revealed a main effect of Rule: $F(1,58)=42.17 ; p=.000$ ). From this it follows that subjects relatively more often selected potentially verifying information (TC cases) in the case of danger rules, whereas they relatively more often selected potentially falsifying information (FC cases) in the case of safety rules. There was no main effect of Condition $[F(1,58)=$ $0.34 ; p=.56]$ nor was there a Condition X Rule interaction $[F(1,58)=0]$. Thus, in contrast to our predictions, the threat confirming reasoning strategy was independent of the threat manipulation.

Figure 1. Mean logical sumscores for the safety and danger rules concerning the low threat condition (left panel) and the high threat condition (right panel).

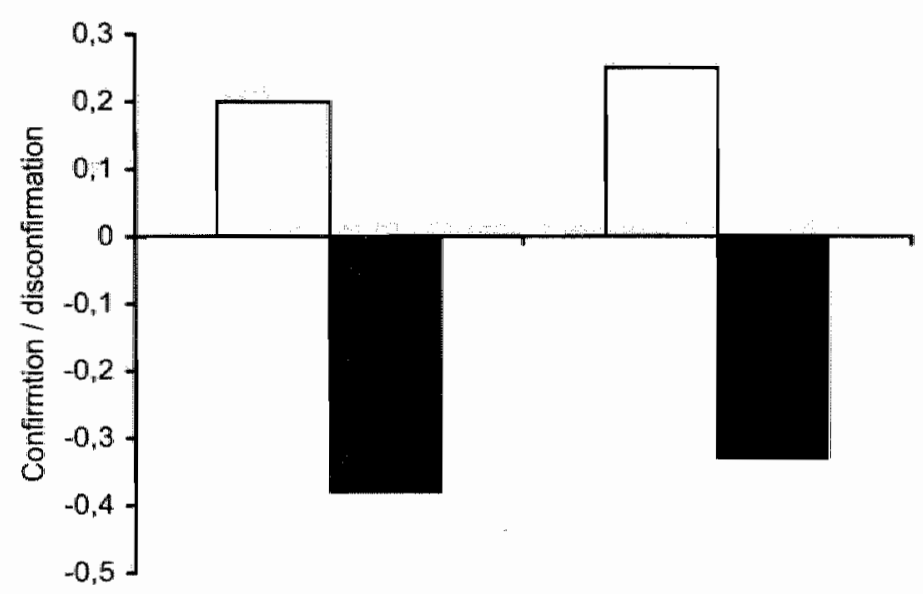

DSafety
EDanger 


\section{DISCUSSION}

The results of Experiment 3 demonstrate once again that the type of rule (safety versus danger) has a strong impact on the reasoning strategy that participants use when they are asked to judge the validity of conditional rules in the context of threat. Replicating the findings in Experiment 1 and 2, it was demonstrated that participants apply a threat confirming strategy. They relatively often selected potentially falsifying information in the case of safety rules and potentially verifying information in the case of danger rules. Again, there was no evidence to suggest that the adopted reasoning strategy was the result of differential believability ratings for safety and danger rules. Surprisingly, participants rated safety and danger rules in the high threat condition as more believable as compared to the low threat condition. Nevertheless, this difference in believability between the high threat and the low threat condition seemed to have had no impact on the reasoning strategy that was applied. That is, if anything, a higher credibility would logically result in relatively more confirmation of both safety and danger rules (i.e., more TC selections). As can be seen in Figure 1, this was certainly not the case.

The present data gave no evidence for the hypothesis that threat confirming reasoning is directly affected by the level of perceived threat. Although the participants perceived the low threat condition as significantly less threatening as compared to the high threat condition, they used the same threat confirming reasoning strategy in both conditions. This finding seems to indicate that the "better safe than sorry" strategy is an all or none phenomenon, which is already triggered by the perception of minimal threat. It should be noted however, that the context stories and conditional rules that were used in the present study might have appeared rather odd to the subjects [e.g., "if the monkeys are screaming then there are (no) bears nearby']. It might well be the 
case that threat-signals about unfamiliar situations provoke a "better safe than sorry" strategy more easily as compared to threat-signals about familiar situations (e.g., if the traffic light is red it is dangerous to cross the street'). Thus, the present finding that confirmatory reasoning was not affected by perceived threat levels, might be due to a relatively low threshold for a "better safe than sorry'strategy in situations that are unfamiliar. Furthermore, it should be emphasized that in the present experiment only the gravity of the possible (aversive) outcome was manipulated. It should be acknowledged that subjective risk perception not only depends on the gravity of the outcome but also on the (subjective) probability that the outcome becomes true (Pollatsek \& Tversky, 1970). Yet in the present experiment, the probabilities of the conditionals were not (systematically) manipulated.

\section{GENERAL DISCUSSION}

The present experiments explored subjects" reasoning pattern in the context of threat. Taken together, the present results provided strong evidence to suggest that reasoning in the domain of threat is goal sensitive. That is, in threatening situations subjects' primary goal would be to prevent any harm. Therefore, it would be adaptive to search for falsifying information concerning safety rules, and to search for verifying information concerning danger rules. In line with this, subjects relatively often selected the potentially disconfirming FC card in case of safety rules, and the potentially verifying TC card in case of danger rules.

Although the pattern of card selection in Experiment 1 was open to an alternative explanation (i.e., matching bias), because the safety rules were systematically associated with a negation in the consequent, Experiment 2 clearly showed that subjects" card selection in the 'threat' tasks can be best explained by perceived utilities and not by a matching bias. 
Experiment 3 failed to find evidence for a dose-response relationship between the level of perceived threat and indivuals' tendency to select threat confirming information. That is, although the high threath condition was evaluated as significantly more threatening than the low threat condition, the degree of perceived threat seemed to have no influence on the degree of threat confirming reasoning bias. Thus, subjects tend to apply a similar 'better safe than sorry' strategy in both high threatening and low threatening situations. This finding seems to indicate that the 'better safe than sorry' strategy is an all or none phenomenon, which is triggered by the perception of minimal threat already. However, as mentioned earlier, it can be argued that threat-signals that were used in the present study concerned unfamiliar situations that might provoke a 'better safe than sorry' strategy more easily as compared to threat signals about familiar situations. Note that in artificial and unfamiliar situations, the subject can not employ previous knowledge and representations about the problem under consideration. Thus, the present study is far from conclusive in this respect.

The finding of goal sensitivity in reasoning performance is not new. What is new, however, is the finding that goal sensitivity is not restricted to deontic conditionals (e.g., permissions/obligations) but is also evident in indicative conditionals pertaining to potentially dangerous situations. The current findings may be relevant for understanding the maintenance of anxiety disorders. That is, a tendency to search for potentially falsifying information in case of safety signals, in combination with a tendency to search for possibly verifying information in case of danger signals is a functional strategy if objective threats are concerned. However, when the perceived threat is irrational (e.g., "if I feel a heart palpitation, then I will get a heart attack") this strategy is destructive. In such a case, actively searching for danger confirming information in combination with neglecting disconfirming evidence, logically serves to maintain or even enhance phobic concerns. 
Preliminary evidence indicates that, in contrast to normal controls, phobic individuals indeed display a threat confirming reasoning strategy in the context of phobia relevant threats (de Jong et al., 1997). Currently we are exploring this issue using Wason selection tasks with safety/danger rules pertaining to phobia-relevant (i.e., irrational) threats in patients with hypochondriasis, panic disorder, and obsessive-compulsive disorder.

\section{REFERENCES}

Cheng, P.W., \& Holyoak, K.J. (1985). Pragmatic reasoning schemas. Cognitive Psychology, 17, 391-416.

Evans, J.St.B.T. (1972). Interpretation and 'matching bias' in a reasoning task. Quarterly Journal of Experimental Psychology, 24, 193-199.

Evans, J.St.B.T., Clibbens, J., \& Rood, B. (1996). The role of implicit and explicit negation in conditional reasoning bias. Journal of Memory and Language, 35, 392-409.

Evans, J.St.B.T., \& Lynch, J.S. (1973). Matching bias in the selection task. British Journal of Psychology, 64, (3), 391-397

Evans, J.St.B.T., Newstead, S.E., \& Byrne, R.M.J. (1993). Human reasoning. The psychology of deduction. Hillsdale: Lawrence Erlbaum Associates.

Griggs, R.A., \& Cox, J.R. (1983). The effects of problem content and negation on Wason's selection task. Quarterly Journal of Experimental Psychology, 35(A), 519-533.

de Jong, P.J., van den Hout, M.A., \& Merckelbach, H., (1995). Covariation bias and the return of fear. Behaviour Research and Therapy, 33, 211-213.

de Jong, P.J., Mayer, B., \& van den Hout, M. (1997). Conditional reasoning and phobic fear: Evidence for a fear-confirming reasoning pattern. Behaviour Research and Therapy ,35, 507-516.

de Jong, P.J., Merckelbach, H., Arntz, A., \& Nijman, H. (1992). Covariation detection in treated and untreated spider phobics. Journal of Abnormal Psychology, 101, 724-727. 
Kirby, KN. (1994). Probabilities and utilities of fictional outcomes in Wason's fourcard selection task. Cognition, $51,1-28$.

Lavy, E.H., van den Hout, M.A., \& Arntz, A. (1993). Attentional bias and spider phobia. Conceptual and clinical issues. Behaviour Research and Therapy, 31, $17-24$

Manktelow, K.I., \& Over, D.E. (1991). Social roles and utilities in reasoning with deontic conditionals. Cognition, 39,85-105.

Matthews, A., \& McLeod, C. (1985). Selective processing of threat cues in anxiety states. Behaviour Research and Therapy, 23, 263-267.

Mineka, S. \& Sutton, S.K. (1992). Cognitive biases and emotional disorders. Psychological Science, 3, 65-69.

Platt, R.D., \& Griggs, R.A. (1993). Darwinian algorithms and the Wason selection task: A factorial analysis of social contract selection task problems. Cognition, $48,163-192$.

Pollatsek, A., \& Tversky, A. (1970). A theory of risk. Joumal of Marhematical Psychology, 7, 540-553.

Smeets, G., \& de Jong, P. J., (2005a). Belief bias and symptoms of psychopathology in a non-clinical sample. Cognitive Therapy and Research, 29, 377-386.

Smeets, G., \& de Jong, P. J. (2005b). Confimatory reasoning in obsessivecompulsive and panic disorder: Belief bias over the course of treatment. Submitted for publication.

Sperber, D., Cara, F., \& Girotto, V. (1995). Relevance theory explains the selection task. Cogmition, 57, 31-95.

Tomarken, A.J Mineka, S., \& Cook, M. (1989). Fear relevant selective associations and covariation bias. Joumal of Abnormal Psychology, 98, 381-394.

Wason, P.C. (1968). Reasoning about a rulle. Quarterly Jownal of Experimental Psychology. 20, 273-281. 


\section{APPENDIX I}

\section{Example of a Threat Problem}

You are spending a few days with your grandmother, who lives in a forest. She often prepares meals on basis of plants and fruits that she finds in the woods and she has a small garden behind her house where she growes vegetables and herbs.

Today, she would like to make mushroomsoup and she sends you out to gather some mushrooms from the woods. In order to distinguish between poisonous and edible mushrooms, she provides you with the following rule:

"If the mushrooms have brown stems, then they are (not) poisonous".

Despite your grandmother's experience with nature, you strongly doubt whether this is true, since she has made a lot of mistakes lately.

The following cards contain information concerning four mushrooms. Each card represents one mushroom. One side of the card says whether or not the mushroom is poisonous and the other side says whether or not it has a brown stem.

Mark only those card(s) that you should definitely turn over to check if your grandmother's rule is true or not for these four mushrooms.
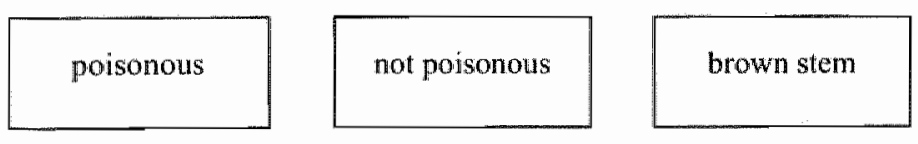
no brown stem 


\section{CHAPTER 5}

\section{"IF YOU SUFFER FROM A \\ HEADACHE, THEN YOU HAVE A BRAIN TUMOUR": DOMAIN-SPECIFIC REASONING 'BIAS' AND HYPOCHONDRIASIS}

Smeets, G., de Jong, P.J., \& Mayer, B. (2000). If you suffer from a headache then you have a brain tumour: Domain-specific reasoning 'bias' and hypochondriasis. Behaviour Research and Therapy, 38,763-776*

\footnotetext{
"This article was awarded the "Artikelprijs EPP", academic year 1998 - 1999 by the Dutch sclnool for research and postgraduate education Experimental Psychopathology (EPP).
} 


\section{Chapier 5}

\section{ABSTRACT}

We explored whether hypochondriacal patients selectively search for threatconfirming information when asked to judge the validity of conditional rules in the context of general and health threats. We also explored several factors that may underly participants' information selection (e.g., believability of the rule). Hypochondriacal patients $(n=20)$ and healthy controls $(n=20)$ were presented with modified Wason Selection Tasks (WSTs). The WSTs contained safety rules and danger rules. In the context of general threat, both groups of participants adopted a verificationistic strategy in the case of danger rules and a Popperian strategy in the case of safety rules. Importantly, only hypochondriacal persons showed a similar threat-confirming reasoning pattern in the context of health threat. The latter finding contrasts with the earlier study of de Jong et al. (1998) in which both hypochondriacs and healthy controls showed a threat-confirming strategy in the domain of health threat. The WSTs in that study however, contained a (unintended) worry manipulation ("after hearing this, you get worried"), which might have induced a reasoning strategy in controls that is normally restricted to hypochondriacs. Taken together, the present results sustain the idea that the perception of threat activates a better safe than sorry strategy. In the case of phobic threats, such a reasoning strategy immunizes against refutation of phobic convictions. 


\section{INTRODUCTION}

The core feature of hypochondriasis is a marked and persistent preoccupation with fears about having a catastrophic disease. Typically, the false beliefs about having a serious disease are based on misinterpretations of physical signs or sensations, and the conviction of being ill persists in spite of medical reassurance (APA, 1994). To explain hypochondriacal complaints, some authors have argued that hypochondriacal patients show an attentional bias towards a focus on bodily sensations which may well lead to an amplification of common physical sensations (e.g., Kellner, Abbott, Winslow, \& Pathak, 1987). In addition, there is some evidence that hypochondriacal patients falsely identify harmless physical sensations as symptoms of catastrophic diseases (Haenen, Schmidt, Schoenmakers, \& van den Hout, 1998). Yet, although such type of mechanisms may be helpful to clarify hypochondriacs' concerns with their health status, they provide no straightforward explanation for their apparent "immunity" with respect to disconfirmatory information.

In an attempt to explain the refractoriness of hypochondriacal beliefs in the face of falsifying information, it has been proposed that (dysfunctional) reasoning patterns may play a role in here (e.g., de Jong et al., 1998). Several aspects of human reasoning may help to explain the persistence of hypochondriacal convictions. First, recent research demonstrated that contrary to normal controls, anxiety patients show an 'ex-consequentia' reasoning style with respect to anxious mood states (Arntz, Rauner, \& van den Hout, 1995). That is, anxiety patients tend to conclude that there must be danger, merely because they feel anxious (cf. emotional reasoning). Such a reasoning pattern logically serves to confirm the threatening properties of the feared stimuli, thereby maintaining the patients' anxiety complaints. Pertinent to the current context of hypochondriacal complaints, one could speculate that in a similar vein, the anxious mood state elicited by the perception of harmless physical 


\section{Chapter 5}

sensations (e.g., headache) may give rise to the inference in hypochondriaca! patients that they have a dangerous disease (e.g., brain tumour).

A second aspect of human reasoning that may act to maintain dysfunctional convictions concerns the finding that, in general, people are apt to confirm rather than to falsify their personal beliefs ("belief bias"; e.g., Evans, Over, \& Manktelow, 1993). More specifically, people tend to endorse information that is in line with their prior beliefs and to reject information that contrasts with their beliefs, irrespective of the information's empirical validity (e.g., Revlin et al., 1980; Evans, Barston, \& Pollard, 1983). Recent evidence suggests that phobic patients are characterized by an even stronger belief bias than individuals without phobic complaints (de Jong, Weertman, Horselenberg, \& van den Hout, 1997). Obviously, such a belief bias logically serves to impede the disconfirmation of irrational beliefs, thereby contributing to the persistence of a phobogenic view.

The present study is concerned with conditional reasoning, a third type of reasoning that may be of relevance within the current context. Note that the frightening convictions of hypochondriacal patients can be condensed into

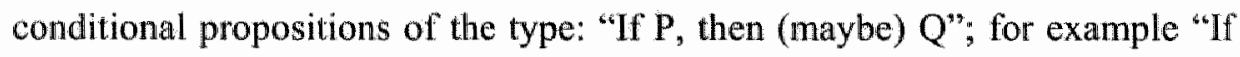
you suffer from a headache (P), then you (may) have a brain tumour (Q)". Testing the logical validity of such conditional beliefs requires an investigation whether $\mathrm{P}$ is, indeed, followed by $\mathrm{Q}$, and a check whether any non-Q is preceded by $\mathrm{P}$. If the latter is true (i.e., no tumour despite headache), the conditional rule is proven to be invalid, the logical consequence of which would be to undermine the believability of the dysfunctional convictions. Meanwhile, incorrect (i.e, illogical) strategies may well add to the believability of dysfunctional concerns.

Pertinent to the latter possibility, a series of recent studies using the Wason Selection Task (WST; Wason, 1968; see Method) as the experimental technique clearly demonstrated that, in general, humans do not reason 
according to the normative rules of formal logic. Rather it appears that subjects" reasoning performance is domain-specific and guided by perceived utilities (e.g., Manktelow \& Over, 1991; Kirby, 1994; Evans \& Over, 1996). In the context of threat the utility levels of potentially verifying and falsifying information highly depends on the type of rule. Note that in the context of threats there are two different types of rules: "If $\mathrm{P}$, then danger" (danger rule) and "If $P$, then safe" (safety rule). In threatening situations, information that may signify danger is of relatively great value. That is, although it seems inefficient to flee for false alarms, a single instance of ignoring a danger signal may be fatal. Therefore, it would be unwise not to rely on danger signals. In the case of safety signals, the opposite is true. Information that may signify that a certain safety signal is not reliable has greater survival value than information which may prove the signal reliable.

In line with this, two recent studies showed that participants, indeed, tend to select potentially verifying information in the case of danger rules and potentially falsifying information in the case of safety rules (Smeets, de Jong \& Mayer, 2004; de Jong et al., 1997; de Jong et al., 1998). Interestingly, there is also evidence indicating that, in contrast to normal controls, clinically diagnosed spider phobic women display a simillar danger-confirming reasoning strategy in the context of phobia-relevant threat (de Jong et al., 1997). In other words, not only objective but also phobic threats appear to activate a danger-confirming reasoning strategy and in case of phobic threats such a reasoning pattern logically serves to maintain or even enhance phobic fears.

In a recent experiment we explored whether hypochondriacal patients are characterized by a similar fear-confirming reasoning pattern in the context of health threats. In line with this, the results of that study clearly demonstrated that hypochondriac individuals, indeed, adopt a verificationistic strategy in the case of danger rules and tend to look for falsifications in the 


\section{Chapter 5}

case of safety rules (de Jong et al., 1998). However, no differences between hypochondriac persons and healthy controls emerged in this respect. That is, both groups of participants selected potentially danger confirming information. Thus, unlike the previous finding that a danger-confirming strategy in the context of spider-phobia-relevant threat is restricted to spiderphobic individuals (de Jong et al., 1997), a danger-confirming strategy in the context of health threats was evident in both hypochondriac and explicitly non-hypochondriac participants. Clearly, this pattern of findings questions the importance of such a reasoning "bias" as a factor in the maintenance of hypochondriac complaints.

To explain this apparent difference between spider phobia and hypochondriasis in this respect, one may argue that in contrast to threatening situations concerning spiders, the possibility of having a serious disease is so threatening that even explicitly non-hypochondriacs tend to be verificationistic regarding warnings and very critical regarding reassurance. However, such an explanation implies that the subjective utility levels of potentially verifying and potentially falsifying information within the domain of health threats would be very similar for hypochondriacal individuals and healthy controls, which does not seem a very plausible implication.

Another testable explanation pertains to the stimulus materials that were used in the latter study. That is, on basis of this previous research we modified the original WST in an attempt to make the task more concrete and easier to understand. In doing so we also added the following sentence to the context stories: "...After hearing this, you get worried". Although this sentence was merely added to enhance the plausibility of the assignment for the participants, it might well be that it also induced a reasoning pattern in controls which is normally restricted to hypochondriac individuals. That is, healthy controls might have selected information as if they were worried concerning their health status. In other words, the specific characteristics of 
the stimulus materials might have undermined the paradigm's sensitivity to detect any differences between hypochondriacs and healthy controls with respect to their habitual reasoning strategies within the domain of health threats. Therefore, the main aim of the present study was to replicate the previous study of de Jong et al. (1998), but without such a threat manipulation.

In addition, we asked participants in the present experiment to indicate the threatening properties of the context stories that were used (e.g., having cancer). This was done to explore the tenability of the alternative explanation for the absence of between-groups differences in our previous study, namely, that the threatening characteristics of the hypochondriasis-relevant contexts may be similar for hypochondriacs and healthy controls.

Finally, as a subsidiary issue, we also investigated an alternative explanation for the participants' response pattern with respect to WSTs in the domain of (hypochondriasis-relevant) threat. More specifically, we tested whether the difference between participants' responses to safety rules and danger rules may be due to differences with respect to the rules' probability and/or believability, rather than being the result of a "better safe than sorry" strategy. That is, it has been suggested that participants may consider safety rules (e.g., if a brown spot itches, it isn't skin cancer) as less believable and/or less probable than danger rules (e.g., if a brown spot itches, then it is skin cancer) (E. Erdfelder, personal communication). If so, this would stimulate a Popperian strategy in the case of safety rules but not for danger rules, which would eventually result in a similar response pattern (but for different reasons) as would be predicted by a "better safe than sorry" algorithm. Thus, for a proper evaluation of participants' responses in the context of threat, it would be important to know whether or not the differential responses with respect to safety and danger rules are confounded by differential levels of the rules' probability and/or believability. 


\section{Chapter 5}

\section{METHOD}

\section{Participants}

There were two groups of participants. They were matched for sex, age, and educational level. One group consisted of 20 patients (10 women) with hypochondriasis. All participants in this group met the DSM-IV criteria for hypochondriasis (APA, 1994). They were recruited through advertisements in a local newspaper in which the central characteristics of hypochondriasis were mentioned (e.g., disease conviction, anxiety despite medical reassurance) as well as fear of cancer. Seventy-five individuals responded to the advertisement. A first selection was made on basis of a telephone interview using the Structured Diagnostic Interview for Hypochondriasis (SDIH; Barsky et al., 1992). Thirty-two responders were selected for an interview at the University. During this interview they were screened with the Structured Clinical Interview for DSM-IV (SCID; Spitzer et al., 1992) by a therapist who was well trained in using this instrument. Eventually, 20 participants fulfilled all DSM-IV diagnostic criteria and were admitted to the patient group. Mean age was 50.8 years $(S D=10.2$ yrs.). Mean educational level [on a scale ranging from 'only primary school' (1) to 'university education completed' (9)] was 4.5 (range $=2-6$ ). Subjects also completed the (Dutch) "Maastrichter Eigen Gezondheids-Attitude en Hypochondrie-schaal" [Maastricht Own Health-attitude and Hypochondriasis Scale] (MEGAH; Schmidt \& Lousberg, 1992). The Angst Eigen gezondheid (AE: fearful preoccupation with own health) subscale of the MEGAH is a validated 12-item self-report measure of hypochondriacal complaints ranging from 12 (maximal complaints) to 60 (minimal complaints). Scores below 40 are indications of (pathological) hypochondriacal fear and insecurity. The mean score on the AE subscale was $29.1(S D=13.8)$. 
The other group consisted of 20 healthy control subjects ( 10 women). After screening for the absence of health problems and health-related worries, they were admitted to the present study. Mean age was 51.6 years $(S D=9.2$ yrs.). Mean educational level was 4.6 (range $=2-6$ ). The mean score on the AE subscale of the MEGAH was $52.9(S D=7.8)$. All participants were paid for their participation in the present experiment.

\section{Materials and Assessment}

As part of a larger research project, all participants were presented with 8 modified Wason Selection Tasks (WST). The WST is a hypothetical deductive reasoning problem, which asks subjects to search for information that can falsify or violate a conditional rule (for an example, see the Appendix). Originally, the WST consisted of four cards and a conditional rule of the form "If $\mathrm{P}$, then $\mathrm{Q}$ " concerning those cards. One side of each card showed whether the antecedent was true or false (i.e., P or Not-P), whereas the other side revealed whether the consequent was true or false (i.e., Q or Not-Q). Only one side of the cards was shown to the subjects. One card made $P$ visible, one Not-P, one $Q$, and one Not-Q. Subjects were asked to indicate the card or cards they definitely needed to turn over in order to find out whether the rule was true or false for those four cards.

In line with our previous study (de Jong et al., 1998) we used modified WSTs, as the original format of the WST is likely to be too abstract for participants with limited educational experience. Thus, in the present study the four cards referred to four different persons to whom a fixed question could be asked. Two persons referred to the antecedent of the conditional rule and two persons referred to the consequent. The question coupled with the 'antecedent-persons' was always "Is the consequent true/false?" whereas the question coupled with the 'consequent-persons' was always "Is the antecedent true/false?". For example, for the rule "If the mushrooms have brown stems 
(i.e., P), then they are potsonous (i.e., Q)", the four cards referred to four different persons: one person ate mushrooms with brown stems $(\mathrm{P})$ and the fixed question was "Did you eat poisonous mushrooms?" ( $Q$ or not-Q); one person ate mushrooms with green stems (not-P) and, again, the fixed question was "Did you eat poisonous mushrooms?" ( $Q$ or not- $Q$ ); one person ate poisonous mushrooms $(Q)$ and the fixed question was "Did you eat mushrooms with brown stems?" ( $P$ or not-P); and, finally, one person ate edible mushrooms (not-Q) and the fixed question was "Did you eat mushrooms with brown stems?" (P or not-P). Participants were instructed to indicate to which person or persons they definitely needed to ask a question in order to check the validity of the conditional rule.

Each task consisted of a context story, a conditional rule, and 4 'persons'. There were 4 different types of selection tasks (for examples see Table 1). Two types of tasks referred to contexts of general threat and were taken from de Jong et al. (1997); one type containing danger rules (i.e., "if P, then danger") and the other containing safety rules (i.e., "if $P$, then safe"). Finally, two types of tasks referred to hypochondriasis-relevant contexts. As for the general threat contexts, one type consisted of danger rules and the other consisted of safety rules.

Although the predominant use of explicit formulations in the present study renders the occurrence of matching bias very unlikely (Evans, Clibbans \& Rood, 1996), we designed WSTs containing negations (e.g., "If the mushrooms have brown stems, then they are not edible") as well as WSTs without such a negation (e.g., "If the mushrooms have brown stems, then they are poisonous") in order to cancel out possible matching bias effects (Evans \& Lynch, 1973; Evans, Newstead \& Byrne, 1993). 
Table 1. Conditional Rules Used in the Present Study

Danger rules $\quad$ Safety rules

General threat If mushrooms have brown stems, then they are poisonous

If mushrooms bave brown stems, then they are not edible

If the monkeys screan, then there are bears nearby

If the monkeys scream, then it is not safe

If the indians have blue stripes on their faces, then they will attack other people

If the indians have blue stripes on their faces, then they are not peaceful

If the light bulb is on, then the machine is not safe

If the light bulb is on, then the machine is going to press

Health threat If a brown spot itches, then if is skin cancer

If a brown spot itches, then it is not an innocent birth-mark

If someone has a painless lump in the neck, then it is a malignant tumour

If someone has a painless lump in the neck, then it is not a berignant tumour

If someone suffers from heart palpitations, then that is a sign of a heart attack

If someone has heart palpitations, then that person does not have healthy heart

If vascular markings are visible on the lung photograph, then you have lung cancer

If vascular markings are visible on the lung photograph, then your lungs are not healthy
If mushrooms lave browin stens, then they are edible

If mushrooms hawe brown stems, then they are not poisonous

If the monkeys scream, then there are no bears nearby

If the monkeys screem then it is safe

If the indians have blue stripes on their faces, then they are peaceful

If the indians have blue stripes on their faces, then they don"t attack other people

If the light bulb is on, then the machine is sate

If the light bulb is on, then the machine is not going to press

If a brown spot itches, then it is not skin cancer

If a brown spot itches, then it is an innocent birth-mark

If someone has a prainless lump in the neck, then if is not a mas lignant tumour

If someone has a painless ltump in the neck, then it is a benign thunour

If someone suffers from theart palpitations, then that is not a sign of a heart altack

If someone has heart palpitations, then that person has a healthy heart

If wascular markings are visible on the lung photograph, then you don't have lung cuncer

If vascular markings are visible on the lumg photograph, then your lungs are healthy. 


\section{Chapter 5}

In addition, to cancel out task irrelevant peculiarities we designed several versions for each type of task. More specifically, we constructed 4 (context stories) $\times 2$ (danger/safe) $\times 2$ (with / without negation in the consequent) WSTs pertaining to general threat; and 4 (context stories) $\times 2$ (danger/safe) $\times 2$ (with/without negation in consequent) WSTs concerning hypochondriacal concerns. The series we used in the present experiment contained two general threat WSTs with a safety rule (one with and one without negation), two general threat WSTs with a danger rule (one with and one without negation), two hypochondriacal threat WSTs with a safety rule (one with and one without negation), and two hypochondriacal threat WSTs with a danger rule (one with and one without negation). For each series a particular context appeared only once, and the order of types was randomized. The order of the four "persons" for each problem was also randomized.

\section{Procedure}

Participants were tested individually. First, the experimenter explained the task by means of a sample item. Then, participants received a booklet containing a written instruction, an example of the WST, and 8 selection task problems (each on a separate sheet). In line with our previous study (de Jong et al., 1998), participants were instructed to mark only those questions they definitely needed to ask to check whether or not the rule is true. There were no time constraints.

To evaluate the rules' believability and probability as well as the threatening properties of the context stories as a function of the type of WST, the 8 context stories were presented for a second time. Yet, this time participants were asked to rate the rules' believability and probability as well as the contexts' threatening characteristics by means of $100 \mathrm{~mm}$ visual analogue scales (VASs) ranging from highly unbelievable to very believable, 
highly unlikely to very likely, and not threatening at all to very threatening, respectively.

\section{Data Reduction and Analysis}

Following the procedure of de Jong et al. $(1997 ; 1998)$, the final analysis for the threat tasks was restricted to the $q(-1)$ and not-q $(+1)$ "persons", as only these "persons" can differentiate between a verificationistic $(q)$ and a Popperian (not-q) strategy. Asking the fixed question to $\mathrm{p}$ "persons" is appropriate for both confirming and disconfirming safety/danger rules, whereas asking questions to not-p "persons" is appropriate for neither verifying nor falsifying safety/danger rules. To examine whether participants, indeed, tend to search for falsifying information (not-q persons) in the case of safety rules and for verifying information ( $q$ persons) in the case of danger rules, as well as to see whether there are (domain-specific) differences between hypochondriacal patients $(\mathrm{H})$ and healthy controls $(\mathrm{C})$ in this respect, sumscores of the threat tasks were subjected to a 2 Group $(\mathrm{H} / \mathrm{C}) \times 2$ Rule (safety/danger) $\times 2$ Theme (general/hypochondriasis) ANOVA with the last 2 factors being within-subjects factors. If differential responding to danger and safety rules is, indeed, guided by perceived threat, one would ecpect that, in the context of health-related threatening situations, especially hypochondriacal patients respond differentially to safety and danger rules. Such a response pattern would result in a Group $\mathrm{x}$ Rule $\mathrm{x}$ Theme interaction.

To investigate the influence of the type of WST on the probability and believability of the rule as well as on the threatening characteristics of the context stories, we performed for each of these variables a 2 Group $(\mathrm{H} / \mathrm{C}) \times 2$ Rule (safety/danger) $\times 2$ Theme (general/hypochondriasis) ANOVA. 
09). Thus, the perceived likelihood of the rules was not systematically affected by the theme of the rule or the type of rule (safe vs. danger) and the probability ratings appeared independent of prior fear. A 2 Group $\times 2$ Rule $\times 2$ Theme ANOVA pertaining to the threat ratings revealed that hypochondriacal patients generally tended to consider the contexts as more threatening than healthy controls $[F(1,38)=3.83, p=.06]$. Yet, this pattern was not particularly pronounced for the health threat WSTs. That is, there was no significant Group $\times$ Theme interaction $[F(1,38)=0.5]$. In addition, none of the other main or interaction effects approached significance (all $F_{\mathrm{s}}<2.2, p \mathrm{~s}$ $>.15)$

Table 2. Means and standard deviations of participants' ratings of the believability and probability of the rules as well as participants' ratings of the threatening properties of the contexts as a function of group (hypochondriacal/control), rule (safety/danger), and theme (general/health threat).

\begin{tabular}{lcclcc}
\hline Ratings & \multicolumn{2}{c}{ General } & & \multicolumn{2}{c}{ Heallth } \\
\cline { 2 - 3 } \cline { 5 - 6 } Hypowhondriacs & Danger & Safe & & Danger & Safe \\
Believability & $59(20)$ & $50(25)$ & & $57(21)$ & $55(20)$ \\
Probability & $66(17)$ & $58(27)$ & & $64(23)$ & $53(25)$ \\
Threat & $85(9)$ & $86(8)$ & & $86(12)$ & $87(9)$ \\
Controls & & & & & \\
Bestiewability & $55(26)$ & $51(26)$ & & $54(24)$ & $49(24)$ \\
Prolsability & $54(27)$ & $55(24)$ & & $51(26)$ & $62(17)$ \\
Thireal & $77(17)$ & $79(15)$ & & $80(15)$ & $81(15)$ \\
\hline
\end{tabular}

\section{DISCUSSION}

Replicating our previous findings (Smeets et al., 2004; de Jong et al., 1998; de Jong et al., 1997), the present results clearly demonstrate that the type of rule (safety vs danger) has strong impact on the reasoning strategy that participants tend to use when they are asked to judge the validity of conditional rules in 
the context of threat. That is, both groups of participants selected more often potentially falsifying information in the case of safety rules than in the case of danger rules. In line with our previous study concerning spider phobic subjects (de Jong et al., 1997), this general 'threat-confirming" selection pattern was not particularly pronounced in high anxious (i.e., hypochondriacal) subjects. Thus, the present data do not support the idea that hypochondriacal patients are characterized by a trait-like reasoning pattern which would make them liable not to correct frightening convictions and, therefore, susceptible to pathological anxiety. Yet, the present data do strongly suggest that typically hypochondriacal subjects display a similar threat-confirming reasoning-bias within the domain of health threats. This pattern of findings suggests that the domain-specific reasoning bias in hypochondriacal patients is an unfortunate consequence of an otherwise very functional reasoning strategy, which logically serves to maintain their hypochondriac concerns.

The findings of the present study are in line with the idea that reasoning is guided by perceived utilities (e.g., Manktelow and Over, 1991; Kirby, 1994). That is, again we found that danger rules activate a confirmatory reasoning strategy, whereas safety rules activate a Popperian reasoning strategy. It has been suggested that this differential response pattern may be confounded by differences with regard to the rule's believability and probability. Indeed, if participants would consider safety rules as generally less believable and / or probable than danger rules, a similar response pattern would emerge. That is, to the extent that rules are perceived as less believable and / or probable, a stronger falsificatory approach may be expected. Yet, this alternative explanation for the differential strategy with regard to danger and safety rules is not supported by the present findings. That is, no differences were found between danger rules and safety rules regarding subjective believability and probability ratings. Thus, the differential selection pattern 


\section{Chapter 5}

between danger rules and safety rules was not merely the consequence of differences in believability or probability between those rules. Therefore, it seems reasonable to conclude that, in general, people tend to employ a goaloriented 'better safe than sorry' strategy in the context of threats. From a Darwinian point of view, the value of a 'better safe than sorry' strategy can easily be explained. That is, a single instance of wrongly ignoring a danger signal as well as a sinle instance of wrongly accepting a safety signal may be fatal.

Most important for the current context, the hypochondriacal individuals in the present study not only displayed a significant threat-confirming strategy in the domain of general threats, but contrary to normal controls, also in the domain of health threats. This finding contrasts with the findings of a previous study in which hypochondriac as well as explicitly non-hypochondriac participants displayed a (similar) danger confirming strategy in the context of health threats (de Jong et al., 1998). However, the stimulus materials used in that study included the sentence "...After hearing this you get worried". The present data sustain the idea that this sentence may have functioned as an unintentional threat manipulation inducing a reasoning pattern in normal controls which is normally restricted to hypochondriacal patients. That is, in the absence of this manipulation, normal controls in the present study did not show a threat-confirming strategy in the domain of health threats. Thus, it appears that the "better safe than sorry" strategy is the habitual strategy for hypochondriacal individuals in the context of health threats, whereas the threat manipulation which was included in the previous study, resulted in healthy controls selecting information as if they were worried. In other words, the inclusion of the sentence "...After hearing this you get worried" in the previous study may well have undermined the sensitivity of the WST to detect differences in habitual reasoning strategies. In support of the idea that, in general, such a threat manipulation indeed provokes a "better safe than sorry" 
strategy, the typical differential response pattern was generally less pronounced in the present study than in the previous study. To settle this issue more definitely, further experimental research is neccesary including both conditions (i.e., threat manipulation/no threat manipulation) in a single experiment.

Analysis of threatening properties of the rules revealed that hypochondriacal patients rated all rules as more threatening than normal controls, independent of the domain (general/health). Surprisingly, the differential reasoning pattern was not paralleled by differential threat-ratings between hypochondriacs and healthy controls. Thus, the present findings are not in line with the idea that the mere perception of threat is sufficient to activate a 'better safe than sorry' strategy, which was proposed by de Jong and his colleagues (de Jong et al., 1997; see also Smeets et al., 2004). It should be noted however, that in the present study we asked subjects to indicate the threatening properties of the consequent part only of the rule (e.g., the threatening properties of having a brain tumour). One could speculate that differential threat-scores would have emerged if subjects had been asked to indicate the threatening properties of the antecedent part of the rule. Note that the antecedent part of both a safety rule as well as a danger rule contains the threat signal (e.g., having a headache; cf. Smeets et al., 2004, Experiment 3). Presumably, 'having a headache' activates many more alternative and less threatening scenarios in normals than in hypochondriacal patients, which in turn could explain why normal controls tend to look for confirming information in safety rules and for falsifying information in danger rules. Of course, the present study is far from conclusive in this respect. Future research is necessary to further investigate the underlying mechanism for the relatively strong threat-confirming reasoning patterns in the context of phobic threats.

Taken together, the present results add to the idea that a "better safe than sorry' strategy is generally activated when individuals are asked to judge 


\section{Chapter 5}

the validity of conditional rules in the context of threat. The finding that such a threat-confirming algorithm in anxiety patients is also present in the context of their specific phobic concern may help to explain the refractoriness of phobogenic (e.g., hypochondriacal) beliefs in the face of falsifying information. The available empirical evidence suggests that this phenomenon may well be relevant for other complaints in which irrational anxiety plays a central part. Therefore, it would be important to see whether a similar domainspecific reasoning bias can indeed be found in other anxiety disordered individuals, for example panic-disordered or obsessive-compulsive patients. Furthermore, it would be important to investigate the influence of (effective) treatment on phobogenic reasoning. That is, if such a domain-specific reasoning strategy is an important factor in the maintenance of phobic complaints, it should be attenuated or even have disappeared after successful treatment. In addition, one would predict a positive relationship between residual concern-specific reasoning bias and the return of fear.

\section{REFERENCES}

American Psychiatric Association (1994). Diagnostic and statistical manual of mental disorders (4th ed.). Washington, DC: Author.

Arntz, A., Rauner, M., \& van den Hout, M.A. (1995). 'If I feel anxious, there must be danger': Ex-consequentia reasoning in inferring danger in anxiety disorders. Behaviour Research and Therapy, 33, 917-925.

Barsky, A.J., Cleary, P.D., Wyshak, G., Spitzer, R.L., Williams, J.B.W.,\& Klerman, G.L. (1992). A Structured Diagnostic Interview for Hypochondriasis - A proposed criterion standard. Journal of Nervous and Mental Disease. 180, 2027.

de Jong, P.J., Haenen, M.-A., Schmidt, A., \& Mayer, B. (1998). Hypochondriasis: The role of fear-confirming reasoning. Behaviour Research and Therapy, 36, $65-74$ 
de Jong, P.J., Mayer, B., van den Hout, M. (1997). Conditional reasoning and phobic fear: Evidence for a fear-confirming reasoning pattern. Behaviour Research and Therapy, 35, 507-516.

de Jong, P.J., Weertman, A., Horselenberg, R., \& van den Hout, M.A. (1997). Deductive reasoning and pathological anxiety: Evidence for a relatively strong "belief bias" in phobic subjects. Cognitive Therapy and Research, 21, 647-662.

Evans, J.St.B.T., \& Lynch, J.S. (1973). Matching bias in the selection task. British Journal of Psychology, 64, 391-397.

Evans, J.St.B.T. Barston, J.L. \& Pollard, P. (1983). On the conflict between logic and belief in syllogistic reasoning. Memory and Cognition, 11 (3), 295-306.

Evans, J.St.B.T., Newstead, S.E. \& Byrne, R.M.J. (1993). Human reasaning: The psychology of deduction. Hove, UK: Psychology Press.

Evans, J.St.B.T, Over, D.E., \& Manktelow, K.I., (1993). Reasoning, decision making and rationality. Cognition, 49, 165-187

Evans, J.St.B.T.\& Over, D.E. (1996). Rationality in the selection task: Epistemic utility versus uncertainty reduction. Psychological Review, 103, 356-363.

Evans, J.St.B.T., Clibbens, J. \& Rood, B. (1996). The role of implicit and explicit negation in conditional reasoning bias. Journal of Memory and Language, 35, 382-409.

Haenen, M.-A., Schmidt, A.J.M., Schoenmaker, M., van den Hout, M.A. (1997). Tactual sensitivity in hypochondriasis. Psychotherapy and Psychosomatics, 66, 128-132.

Kellner, R., Abbott, P., Winslow, W.W., Pathak, D. (1987). Fears, beliefs, and attitudes in DSM-III hypochondriasis. Journal of Nervous and Mental Disease, $175,20-25$.

Kirby, K.N. (1994). Probabilities and utilities of fictional outcomes in Wason's fourcard selection task. Cognition, 5/, 1-28.

Manktelow, K.I., \& Over, D.E. (1991). Social roles and utilities in reasoning with deontic conditionals. Cognition, 39, 85-105.

Pennebaker, J.W. (1982). The psychology of physical symptoms. New York: Springer Verlag. 
Platt, R.D. \& Griggs, R.A. (1993). Darwinian algorithms and the Wason selection task: A factorial analysis of social contract selection task problems. Cognition, 48, 163-192.

Revlin, R., Leirer, V., Yopp, H., Yopp, R. (1980). The belief-bias effect in formal reasoning: The influence of knowledge on logic. Memory and Cognition 8 (6), $584-592$

Schmidt, A.J.M. \& Lousberg, R. (1992). Maastrichtse Eigen Gezondheids-Attitude en Hypochondrie schaal: MEGAH-schaal [Maastricht Own Health-attitude and Hypochondriasis Scale: MEGAH-Scale]. Lisse: Swets en Zeitlinger.

Smeets, G., de Jong, P.J., Mayer, B. (2004). Better safe than sorry: Reasoning with conditionals in the context of threat. Submitted for publication.

Spitzer, R.L., Williams, J.B., Gibbon, M., \& First, M.B. (1992). The Structured Clinical Interview for DSM-III-R (SCID): I. History, rationale and description. Archives of General Psychiatry, 49, 624-629.

Wason, P.C. (1968). Reasoning about a rule. Quarterly Joumal of Experimental Psychology, 20, 273-281. 


\section{APPENDIX}

Example of a health threat problem with danger rule

You have a brown spot on your arm and it seems that its colour has been changing. It has also started to itch. During a family visit someone says to you: "If a brown spot itches, then it is skin cancer"

There are four people. You can ask each of them a fixed question:

\begin{tabular}{|c|c|c|c|}
\hline person 1 & person 2 & person 3 & person 4 \\
\hline has skin cancer & $\begin{array}{l}\text { has an itching } \\
\text { spot }\end{array}$ & $\begin{array}{l}\text { doesn't have } \\
\text { skin cancer }\end{array}$ & $\begin{array}{l}\text { has a spot that } \\
\text { doesn't itch }\end{array}$ \\
\hline question: & question: & question: & question: \\
\hline $\begin{array}{l}\text { Does the brown } \\
\text { spot itch? }\end{array}$ & $\begin{array}{l}\text { Is it skin } \\
\text { cancer? }\end{array}$ & $\begin{array}{l}\text { Does the brown } \\
\text { spot itch? }\end{array}$ & Is it skin cancer? \\
\hline
\end{tabular}

\section{Assignment:}

Which person or persons do you need to ask a question in order to be absolutely sure whether or not the rule is correct? Mark each person who you will approach.

Try to ask only questions that are necessary.

$\begin{array}{llll}\text { person } 1 & \text { person } 2 & \text { person } 3 & \text { person } 4\end{array}$




\section{CHAPTER 6}

\section{PANIC DISORDER AND RIGHT-HEMISPHERE RELIANCE}

Smeets, G., Merckelbach, H., \& Griez, E. (1997). Panic disorder and righthemisphere reliance. Anxiety, Stress and Coping, 10, 245-255 


\section{Chapter 6}

\section{ABSTRACT}

Panic patients $(n=22)$ and normal controls $(n=26)$ completed the Preference Test (PT) and a Conjugate Lateral Eye Movements (CLEMs) task as measures of hemisphere reliance. Furthermore, they completed the Spielberger StateTrait Anxiety Inventory (STAI) and the Anxiety Sensitivity Index (ASI) as indices of self-reported anxiety. While panic patients and controls did not differ with regard to the $\mathrm{PT}$, panic patients displayed significantly more left lateral eye movements than controls. Additionally, across both groups, significant positive correlations were found between right-hemisphere activation (as indexed by CLEM scores) and ASI, suggesting that stronger right-hemisphere reliance is related to greater interoceptive fear. Thus, some indications were found for a relative right-hemisphere overactivation in panic disorders. 


\section{INTRODUCTION}

Panic disorder is a prevalent psychiatric illness with poor prognosis (Wittchen, 1988). The syndrome is characterized by recurrent, unexpected attacks of intense anxiety in the absence of an external frightening stimulus (DSM-IV; American Psychiatric Association, 1994) Typically, panic patients complain about a number of bodily sensations (e.g., palpitations, dyspnea, paresthesias) that the experience during panic attacks. Several authors have argued that panic attacks originate from a cognitive predisposition to interpret bodily arousal symptoms as highly threatening (e.g., Clark, 1986). What is the source of this cognitive misinterpretation?

One could argue that both panic patients and controls have the same amount of bodily sensations, but that panic patients tend tot misinterpret them in a catastrophic fashion (Clark, 1986). Alternatively, it is possible that panic patients have a better interoceptive perception than normals (Ehlers, Breuer, Dohn, \& Fiegenbaum, 1995). In both cases, it would be interesting to examine whether the right hemisphere plays a special role in panic. Germane to this issue are two separate lines of research. The first line concerns the differential involvement of the two hemisphere in emotions. While the details are still a matter of some debate (see Gainotti, Caltagirone, \& Zoccolotti, 1993), there is growing evidence for the claim that left cortical areas are critically involved in approach behaviour and positive affect, while right cortical areas play a special role in avoidance behaviour and negative affect (e.g., Davidson, 1992) Accordingly, a relative hypo activation of the left hemisphere and/or a hyper activation of the right hemisphere would contribute to anxious feelings. Following this line of reasoning, several authors have proposed that certain anxiety symptoms may be related to a habitual right-hemisphere overactivation (e.g., Heller, Etienne, \& Miller, 1995). Indeed, Merckelbach and colleagues (De Jong, Merckelbach, \& Nijman, 1995; Merckelbach and 


\section{Chapter 6}

colleagues (De Jong, Merckelbach, \& Nijman, 1995; Merckelbach, Muris \& De Jong, 1990) found evidence to suggest that persons who prefer a righthemisphere thinking style (e.g, an imaginal and holistic mode of thinking) report more anxiety symptoms than do persons with a left-hemisphere thinking style (i.e., a verbal and analytic thinking mode). Their studies relied on the Preference Test (PT), a paper-and-pencil task that presumably measures hemisphere-linked cognitive styles (Zenhausern, 1978). While this task provides a rather indirect approach of hemisphere processes, there are strong indications that, at least in undergraduate students, PT scores correspond tot asymmetries in background EEG activity (Merckelbach, Muris, Pool, \& De Jong, 1996).

The second line of research emphasizes individual differences in autonomic self-perception. It is a well-established fact that compared to normal control subjects, panic patients perform superior on autonomic perception tasks (e.g., heartbeat perception; Ehlers et al., 1995). Interestingly, there are reasons to believe that the right hemisphere is involved in the perception of interoceptive signals. For example, several studies reported that persons with a strong right-hemisphere activation perform better on heartbeat perception tasks than persons with a strong left-hemisphere activation (Katkin, 1985; Weisz, Balazs, Lang, \& Adam, 1990). As an index of hemisphere activation, these studies relied on conjugate lateral eye movements (CLEMs), i.e., involuntary left- or right- sided shifts of individuals' gaze that usually occur immediately following the end of a question requiting reflective thought. CLEMs are often interpreted as an index of cerebral hemisphere activation contra lateral to the direction of the eye movement (e.g., Kinsbourne, 1972). Moreover, as the direction of such eye movements is fairly consistent for a given individual, predominant lateral eye movements to the left or to the right are thought to reflect habitual contra lateral activation of the right or the left hemisphere, respectively. While the 
validity of CLEMs as an index of hemisphere activation has been challenged by some authors (e.g., Raine, 1991); EEG studies (Newlin, Rohrbaugh, \& Vamer, 1982) and regional cerebral bloodflow studies (Gur \& Reivich, 1980) provide support for the idea that CLEMs represent a useful hemisphere activation measure. With these two lines of research in mind, it seems intuitively plausible to argue that panic disorder is accompanied by a relatively strong reliance on or overactivation of the right hemisphere. A connection between panic disorder and the right hemisphere could evolve in either of two ways. To begin with, there are straightforward differences in cognitive functioning between the two hemispheres. Most researchers agree that the left hemisphere is involved in verbal and analytic processes, whereas the right hemisphere sustains an imaginal and holistic mode of information processing (e.g., Zenhausern, 1978). It has been argued that a left-hemisphere mode of reasoning may inhibit emotional reactions, whereas a righthemisphere mode of reasoning may intensify emotional reactions (e.g., Tucker \& Newman, 1981). By this view, a predominant reliance on righthemisphere thinking process could contribute tot neurotic complaints such as panic disorder. Secondly, given the special role of the right hemisphere in negative emotions (Davidson, 1992), the initiation of emotional responses (e.g., Wittling \& Pfluger, 1990), and the perception of bodily arousal symptoms (Katkin, 1985), one would expect that a chronic overactivation of the right hemisphere contributes to a heightened sensitivity for interoceptive fear and eventually panic symptoms.

The present study examined the connection between panic disorder on the one hand and hemisphere thinking style and hemisphere activation on the other hand. More specifically, it was tested whether panic patients have a stronger preference for a right-hemisphere mode of thinking (as indexed by the PT) and/or display a stronger right-hemisphere activation (as indexed by CLEMs) than normal control subjects. 


\section{METHOD}

\section{Participants}

Twenty-two patients (14 women) who met DSM-IV criteria (APA, 1994) for panic disorder with or without agoraphobia were included. Their mean age was $38.9(S D=9.5)$. Patients were diagnosed by a team of clinicians at the Academic Anxiety Centre Maastricht, using standardized protocols. Five patients had comorbid depression and four others had comorbid dysthymia. Seven patients were on medication, while the other 15 were medication-free. Three patients were left-handed, while 19 patients were right-handed.

Twenty-six healthy control subjects ( 20 women) were recruited through advertisements in a local newspaper. Their mean age was $38.8(S D=15.1)$. Controls were included after extensive screening on psychiatric morbidity and substance abuse. Six control subjects were left-handed, while 20 were righthanded. Control subjects were paid for their participation in the current study. A chi-square test for gender $\left(\chi^{2}=1.0 ; n=48 ; p=.31\right)$ and a Fisher's Exact test for handedness ( $p=.48$; two-tailed) revealed no significant differences between patients and controls. Also, the groups did not differ with respect to age $[r(46)<1.0]$.

\section{Assessment}

All subjects were tested individually. The following instruments were used: the Preference Test (PT; Zenhausern, 1981), the Conjugate Lateral Eye Movements test (CLEM-test; De Jong, Merckelbach, \& Muris, 1990), the State-Trait-Anxiety Inventory (STAI; Spielberger, Gorsuch, \& Lushene, 1970), and the Anxiety Sensitivity Index (ASI; Peterson \& Reiss, 1987). Assessment took place in a silent and stimulus poor room. The PT is a 20item self rating scale which asks the subject to indicate to what extent they prefer an analytical, verbal versus an intuitive, non-verbal style of reasoning. 
Ten items presumably address a left-hemisphere mode of thinking (e.g., "How good is your ability to think of synonyms for words?") and 10 items presumably address a right-hemisphere mode of thinking (e.g., "Do you like using symbols and/or images in solving problems?"). Items are rated on 10points scales (ranging from $0=$ not at all/never to $10=$ very much/always). To obtain a total PT score, the mean score on the right-hemisphere items is subtracted from the mean score on the left-hemisphere items. Consequently, a positive difference score reflects a relative preference for a left-hemisphere mode of thinking, whereas a negative difference score reflects a relative preference for a right-hemisphere mode of thinking. The PT has good testretest stability and internal consistency, and previous studies have found that PT scores are related to EEG measures of hemispherecity (e.g., Merckelbach et al., 1996). The CLEM test (De Jong et al., 1990) is a 20-item task based on the phenomenon of CLEMs. The task consists of ten verbal and ten spatial questions, designed to elicit lateral eye movements. The questions are posed by an interviewer facing the subject. Immediately after each question, the experimenter records the direction of the first gaze shift as either "left" (CLEML), "right"(CLEMR) or "not scorable". The total CLEM score is calculated as follows: $\mathrm{CLEM}=\mathrm{CLEML} /(\mathrm{CLEML}+\mathrm{CLEMR})$. Consequently, CLEM scores range between 0 (of all scorable eye movements, none was leftward) to 1 (all scorable eye movements were leftward). There are indications that CLEMs reflect contra lateral activation (Newlin et al., 1982). Thus, the higher the total CLEM score, the stronger a subject's righthemisphere activation.

The STAI (Spielberger et al., 1970) is a widely used paper-and-pencil questionnaire with good psychometric properties. It contains two subscales: one that measures state anxiety (e.g., "I am nervous"; STAl-state) and another measuring trait anxiety (e.g., "I am quiet person"; STAI-trait). The range of the subscale scores is $20-80$, with higher values indicating more anxiety. The 


\section{Chapter 6}

ASI (Peterson \& Reiss, 1987) is a 16-item self-report instrument that measures fear of anxiety sensations. Subjects indicate on five-point scales to what extent they are concerned with the possible aversive consequences of anxiety symptoms (e.g., "When I notice that my stomach is upset, I worry that I might be seriously ill"): Total scores range from 16 to 80 , with higher scores indicating higher fear of anxiety symptoms. The ASI has acceptable test-retest stability and has good construct validity (e.g., Donnell \& McNally, 1990). For example, persons with high ASI-scores are very sensitive to panic induction procedures (Rapee \& Medoro, 1992).

Tests were administered in the following order: CLEM, PT, ASI and STAI. Panic patients were tested before of during the early phase of their treatment.

\section{Data Analyses}

Due to a procedural error, the ASI data of six panic patients and the STAItrait data of three patients were unusable. Employing separate $t$-tests, group differences in PT, CLEMs, STAI and ASI were evaluated. For PT and CLEMs, a set of follow-up $t$-tests were carried out to control for the influence of potential confounding factors. In these follow-up $t$-tests, patients with comorbid depression, patients with medication or left-handed subjects were excluded from the analyses. Additionally, for the whole sample (i.e., patients and controls with complete data records; $n=42$ ). Pearson product-moment correlations were calculated between anxiety indices (ASI; STAI) and hemisphericity measures (PT; CLEM). 


\section{RESULTS}

\section{Anxiety Measures}

Mean STAI, ASI, PT and CLEM scores of both groups are presented in Table 1. As expected, patients scored significantly higher on all anxiety measures than controls: STAI-state $t(46)=10.1, p<.001$; STAI-trait, $t(43)=12.3, p<$ $.001 ;$ ASI, $t(40)=8.2, p<.001$.

Table 1. Mean STAI-State, STAI-Trait, ASI, PT, and CLEM Scores of Panic Patients and Normal Controls (Standard Deviations in Parentheses)

\begin{tabular}{lcl}
\hline & $\begin{array}{c}\text { Patients } \\
(n=22)\end{array}$ & $\begin{array}{l}\text { Controls } \\
(n=26)\end{array}$ \\
\hline STAI-state & $53.8(13.4)$ & $25.3(4.8)$ \\
STAI-trait $^{\mathrm{n}}$ & $57.2(11.7)$ & $26.5(4.6)$ \\
ASI $^{b}$ & $43.6(13.8)$ & $20.0(4.1)$ \\
PT & $0.40(1.4)$ & $0.63(1.2)$ \\
CLEM & $0.86(0.15)$ & $0.61(0.29)$ \\
\hline
\end{tabular}

Notes. ${ }^{\text {a }}$ Missing data for 3 panic patients. ${ }^{b}$ Missing data for 6 panic patients; STAI $=$ Spielberger. State-Trait Anxiety Inventory. ASI $=$ Anxiety Sensitivity Index, PT= Preference Test. CLEM=Conjugate Lateral Eye Movements.

\section{Hemisphericity Measures}

Mean PT scores of patients and controls were $.40(S D=1.4)$ and $.63(S D=1.2)$, respectively. This difference did not attain significance $(t(46)<1.0$ ). Statistical tests were repeated after exclusion of possible confounding factors (comorbid depression, medication or left handedness), but again, no significant differences between patients and controls emerged.

Mean CLEM scores of the patients and controls were $.86(S D=.15)$ and $.61(S D=.29)$, respectively. This difference was significant $(t(46)=3.7 ; p<$ $.001)$. Thus, panic patients displayed more left-sided lateral eye movements 
(i.e., more right-hemisphere activation) than normal subjects. Follow-up $t$ tests after exclusion of possible confounding factors revealed similar significant differences.

\section{Pearson Correlations}

Correlations among the anxiety measures (STAI-state, STAI-trait, and ASI) were all high and significant (all $r s>.82, p s<.001$ ). Table 2 shows correlations between PT, CLEM, STAI, and ASI scores. No significant associations were found between PT, on the one hand, and anxiety measures (STAI-state; STAI-trait; ASI), on the other hand, although correlations were in the right direction and approached borderline significance (all $r s>-.23$, ps $<.07$, one tailed). Furthermore, PT was not associated with CLEM, indicating that both measures of hemisphere were unrelated. However, positive correlations were found between CLEM and STAI-state and between CLEM and STAI-trait. Also, a positive correlation emerged between CLEM and ASI. That is, leftward eye movements (i.e., right-hemisphere activation) were associated with heightened levels of subjective anxiety.

Table 2. Pearson correlations between anxiety measures (STAI, AS1) and hemisphericity measures (PT, CLEM) for the combined sample $(n=42)$

\begin{tabular}{lcccc}
\hline & CLEM & STAI-state & STAI-trait & ASI \\
\hline PT & .15 & -.23 & -.24 & -.24 \\
CLEM & & $.38^{*}$ & $.41^{*}$ & $.38^{*}$ \\
\hline
\end{tabular}

Notes. Only relevant correlations are presented. ${ }^{*} p<.01$. STAI=Spielberger StateTrait Anxiety Inventory, ASI $=$ Anxiety Sensitivity Index, PT $=$ Preference Test, CLEM $=$ Conjugate Lateral Eye Movements. 


\section{DISCUSSION}

The main results of the present study can be summarized as follows. Firstly, no evidence was found to suggest that panic patients and normal controls differ with regard to verbal and analytic versus imaginal and global thinking styles. That is to say, the current PT findings do not support the idea that panic disorder is characterized by a right-hemisphere mode of thinking. Secondly, panic patients and normal controls did differ with regard to CLEMs in that patients exhibited more leftward eye movements compared to normal controls. To the extent that a relative predominance of leftward eye movements reflects right-hemisphere overactivation, this finding supports the idea that panic disorder is characterized by right-hemisphere over reliance. Thirdly, across the whole sample, only marginally significant associations were found between PT defined thinking styles and anxiety measures. Fourthly, CLEMs were correlated with self reported state anxiety, trait anxiety, and fear of anxiety sensations (ASI).

The present study's failure to find differences between patients and controls in hemisphere-related thinking styles deserves some comment. Earlier studies have found that there is a positive correlation between a righthemisphere thinking style as indexed by the PT and self-reported anxiety (e.g., De Jong et al., 1995). Furthermore, recent studies indicate that the PT has good psychometric properties and is correlated with EEG asymmetry profiles (e.g., Merckelbach et al., 1996). However, most of this work is based on undergraduate samples, and it may well be the case that the PT is not a valid and stable index in other samples. Note that for subjects with a limited education, some PT items (e.g., "Do you like using symbols and/or images in solving problems") might be difficult to understand. The majority of the subjects in the present study had a limited education and this may have undermined the validity of the PT measure. Another explanation for the 


\section{Chapter 6}

failure to obtain PT differences between panic patients and normal controls might be that, unlike the CLEM task, the PT taps an aspect of hemisphere asymmetry that is less relevant to panic disorder. The absence of a correlation between PT and CLEM supports such an interpretation. Perhaps, then, not only left-right differences, but also anterior- posterior differences might be important to evaluate the role of hemisphere reliance in panic disorder.

While panic patients and normal subjects did not differ with regard to the PT, there were convincing differences between the two groups with regard to CLEMs. The fact that panic patients exhibited more leftward eye movements than controls suggests that panic patients are characterized by a right-hemisphere overactivation. Assuming that the right hemisphere plays a pivotal role in the perception of interoceptive signals and in the initiation of negative emotions, this finding fits well with panic patients' superior performance on heartbeat perception tasks (Ehlers et al., 1995). Yet, it should be noted that the present study did not include a psychiatric control group. Consequently, it remains to be seen whether a high frequency of leftward eye movements is specific for panic disorder or is a general characteristic of various psychopathological conditions. Note in passing that there is little reason to suspect a right-hemisphere involvement in all anxiety conditions. For example, Carter, Johnson, and Borkovec (1986) have pointed to the prominent role of the left frontal areas in anxiety states that are characterized by worrying.

The validity of eye movements as an index of hemisphere activation is in dispute. Some authors have claimed that CLEMs do reflect contra lateral hemisphere activation (Gur \& Reivich, 1980; Newlin et al., 1982). Others have argued that CLEMs may tap transient hemisphere asymmetries, but not habitual differences in hemisphere overactivation (Raine, 1991). However that may be, the extensive work of Katkin (1985) demonstrates that there is a strong connection between leftward CLEMs and superior performance on 
hearbeat detection tasks. Note also that there are more direct indications that panic patients show an increased regional cerebral blood flow in the right hemisphere (De Cristofaro, Sessarego, Pupi, Biondi, \& Faravelli, 1993). These results as well as the findings of the present study warrant further research. Future studies should preferably employ direct indices of anterior and posterior hemisphere activation (e.g., EEG) in panic patients and should also include psychiatric control samples. This type of study is important because it could elucidate why autonomic perception is a good predictor of relapse and maintenance of panic disorder and panic attacks (Ehlers, 1995).

\section{REFERENCES}

American Psychiatric Association (1994). Diagnostic and statistical manual of mental disorders ( $4^{\text {th }}$ ed.). Washington, DC: Author.

Carter, W.R., Johnson, M.C., \& Borkovec, T.D. (1986). Worry: an electrocortical analysis. Advances in Behaviour Research and Therapy, 8, 193-204.

Clark, D.M. (1986). A cognitive approach to panic. Behaviour Research and Therapy, $24,461-470$.

Davidson, R.J. (1992). Emotion and affective style: Hemisphere substrates. Psychological Science, 3, 39-43.

De Cristofaro, M.T.R. Sessarego. A., Pupi, A., Biondi, F., \& Faravelli, C. (1993). Brain perfusion abnormalities in drug-naîve, lactate sensitive panic patients: $\mathrm{A}$ SPECT study. Biological Psychiatry, 33, 505-512.

De Jong, P.J., Merckelbach, H., \& Muris, P., (1990). Conjugate lateral eye movements, cerebral dominance, and anxiety. In R.I. Takens (Ed.). European perspectives in psychology, Vol. 2. (pp. 369-379) New York: Wiley.

De Jong, P.J., Merckelbach, H., \& Nijman H. (1995). Hemisphere preference, anxiety, and covariation bias. Personality and Individual Differences, 18, 363371.

Donnell, C.D. \& McNally. R.J. (1990). Anxiety sensitivity and panic attacks in a nonclinical population. Behaviour Research and Therapy, 28, 83-85. 
Ehlers, A. (1995). A 1-year prospective study of panic attack: Clinical course and factors associated with maintenance: Joumal of Abnomal Psychology, 104, $164-172$

Ehlers, A., Breuer, P., Dohn, D. \& Fiegenbaum, W. (1995). Heartbeat perception and panic disorder: Possible explanations for discrepant findings. Behaviour Research and Therapy, 33, 69-76.

Gannotti, C., Caltagirone. G., \& Zoccolotii, P. (1993). Left/right and cortical/subcortical dichotomies in the neuropsychological study of human emotions. Cognition and Emotion, 7, 71-79.

Gur, R.C., \& Reivich, M., (1980). Cognitive task effects on hemispheric blood flow in humans: Evidence for individual differences in hemispheric activation. Brain and Language, 9, 78-92.

Heller, W., Etienne, M.A., \& Miller, C.A., (1995). Patterns of perceptual asymmetry in depression and anxiety: implications for neuropsychological models of emotions and psychopathology. Joumal of Abnormal Psychology, 104, 327333.

Katkin, E.S. (1985). Blood, sweat, and tears: Individual differences in autonomic selfperception. Psychophysiology, 22, 125-137.

Kinsbourne, M. (1972). Eye and head turning indicates cerebral lateralization. Science, $176,539-541$.

Merckelbach, H., Muris, P., \& De Jong, P., (1990) Hemispheric preference, phobia and depression. Imternational Joumal of Neuroscience, 55, 119-123.

Merckelbach, H., Muris, P., Pool, K., \& De Jong, P., (1996). Reliability and validity of a paper-and-pencill test measuring hemisphere preference. European Journal of Personality, 10,221-231.

Newlin, D.B.s Rohrbaugh, J.W., \& Varner, J.L. (1982). Lateral eye movement tendency related to alpha asymmetry (Abstract). Psychophysiology, 19, 338.

Peterson, R.A., \& Reiss, R.L. (1987). The anxiety sensitivity index: Construct validity and factor analytic structure. Journal of Anxiety Disorders, 1, 265-277.

Raine, A. (1991). Are lateral eye-movements a valid index of functional hemispheric asymmetries? British Journal of Psychology, 82, 129-135. 
Rapee, R.M. \& Medoro, L. (1992). Response to hyperventilation in subjects high and low in fear of physical sensations. International Journal of Psychology, 27, 470 .

Spielberger, C.D., Gorsuch, R.L., \& Lushene, R.E. (1970). Mamual for the State-Trait Anxiety Inventory. Palo Alto, CA: Consulting Psychologists Press.

Tucker, D.M. \& Newman, J.P. (1981). Verbal versus imaginal cognitive strategies in the inhibition of emotional arousal. Cognitive Therapy and Research, 5, 197202.

Weisz, J., Balazs, L., Lang, E., \& Adam, G. (1990). The effect of lateral visual fixation and the direction of eye movements on heartbeat perception. Psychophysiology, 27, 523-528.

Wittchen, H.U. (1998). Natural course and spontaneous remissions of untreated anxiety disorders: Results of the Munich follow-up study (MFS). In I. Hand \& H.U. Wittchen (Eds.). Panic and phobias 2 (pp. 3-17). Berlin: Springer.

Wittling, W., \& Pfluger, M. (1990). Neuroendocrine hemisphere asymmetries: Salivary cortisol secretion during lateralized viewing of emotion-related and neutral films. Brain and Cognition, 14, 243-265.

Zenhausern, R. (1978). Imagery, cerebral dominance and style of thinking: A unified fieid model. Bulletin of the Psychonomic Society, 12, 381-384. 
Summary and conchusions 151

\section{CHAPTER 7}

\section{SUMMARY AND CONCLUSIONS}




\section{SUMMARY AND CONCLUSIONS}

The objective of the present dissertation was to test the hypothesis that inappropriate reasoning strategies and specific thinking styles are responsible for the persistence of irrational fears. This hypothesis was tested along three lines of research.

\section{Belief bias and pathological anxiety}

The first line of research is concerned with the tendency of human beings to allow the subjective believability they attach to a certain statement to influence the judgement of the logical validity of that statement. It is argued that a general tendency to judge believable information as logically valid and unbelievable information as logically invalid (i.e., belief bias) would be a factor of importance in the persistence of dysfunctional convictions that play a role in psychopathology, for example in phobic disorders. This hypothesis was elaborated in two experimental studies.

In Chapter 2, the hypothesis was tested that belief bias is associated with levels of self-reported psychopathological symptoms in non-clinical subjects. It was examined whether a general tendency to confirm rather than to falsify personal beliefs (i.e., belief bias) is responsible for the general refractoriness of dysfunctional convictions that play a role in psychopathology. For this purpose the relationship between the level of belief bias and the severity of self-reported psychopathological symptoms was investigated in a non-clinical sample. Participants $(n=200)$ solved a series of lincar syllogisms concerning neutral themes (de Jong, Weertman, Horselenberg \& Van den Hout, 1997). They were asked to judge the syllogisms" logical validity, without taking the believability of the syllogisms into account. Participants performed relatively poor (i.e., they displayed more errors and longer response latencies) when there was a mismatch between the 
logical validity and believability of the syllogisms (belief bias). However, we found no linear association between the severity of this general belief bias and the severity of psychopathological complaints. Thus, the study lends no support to the idea that a generally enhanced tendency to confirm rather than to falsify prior beliefs acts as a diathesis for the development of psychopathology.

In an attempt to explain the absence of a relationship between belief bias and psychopathological complaints, it can be argued that the study might have lacked sufficient sensitivity to detect such a relationship. Further, the study did not control for the presence or the intensity of particular personal experiences that are thought to be crucial for the development of particular dysfunctional convictions. It may well be the case that the joint influence of such experiences and an enhanced belief bias that eventually facilitates the generation/consolidation of dysfunctional beliefs. A final explanation for the absence of a relationship between belief bias and psychopathological complaints, we argued that the reasoning errors that were previously found in phobic individuals (De Jong et al., 1997) should be interpreted as the result rather than the cause of phobic anxiety. For example, Keinan (1987) argued that anxiety might generate a general. sense of insecurity and stress, as a consequence of which subjects may jump to inappropriate conclusions. Another line of research has shown that restricted working memory capacity in high anxious subjects affects attention, storage and manipulation of information, resulting in performance deficits (e.g., Eysenck, 1985; Tohill \& Holyoak, 2000).

To conclude, although no evidence was obtained for a link between belief bias and psychopathological symptoms, it would be premature to completely dismiss the idea that belief bias is involved in the persistence of psychopathological complaints. Indeed, it is not clear whether in clinical disorders, belief bias is a cause or a consequence of psychopathology. Either 


\section{Chapter 7}

way, it should be acknowledged that once pathogenic concerns are present, belief bias logically acts in a way that hinders the realistic evaluation of critical situations, thereby sustaining irrational concerns.

In Chapter 3, a quasi experimental study was carried out to test whether (i) anxiety disordered patients [i.e., patients with obsessive-compulsive disorder (OCD) or panic disorder (PD)] are characterized by a relatively enhanced belief bias, (ii) whether belief bias is restricted to the domain of phobic concern and (iii) whether belief bias predicts treatment outcome and relapse. A group of OCD $(n=25)$, a group of PD patients $(n=36)$ and a group of normal controls $(n=20)$ was presented with a series of linear syllogisms concerning neutral, OCD-relevant, and PD-relevant themes. The reasoning task was administered before and after treatment. Self-report measures of general psychopathology (SCL-90; Arrindell \& Ettema, 1986) and anxiety (FQ; Marks \& Matthews, 1979) were administered before treatment, after treatment and at six month follow-up.

In general, all groups displayed a belief bias. However, we found no evidence for a generally enhanced belief bias at pre-treatment, neither in patients with panic disorder nor in patients with obsessive-compulsive disorder. In line with the study described in Chapter 2, we concluded that the study found no support for the idea that subjects with high levels of psychopathological symptoms are characterized by a trait-like generally enhanced confirmatory reasoning bias that could have acted as a diathesis in the development of these problems. It should be emphasized however that, although not generally enhanced, belief bias logically hinders the falsification of pathogenic concerns that characterize subjects who suffer from psychopathological complaints..

Domain-specific reasoning bias could be demonstrated in patients with panic disorder but not in patients with obsessive-compulsive. It was argued 
that the failure to detect domain-specific belief bias in patients with obsessivecompulsive disorder might be due to a lack of sensitivity of the reasoning task within the obsessive-compulsive domain, which might be related to the heterogeneity of the obsessive-compulsive beliefs within this patient group. Altogether, the results seem to support the idea that the incorrigibility of anxiogenic beliefs is not the result of a reasoning abnormality in anxiety disordered patients, but would merely represent a normal manifestation of personally relevant beliefs.

With respect to treatment effects, it was found that in panic patients, higher levels of domain-specific reasoning bias at pre-treatment strongly predicted better treatment outcome at post-treatment as well as at follow-up. No such association was found in patients with obsessive-compulsive disorder, which again, might be due to a lack of sensitivity of the reasoning task for this particular group. It was argued that those patients in which cognitive factors play an important role in the maintenance of the disorder may take more profit from a treatment that focuses on the correction of their dysfunctional beliefs (i.e., cognitive therapy).

Although treatment resulted in a significant decrease of self-reported anxiety and general psychopathology in both patient groups, belief bias levels were not found to be influenced by effective treatment. It can be concluded that belief bias is neither an epiphenomenon of the disorder nor sufficient for the persistence of anxiety complaints. The finding that domain-specific belief bias was not affected by the reduction of dysfunctional beliefs (i.e., effective treatment) appears somewhat in contrast with the idea that belief bias is a common consequence of personally held beliefs. However, although dysfunctional beliefs diminish after succesful treatment (e.g., Arntz, 2002), they might still exist on a low or even non-conscious level when the clinical symptoms of the disorder have disappeared (e.g., Wilson, Lindsey \& Schooler, 2000). Thus, it is possible that the reasoning task taps automatically 


\section{Chapter 7}

activated beliefs rather than more deliberate, reflexive beliefs (cf. Strack \& Deutsch, 2004).

In patients with obsessive-compulsive disorder but not in panic disorder patients, it was found that higher levels of residual domain-specific belief bias at post-treatment were associated with the return of general psychopathology complaints (SCL-90) at six months follow-up. No such association was found with the retum of self-reported anxiety. Thus, although belief bias alone does not seern to be sufficient for complaints to occur, it might play a significant role in the persistence and the return of such complaints.

Taken together, the two studies on the role of belief bias in the aetiology and the persistence of anxiety disorders reveal that (i) higher belief bias is not associated with higher levels of psychopathological complaints in normal subjects, (ii) belief bias is not generally enhanced in patients with panic disorder and obsessive-compulsive disorder, (iii) patients with panic disorder are characterized by a domain-specific reasoning bias (iv) pretreatment belief bias levels can predict treatment outcome and relapse, and (v) belief bias is not systematically affected by effective treatment.

\section{Threat-confirmation bias and pathological anxiety}

The second line of research in this dissertation is built upon another reasoning strategy that might add tot the refractoriness of phobic views, and which is known as the 'better safe than sorry' strategy or threat confirmation bias. Confirmation bias refers to the tendency to selectively search and select information in the environment that confirms rather than falsifies an idiosyncratic point of view. In the case of anxiety disorders, a selective search for information that only confirms a once acquired phobic conviction would hamper the disconfirmation and readjustment of such convictions, thereby sustaining the disorder. Derivatives of this hypothesis were tested in a series of experimental studies using adapted versions of the Wason selection task 
(Wason, 1968) as the experimental paradigm. As compared to the syllogistic reasoning task that was used in the experiments described in Chapter 2 and Chapter 3, the Wason selection task requires a more active search of information. That is, in the syllogistic reasoning task, all information that is required to solve the problem is explicitly presented. Note however, that in real life a distinction can be made between situations in which the subject is passively confronted with appropriate information as well as with situations that require an active approach to search for relevant information. In the Wason selection task, subjects are not passively confronted with information, but they have to search for information that could be relevant to solve the problem.

Chapter 4 describes three experiments in which it was tested whether (i) in threatening situations, people are apt to search for threat-confirming evidence, (ii) it could be ruled-out that irrelevant selection biases confounded threat-confirming effects, and (iii) the level of subjective perceived threat was associated with the level of threat-confirmative reasoning. In Experiment 1, female undergraduates $(n=40)$ were presented with Wason selection tasks (WST; Wason, 1968) pertaining to threatening situations. The selection tasks contained safety rules ("if $p$ then safe') and danger rules ('if $p$ then danger"). Participants relatively often selected potentially falsifying cards in case of safety rules whereas they relatively often selected potentially verifying cards in case of danger rules. It can be concluded that reasoning in the domain of threat is goal sensitive. That is, in threatening situations, it seems most adaptive to search for falsifying information in the case of safety rules, and to search for verifying information in the case of danger rules. In experiment 2 $(n=48)$, the type of rule (safe/danger) and the absence/presence of a negation in the consequent (i.e., if $\mathrm{p}$ then safe/if $\mathrm{p}$ then no danger/if $\mathrm{p}$ then not safe/if $\mathrm{p}$ then danger) was systematically varied to disentangle the relative contributions of a danger-confirming strategy and a matching bias (i.e., the 
selection of those cards which represent the information that matches with the rule; e.g., Evans \& Lynch, 1973). Again, subjects displayed a dangerconfirming strategy. Meanwhile, no evidence for a matching bias was found. In Experiment $3(n=60)$, the influence of perceived threat on the degree of danger-confirming reasoning was explored. For this purpose a highthreatening and a low-threatening version of the WST was created. In both conditions, subjects displayed a danger-confirming strategy, while no effect of threat intensity emerged. That is, although the high threat condition was evaluated as significantly more threatening than the low threat condition, perceived threat had no influence on the degree of threat confirmation bias. On the basis of these findings, one could argue that the "better safe than sorry" strategy is an all or none phenomenon, which is already triggered by the perception of minor threat. However, as an alternative explanation it can be argued that threat-signals about unfamiliar situations might provoke a 'better safe than sorry' strategy more easily as compared to threat signals about familiar situations, because the subject can not employ previous knowledge and representations about the problem under consideration. Thus, the finding that confirmatory reasoning was not affected by perceived threat levels, might be due to a relatively low threshold for a 'better safe than sorry'strategy in situations that are unfamiliar.

In the case of objective threats, a 'better safe than sorry' strategy can be viewed as functional. Although it may be rather unpleasant to flee frequently for false alarms, the consequences of not taking a danger alert seriously on just one occasion might be catastrophic. However, when the perceived threat is irrational, an active search for danger confirming information in combination with a neglect of disconfirming evidence logically serves to maintain or even enhance phobic fears.

To test the clinical significance of the paradigm and to explore whether threat-confirmation bias reflects a general rather than a domain-specific trait 
in anxiety-disordered patients, Chapter five describes an experiment in which threat-confirmative reasoning was measured in hypochondriacal patients and healthy control subjects. It was investigated whether hypochondriacal patients selectively search for threat-confirming information when asked to judge the validity of conditional rules in the context of general and health threats. Several factors that may underlie participants' information selection (e.g., believability of the rule) were also explored. Hypochondriacal patients $(n=$ $20)$ and healthy controls $(n=20)$ were presented with modified Wason selection tasks (WSTs), which contained safety rules and danger rules in the context of general threat and health threat.

In the context of general threat, both groups of participants adopted a verificationistic strategy in case of danger rules and a falsificationistic strategy in case of safety rules. This general threat confirmation bias was not particularly pronounced in hypochondriacal patients. It was concluded that hypochondriacal patients are not characterized by a trait-like reasoning bias which would hinder them from correcting anxiogenic convictions and, therefore, susceptible to pathological anxiety. Importantly however, in contrast to normal controls hypochondriacal patients adopted a similar threatconfirming reasoning pattern in the context of health threat. This finding suggests that the domain-specific reasoning bias in hypochondriacal patients is an unfortunate consequence of an otherwise very functional goal-oriented strategy.

The finding that hypochondriacal patients display a domain-specific threat-confirming reasoning bias might have clinical implications. That is, to the extend that such a bias logically acts as a causal agent in the persistence of irrational anxiogenic beliefs, one would expect that a reduction of this bias should result in a reduction of psychopathological complaints.

As an alternative explanation for the differential response pattern to safety and danger rules, it has been suggested that participants might consider 
safety rules as generally less believable and/or probable than danger rules. That is; to the extent that rules are perceived as less believable/probable, a stronger falsificatory approach may be expected. However, no differences were found between danger and safety rules regarding subjective believability and probability ratings. Thus, it can be concluded that the differential selection pattern with regard to safety and danger rules was not merely the consequence of differences in subjective believability and/or probability of safety and danger rules.

The finding that hypochondriacal patients display a domain-specific threat-confirming reasoning bias is in contrast with an earlier study of de Jong et al. (1998) in which healthy controls displayed such a strategy in the domain of health threat. In an attempt to explain these apparently contrasting findings, it can be argued that the WSTs in the earlier study contained a (unintended) worry manipulation ("after hearing this, you get worried") which might have induced a reasoning strategy in healthy controls, which is normally restricted to hypochondriacal patients. Thus, in the context of health threats, the "better safe than sorry' strategy seems to be the habitual strategy for hypochondriacal patients.

Taken together, the results of the study sustain the idea that the perception of threat activates a 'better safe than sorry' strategy. In case of phobic threat such a reasoning strategy immunizes against refutation of phobic convictions, which in turn might explain the refractoriness of phobogenic beliefs in the face of falsifying information.

\section{Hemisphericity, cognitive styles and pathological anxiety}

The third research line in this dissertation concerns the connection between specific thinking styles, neurobiology and anxiety. It can be hypothesized that the catastrophic misinterpretation of bodily sensations as well as the superior 
interoceptive perception that are typical for panic disorder patients both point in the direction of a relative dominance of the right cerebral hemisphere.

In Chapter 6 , the hypothesis was tested whether panic disorder patients as compared to healthy controls are characterized by cognitive styles that are supposed to be typical for the right hemisphere and whether, in line with this, panic patients display relative right hemisphere overactivation. Panic disorder patients $(n=22)$ and normal controls $(n=26)$ completed the Preference Test (PT; Zenhausern, 1978) and were tested with the Conjugate Lateral Eye Movements test (CLEM-test; De Jong, Merckelbach \& Muris, 1990) as measures of hemisphere-reliance. Furthermore, subjects completed the Spielberger State-Trait Anxiety Inventory (STAI; Spielberger, Gorsuch \& Lushene, 1970) and the Anxiety Sensitivity Index (ASI; Peterson \& Reiss, 1987) as indices of self-reported anxiety.

On the PT, panic patients and controls did not differ with regard to verbal and analytic (cf. left hemisphere) versus imaginal and global (cf. right hemisphere) thinking styles. In other words, these findings do not support the idea that panic disorder is characterized by a right-hemisphere mode of thinking. However, panic patients exhibited significantly more left lateral eye movements as compared to controls. Assuming that a relative predominance of leftward eye movements reflects right hemisphere overactivation, this finding supports the idea that panic disorder is characterized by righthemisphere overreliance. Thus, some indications were found for a relative right-hemisphere overactivation in panic disorder patients.

Across both groups, significant positive correlations were found between right-hemisphere activation on the one hand (as indexed by CLEMtest scores), and self-reported state and trait anxiety (STAI) and interoceptive fear (ASI) on the other hand. As the right hemisphere is thought to play a pivotal role in the perception of interoceptive signals and the initiation of negative emotions, this finding fits well with panic patients' superior 
performance on heartbeat perception tasks (cf. Ehlers, Breuer, Dohn, \& Fiegenbaum, 1995).

In an attempt to explain the failure to find differences between patients and controls with regard to their hemisphere-related thinking styles, it was argued that the Preference Test may not be a valid and stable index in samples with limited education. Further, the absence of a correlation between PT and CLEM-test points to the possibility that, unlike the CLEM-test, the Preference Test taps an aspect of hemisphere asymmetry that is less relevant to panic disorder.

\section{FUTURE RESEARCH}

\section{Belief bias and psychopathology}

First of all, more research is necessary that is aimed at the further improvement of the sensitivity of the syllogistic reasoning task, with respect to specific populations and specific domains. It should be acknowledged that the reasoning tasks that were used in the studies that were conducted in this thesis might have lacked sufficient sensitivity and specificity to assess (domain-specific) belief bias.

Second, in future research on the role of belief bias in the development of psychopathology, it will be necessary to control for the presence and the intensity of specific personal experiences that are crucial for the development of particular dysfunctional convictions. One way to do this would be to investigate the influence of belief bias in a laboratory setting that allows controlling for the relevant experiences, for example by assessing individuals UCS-expectancies in the context of a differential aversive conditioning paradigm (e.g., Öhman, Erixon, \& Lofberg, 1975). If belief bias plays an essential role in the acquisition and maintenance of dysfunctional convictions, one would expect that subjects with a relatively high belief bias would show a 
relatively steep acquisition curve and a relatively strong resistance to subsequent extinction of aversive UCS-expectancies.

Third, more research is necessary to explore the specific role of belief bias in the persistence and the return of complaints. It would be worthwhile to test for example, whether a cognitive treatment that is tailored to undermine belief bias would result in a reduction of psychopathological complaints and prevent relapse. The target of such an intervention would be to reduce the automatic inference of dysfunctional beliefs and to induce a more falsificationistic type of reasoning. To experimentally manipulate belief bias so that its causal properties can be tested, a similar approach could be followed as which was recently employed to reduce attentional bias in social phobics (McLeod, Rutherford, Campbell, Ebsworthy \& Holker, 2002). More specifically, anxiety patients could be exposed to an extensive series of (domain-specific) syllogisms that have systematically mismatching believability and validity. If belief bias is indeed a causal factor in the maintenance of complaints, one would expect that a reduction in belief bias is accompanied by a similar reduction of complaints (cf. McLeod et al, 2002; De Jong \& Vroling, 2005). To the extent that a computerized modification of belief bias may show clinically relevant improvement of complaints, this would be a very welcome addition to the therapeutic arsenal (in terms of efficiency, cost-effectiveness, and applicability).

\section{Threat-confirmation bias and psychopathology}

The reasoning tasks that were used in the present thesis clarify how people reason about threatening situations. What they don't explain however, is how people reason when they (think they) actually are in a threatening situation. It should be noted that, although the threatening properties of the rules in our studies were manipulated by means of context stories, participants were not actually at risk when they were asked to solve the reasoning tasks. Therefore, 


\section{Chapter 7}

the participants' primary goal was not to prevent harm, but merely to indicate what he or she would be expected to do, namely to select those cards that seem essential to test the conditionals. Although it can be very fruitful to understand how people reason about situations they imagine, it would perhaps be even more important to know more about whether and how people reason when they actually are in a threatening situation. Clearly, this would add to the understanding of specific cognitive processes that occur during exposure treatments. One possibility to achieve this goal could be to develop simulations of threatening situations (for example in a laboratory setting or in virtual reality), in which certain information (i.e., danger-signals vs. safety signals) is systematically manipulated. Although strong evidence was found for the presence of a threat-confirming algorithm, it can be speculated that exposure to such situations might provoke even stronger goal-oriented, harm avoiding biases.

The use of ambiguous safety and danger signals might further improve the sensitivity of the Wason Selection Task to discriminate between normal and abnormal reasoning strategies. Note that anxiety patients typically misinterpret harmless stimuli as signals of an oncoming catastrophe. It might well be the case that patients do not only differ from normals with respect to the domain-specificity of the reasoning bias, but also with respect to the threshold of what is subjectively experienced as a threatening stimulus which subsequently provokes a threat-confirming mode of information processing (cf. Beck \& Clark, 1997).

More research is necessary to further explore the role of threatconfirmation bias in the development and maintenance of anxiety disorders. In particular it would be necessary to test whether phobogenic reasoning is the result or the cause of the disorder under consideration. Although the main hypothesis of the present thesis concerns the influence of reasoning on (the maintenance of) anxiety, it should be acknowledged that there is considerable 
literature about a relationship in the opposite direction, namely that anxiety influences reasoning and decision making (e.g., Eysenck, 1985; Keinan, 1978; Darke, 1988; Tohill \& Holyoak, 2000). Notwithstanding the direction of the relationship between reasoning bias and anxiety, it remains clear that a threatconfirming reasoning strategy immunizes against the refutation of irrational anxiogenic beliefs.

To further examine the role of threat-confirmation bias in the maintenance of anxiety disorders, it would be important to study whether (domain-specific) threat-confirmation bias is a general characteristic in anxiety disorders. Therefore, it would be worthwhile to test whether the current findings can be replicated in other anxiety disorders, for example panic disorder and obsessive-compulsive disorder. If anxiety patients are indeed characterized by domain-specific threat-confirmation bias, this might have clinical implications. That is, to the extent that such a bias logically acts as a causal agent in the persistence of irrational anxiogenic beliefs, one would expect that a reduction of this bias should result in a reduction of psychopathological complaints (e.g., MacLeod, et al., 2002). To the extend that threat-confirmation bias is a result from, rather than a causal agent in the disorder, it would be important to investigate for example whether effective treatment affects (domain-specific) threat confirmation bias and whether residual phobogenic reasoning bias can predict relapse (cf. Smeets \& de Jong, 2005). To further test the causal properties of threat-confirmation bias in the development and maintenance of anxiety disorders, more experimental research is required in which it is tested whether systematically induced or reduced reasoning bias is connected to the acquisition and reduction of fear.

In the present thesis, the role of belief bias (i.e., syllogistic reasoning) and the role of confirmation bias (i.e., conditional reasoning) were examined in separate studies. Indeed, there are clear differences between both types of reasoning biases that even go beyond the fact that different experimental 


\section{Chapter 7}

paradigms are used. For example, as compared to the syllogistic reasoning task, the Wason selection task requires an active rather than a passive search for information. Nevertheless, in future research it would be interesting to study whether subjects that display relatively high levels of (domain specific) belief bias also display relatively high levels of (domain-specific) confirmation bias. Pertinent to the context of psychopathology, one could speculate that patients display a reasoning bias that is generalized across different types of reasoning.

More insight in specific manifestations of biased reasoning in psychopathology might add to the understanding of the actiology and maintenance of psychopathological disorders, and in turn guide us to the development of more effective treatments. Future research should therefore be aimed at the disclosure of (other) reasoning biases that disrupt adaptive information processing and install or maintain dysfunctional beliefs. Subsequently, more knowledge about dysfunctional reasoning patterns that contribute to the persistence of irrational beliefs could result in a further refinement of the available interventions. In particular with a view to the long term effects of treatment and the transfer of treatment effects beyond the domain of training, it might be very useful to put more emphasis on teaching reasoning skills that can be applied to deal with dysfunctional beliefs (e.g., Nisbett, Fong, Lehman \& Cheng, 1987; see also Klayman \& Brown, 1993).

\section{Hemisphericity, cognitive styles and psychopathology}

Support for a right hemisphere overactivation in panic disorder patients as described in this thesis was based on a test that used eye-movements as an index for hemisphere activation. However, the validity of eye-movements as an index of stable individual differences in hemisphere utilization is in dispute (e.g., Raine, 1991). To further explore the role of habitual right hemisphere 
preference in anxiety disorders, more research is needed using modern neuroimaging techniques as direct measures of cerebral activation.

The recent finding that that both syllogistic and conditional reasoning specifically activate left frontal-temporal regions (Goel, Gold, Kapur \& Houle, 1997; Goel \& Dolan, 2004; Wagner, Maril, Bjork \& Schacter, 2001; Goel, Shuren, Sheesley \& Grafman, 2004; Noveck, Goel \& Smith, 2004) suggests that people who predominantly rely on their right-hemisphere experience more difficulties with reasoning tasks. Hence, one could speculate that the finding that anxiety patients are characterized by a domain-specific reasoning bias is associated with the (habitual) activation of non-analytic right-lateral regions of the cerebral cortex, resulting in a more intuitive mode of solving reasoning problems. In future research, it would be worthwhile to test to what extent domain-specific reasoning errors are related to the activation of the right hemisphere.

Further progress in the science of emotional disorders may depend on the conjunction of neuroscience and experimental psychopathology (cf. McNally, 1998). More information is needed about how emotion interacts with information processing (e.g., Dolan 2002) and it would be worthwhile to find out how specific cognitive biases in anxiety disorders and affective disorders are instantiated in the brain.

\section{REFERENCES}

Arntz, A. (2002). Cognitive therapy versus interoceptive exposure as treatment of panic disorder without agoraphobia. Behaviour, Research and Therapy, 40, $325-341$.

Arntz, A. (2003). Cognitive therapy versus applied relaxation as treatment of generalized anxiety disorder. Behaviour Research and Therapy, 41, 633-646. 
Arrindell, W. A., \& Ettema, J. H.M., SCL-90 (1986). Handleiding bij een multidimensionele psychopathologie-indicator. Lisse, The Netherlands: Swets and Zeitlinger.

Beck, A.T., \& Clark, D.A. (1997). An information processing model of anxiety: Automatic and strategic processes. Behaviour Research and Therapy, 35, 4958.

Darke, S. (1988). Effects of anxiety on inferentional reasoning task performance. Jounal of Personality and Social Psychology, 55, 499-505

de Jong, P.J, Merckelbach, H., \& Muris, P., (1990). Conjugate lateral eye movements, cerebral dominance, and anxiety. In R.I. Takens (Ed.). European perspectives in psychology, Vol. 2. (pp. 369-379) New York: Wiley.

de Jong, P.J., Weertman, A., Horselenberg, R., \& Van den Hout, M.A. (1997). Deductive reasoning and pathological anxiety: Evidence for a relatively strong "belief bias" in phobic subjects. Cognitive Therapy and Research, 21, 647 662.

de Jong, P.J., Haenen, M-A., Schmidt, A. \& Mayer, B. (1998). Hypochondriasis: The role of fear-confirming reasoning. Behaviour Research and Therapy, 36, 6574.

de Jong, P.J., \& Vroling, M. (2005). Confirmatory reasoning style and psychopathology: The role of "belief bias" in the persistence of dysfunctional convictions. Research project at the university of Groningen, supported by the Netherlands Organization for Scientific Research (NWO).

Dolan, R.J. (2002). Emotion, cognition and behavior. Science, 298, 1191-1194.

Ehlers, A., Breuer, P., Dohn, D., \& Fiegenbaum, W. (1995). Heartbeat perception and panic disorder: Possible explanations for discrepant findings. Behaviour Research and Therapy, 33, 69-76.

Evans, J.St.B.T., \& Lynch, J.S. (1973). Matching bias in the selection task. British Journal of Psychology, 64, 391-397.

Eysenck, M.W. (1985). Anxiety and cognitive task performance. Personality and Individual Differences, 6, 579-586. 
Goel, V., \& Dolan, R.J. (2004). Differential involvement of left prefrontal cortex in inductive and deductive reasoning. Cognition, 93, B109-B121.

Goel, V., Gold, B., Kapur, S., \& Houle, S. (1997). The seats of reason: A localization study of deductive and inductive reasoning using PET (O15) blood flow technique. NewroReport, 8; 1305-1310.

Gioel, V., Shuren, J., Sheesley, L., \& Grafman, J. (2004). Asymmetrical involvement of frontal lobes in social reasoning. Brain, 127, 783-790.

Keinan, G. (1987). Decision making under stress: Scanning of altematives under physical threat. Acta Psychologica, 64, $219-228$.

Klayman, J., \& Brown, K. (1993). Debias the environment instead of the judge: An alternative approach to reducing error in diagnostic (and other) judgment. Cognition, 49, 97-122.

Marks, 1. M. \& Mathews, A. M. (1979). Brief standard self-rating for phobic patients. Behaviour Research and Therapy, 17, 263-267.

MacLeod, C., Rutherford, E., Campbell, L., Ebsworthy, G., \& Holker, L. (2002), Selective attention and emotional vulnerability: Assessing the causal basis of their association through the experimental manipulation of attentional bias. Journal of Abnormal Psychology, 111, 107-123.

McNally, R.J. (1998), Information-processing abnormalities in anxiety disorders: Implications for cognitive neuroscience. Cognition and Emotion, 12,479-495.

Nisbett, R.E., Fong, G.T., Lehman, D.R., \& Cheng, P.W. (1987). Teaching reasoning. Science, $238,625-631$

Noveck, I.A., Goel, V., \& Smith, K.W. (2004). The neural basis of conditional reasoning with arbitrary content. Cortex, 40,613-622.

Ỏhman, A., Erixon, G., \& Lofberg, I. (1975). Phobias and preparedness: Phobic versus neutral pictures as conditioned stimuli for human autonomic responses. Journal of Abnormal Psychology, 84, 41- 45.

Peterson, R.A., \& Reiss, R.L. (1987). The anxiety sensitivity index: Construct validity and factor analytic structure. Jownal of Anxiety Disorders, 1, 265-277.

Raine, A. (1991). Are lateral eye-movements a valid index of functional hemispheric asymmetries? British Journal of Psychology, 82, 129-135. 
Smeets, G., \& de Jong, P.J. (2005). Confirmatory reasoning in obsessive-compulsive and panic disorder: Belief bias over the course of treatment. Submitted for publication.

Spielberger, C.D., Gorsuch, R.L., \& Lushene, R.E. (1970). Manual for the State-Trait Anxiety Inventory. Palo Alto, CA: Consulting Psychologists Press.

Strack, F., \& Deutsch, R. (2004). Reflective and impulsive determinants of social behaviour. Personality and Social Psychology Review, 8, 220-247.

Tohill, J.M., \& Holyoak, K.J. (2000). The impact of anxiety on analogical reasoning. Thinking and Reasoning, $6,27-40$.

Wagner, A.D., Maril, A., Bjork, R.A., \& Schacter, D.L. (2001). Prefrontal contributions to executive control: fMRI evidence for functional distinctions within lateral prefrontal cortex. Neurolmage, 14, 1337-1347.

Wason, P.C. (1968). Reasoning about a rule. Quarterly Joumal of Experimental Psychology, 20, 273-281.

Wilson, T.D., Lindsey, S., \& Schooler, T.Y. (2000). A model of dual attitudes. Psychological Review, 107, 101-126.

Zenhausern, R. (1978). Imagery, cerebral dominance and style of thinking: A unified field model. Bulletin of the Psychonomic Society, 12, 381-384. 


\section{SAMENVATTING}

Observatie van menselijk gedrag leert ons dat we in ons dagelijks leven alles behalve vanuit een logische rationaliteit te werk gaan. Inschattings- en redeneerfouten zijn aan de orde van de dag. We maken ons er allemaal schuldig aan, we laten ons in de maling nemen door onze eigen cognitieve illusies. We schatten onze kansen verkeerd in en in onze redeneringen is de logica vaak ver te zoeken. Toch functioneren we ondanks alles doorgaans prima. Meestal is er genoeg tijd en gelegenheid om ons gedrag te corrigeren en onze beslissingen te herzien.

De vraag waarom mensen beoordelings- en redeneerfouten maken, terwijl ze tegelijkertijd goed in staat zijn om logisch te redeneren, wordt met name relevant wanneer redeneerfouten leiden tot systematisch disfunctioneel en onaangepast gedrag, zoals dat het geval is bij mensen met een psychische stoornis. Een groep mensen bij wie de ervaren dreiging in specifieke situaties per definitie niet in verhouding staat tot het reële, objectieve gevaar wordt gevormd door angstpatiënten. Volgens cognitief-psychologische onderzoekers is er bij mensen met angststoornissen sprake van gevaarschema's die de informatieverwerking overheersen. Deze gevaarschema's hebben een disfunctioneel karakter: ze stemmen niet overeen met de objectieve werkelijkheid en ze leiden tot onaangepast gedrag en negatieve emoties. De angstige overtuigingen van angstpatiënten zijn irrationeel, maar blijven ondanks de overvloedig aanwezige disconfirmerende informatie uit de buitenwereld hardnekkig voortbestaan. Gegeven het feit dat de gevreesde catastrofe zich nooit voordoet, dient de vraag zich aan waarom deze patiënten niet na verloop van tijd in de gaten krijgen dat hun overtuiging niet klopt.

Voor de hardnekkigheid van de irrationele cognities van angstpatiënten zijn inmiddels verschillende verklaringen geopperd die zich baseren op verstoorde informatieverwerkingsprocessen bij fobici. In eerste instantie 
waren deze verklaringen gericht op gestoorde waarnemings- en aandachtsprocessen. Vrij nieuw is de opvatting dat ongeldige deductieve redeneerstrategieën verantwoordelijk kunnen zijn voor de instandhouding van irrationele angst. Deze opvatting baseert zich met name op de bevinding dat disconfirmatie van de irrationele cognities van angstpatiënten leidt tot vermindering van angst. Disconfirmatie vormt namelijk de kern van cognitieve gedragstherapie, verreweg de meest effectieve behandeling van fobische angst. In de therapie leert de patiënt met de hulp van een therapeut, om op geleide van empirische toetsing in te zien dat zijn of haar overtuiging onjuist is en moet worden bijgesteld. De gedachte is nu dat angstpatiënten bij het zelfstandig doorlopen van de 'empirische cyclus' redeneerfouten maken, waardoor disconfirmatieve informatie helemaal niet, of onjuist wordt verwerkt. Het gevolg daarvan is dat er ongeldige conclusies worden getrokken en dat ongeldige overtuigingen niet worden bijgesteld.

Om bepaalde opvattingen te toetsen, moet men in staat zijn om de logische implicaties van nieuwe informatie af te leiden. Een fout die mensen echter vaak maken is dat ze zich daarbij laten leiden door de subjectieve geloofwardigheid van de informatie. Deze redeneerfout staat in de cognitieve psychologie bekend als belief bias. Belief bias verwijst naar de neiging van mensen om geloofwaardige informatie als logisch geldig en ongeloofwaardige informatie als niet geldig te beoordelen, ongeacht de daadwerkelijke logische status van informatie. Bij angstpatiënten zou een dergelijke confirmerende redeneerstijl kunnen leiden tot instandhouding van de fobische angst, omdat ongeldige opvattingen van de werkelijkheid niet worden gefalsificeerd.

In hoofdstuk 2 en 3 van dit proefschrift staat de vraag centraal of belief bias een verklaring kan bieden voor de hardnekkigheid van de disfunctionele opvattingen die een rol spelen bij angststoornissen en andere vormen van psychopathologie. In hoofdstuk 2 werd onderzocht of er bij gezonde proefpersonen een relatie bestaat tussen de mate van belief bias en hun scores 
op psychopathologie-vragenlijsten. Hoewel belief bias kon worden vastgesteld, werd er geen lineair verband gevonden tussen de mate van belief bias en de mate van psychopathologische klachten. De studie leverde dus geen ondersteuning voor de hypothese dat een algemene neiging om persoonlijke opvattingen eerder te bevestigen dan te ontkrachten een rol speelt bij het ontstaan van psychopathologie. In een poging te verklaren waarom er geen relatie werd gevonden tussen belief bias en de mate van psychopathologische klachten zijn er verschillende kanttekeningen bij deze studie geplaatst. Gezien de mogelijke tekortkomingen van de studie zou het te vroeg zijn om de hypothese geheel te verlaten dat belief bias een rol speelt bij de instandhouding van psychopathologische klachten.

In hoofdstuk 3 werd onderzocht of (i) angstpatiënten (i.e., patienten met paniekstoornis of dwangstoornis [OCD]) zich kenmerken door een algemeen versterkte belief bias, (ii) of versterkte belief bias zich beperkt tot het domein van de stoornis en (iii) of belief bias het behandelresultaat en terugval kan voorspellen. Uit de resultaten bleek dat alledrie de groepen belief bias vertoonden. Er werd geen bewijs gevonden voor een algemeen versterkte belief bias bij angstpatiënten. Domein-specifieke belief bias kon worden aangetoond bij paniekpatiënten, maar niet bij OCD-patiënten. Met betrekking tot behandeleffecten werd gevonden dat hogere niveau's van domeinspecifieke belief bias bij paniekpatiënten in sterke mate een beter behandelresultaat voorspelt. Een dergelijk verband werd niet gevonden bij patiënten met obsessief-compulsieve stoornis. Hoewel de behandeling in beide patiëntengroepen resulteerde in een significante daling van zelfgerapporteerde angst en psychopathologie, bleek belief-bias niet gevoelig voor effectieve behandeling. In tegenstelling tot paniekpatiënten waren hogere niveau's van domein-specifieke belief bias direct na afloop van de behandeling bij OCD-patiënten gerelateerd aan terugval in de ernst van de psychopathologische klachten 6 maanden later. Een dergelijke relatie deed 
zich niet voor met betrekking tot zelfgerapporteerde angst. De bevindingen van hoofdstuk 3 lijken de opvatting te ondersteunen dat angstpatiënten niet zozeer lijden aan redeneerstoornissen, maar dat de domeinspecifieke redeneerfouten die zij maken een normale consequentie zijn van hun persoonlijke overtuigingen. Hoewel het vooralsnog niet duidelijk is of belief bias een oorzaak of een bijprodukt van psychopathologie is, blijft overeind, dat wanneer er eenmaal sprake is van disfunctionele opvattingen, de realistische evaluatie van cruciale situaties en ervaringen zal worden verhinderd door belief bias, waardoor irrationele opvattingen in stand blijven.

Een tweede redeneerfout die kan bijdragen aan de instandhouding van irrationele angst en die centraal staat in hoofdtuk 4 en 5 betreft confirmatie bias. Confirmatie bias verwijst naar de neiging van mensen om selectief op zoek te gaan naar informatie die hun a priori opvattingen bevestigt. De fobogene overtuigingen van angstpatiënten hebben betrekking op potentiëel bedreigende situaties. In dergelijke situaties kan er sprake zijn van "gevaarssignalen" (e.g., "deze hartkloppingen zijn een teken van een naderende hartaanval") en van "veiligheidssignalen' (e.g., "deze hartkloppingen zijn onschuldig"). Het selectief zoeken naar informatie die de fobogene overtuigingen kan bevestigen, uit zich in de selectie van potentiëel verifiërende informatie bij gevaarssignalen en potentiëel falsificerende informatie bij veiligheidssignalen. Deze gevaarsbevestigende strategie wordt ook wel de "better safe than sorry"-strategie genoemd

Hoofdstuk 4 beschrijft een drietal experimenten waarin bij gezonde proefpersonen werd onderzocht of (i) men in bedreigende situaties selectief op zoek gaat naar potentieel gevaarsbevestigende informatie (ii) het kan worden uitgesloten dat irrelevante confounders de gevaarsbevestigende redeneerbias zouden kunnen verklaren en (iii) of de mate van subjectief ervaren dreiging gerelateerd is aan de mate van gevaarsbevestigend redeneren. In Experiment 1 moesten proefpersonen de geldigheid van veiligheidsregels ('als $\mathrm{p}$ dan veilig') 
en gevaarsregels ('als $\mathrm{p}$ dan gevaar') testen. Uit de resultaten bleek dat proefpersonen een gevaarsbevestigende strategie hanteerden. In het geval van veiligheidsregels selecteerden ze relatief vaak potentieel falsificerende kaarten, terwijl ze juist relatief vaak potentieel verifiërende kaarten selecteerden in het geval van gevaarsregels. In Experiment 2 werden de gevaars- en veiligheidsregels zodanig gemanipuleerd dat het relatieve aandeel van 'matching bias' (i.e., de selectie van die kaarten die overeenkomen met de informatie die genoemd wordt in de regel) als potentiële confounder kon worden onderscheiden van de gevaarsbevestigende redeneerstrategie. Ook in dit exeriment lieten de proefpersonen een gevaarsbevestigende redeneerstijl zien. Er werd geen bewijs gevonden voor de aanwezigheid van matching bias. In Experiment 3 werd de invloed van waargenomen dreiging op de mate van gevaarsbevestigend redeneren onderzocht. Hiertoe werd een hoge- en een lage dreigingsconditie gecreëerd. In beide condities vertoonden de proefpersonen een gevaarsbevestigende redeneerstijl. Ondanks het feit dat de hoge dreigingsconditie als significant bedreigender werd ervaren dan de lage dreigingsconditie, had dit verschil geen effect op de mate waarin de proefpersonen zochten naar confirmatie van het vermeende gevaar. Uit de resultaten kan men concluderen dat redeneren in het gevaarsdomein zich kenmerkt door een 'better safe than sorry'-strategie die doelgericht is, namelijk op het vermijden van gevaar. In objectief bedreigende situaties is een dergelijke strategie functioneel. Hoewel het vervelend kan zijn om regelmatig voor loos alarm te vluchten, kunnen de gevolgen catastrofaal zijn wanneer men slechts één keer een gevaarssignaal ten onrechte niet serieus neemt. Echter, wanneer de ervaren dreiging irrationeel is, zoals bij angststoornissen, verhindert een selectieve zoektocht naar potentiële bevestiging van het vermeende gevaar de correctie van de irrationele opvatting, waardoor de ongegronde angst blijft bestaan of zelfs wordt versterkt. 
In hoofdstuk 5 werd onderzocht of hypochondrische patiënten vergeleken met gezonde controlepersonen een sterkere gevaarsbevestigende redeneerstrategie vertonen en of deze strategie specifiek is voor het domein van de stoornis. Beide groepen vertoonden een gevaarsbevestigende strategie bij regels die betrekking hadden op algemene bedreigende situaties. Deze gevaarsbevestigende strategie was niet in versterkte mate aanwezig in de patiëntengroep. In tegenstelling tot de controlepersonen vertoonden de hypochondriepatiënten echter ook een gevaarsbevestigende strategie wanneer de regels betrekking hadden op gezondheidsbedreigende situaties. In overeenstemming met hoofdstuk 3 lijken deze bevindingen erop te wijzen dat angstpatiënten niet zozeer lijden aan redeneerstoornissen, maar dat de domeinspecifieke redeneerfouten die zij maken een normale consequentie zijn van hun persoonlijke overtuigingen. Hoewel deze redeneerfouten het gevolg zijn van een strategie die in daadwerkelijk bedreigende situaties uitermate functioneel kan zijn, verhinderen ze logischerwijs de disconfirmatie van de fobische overtuiging, waardoor de stoornis in stand kan blijven.

De derde onderzoekslijn in dit proefschrift heeft betrekking op de relatie tussen bepaalde denkstijlen, hemisfeer preferentie en angst. De meeste onderzoekers zijn het erover eens dat de linker hemisfeer betrokken is bij verbale, analytische en rationele processen, terwijl de rechter hemisfeer zich juist kenmerkt door een imaginaire, holistische en intuïtieve manier van informatieverwerking. Het idee dat de linker hemisfeer is betrokken bij rationele en analytische processen wordt ondersteund door recente onderzoeken waarin met beeldvormende technieken werd aangetoond dat tijdens deductieve redeneertaken specifiek de linker frontaal-temporale cortex wordt geactiveerd. De vaststelling dat de twee hemisferen gespecialiseerd zijn in verschillende aspecten van de informativerwerking heeft geleid tot het concept hemisfericiteit, hetgeen inhoudt dat mensen kunnen verschillen in de mate waarin ze zich kenmerken door een cognitieve stijl die kenmerkend is 
voor de linker, danwel de rechter hemisfeer. Hoewel de details nog steeds onderwerp van discussie zijn is er tegelijkertijd groelend bewijs voor de stellingname dat links-corticale gebieden betrokken zijn in toenaderingsgedrag en positief affect, terwijl rechter cortex een rol speelt bij vermijdingsgedrag en negatief affect. Volgens deze theorie zou een relatieve subactivatie van de linker hemisfeer en/of een overactivatie van de rechter hemisfeer bijdragen aan angstige gevoelens. Op basis van deze theorie stellen sommige onderzoekers dat angststoornissen gepaard zouden gaan met een habituele overactivatie van de rechter hemisfeer.

In hoofdstuk 6 werd de hypothese getoetst of paniekpatiënten zich kenmerken door een cognitieve stijl die typisch is voor de rechter hemisfeer en in aansluiting daarop, of zij een habituele overactivatie van de rechter hemisfeer vertonen. Paniekpatiënten en gezonde controles verschilden niet met betrekking tot hun cognitieve stijl. Beide groepen proefpersonen lieten een vergelijkbare variatie zien in de mate waarin ze een voorkeur hadden voor analytische, rationele denkstijlen versus imaginaire, intuittieve denkstijlen. Wel werd er ondersteuning gevonden voor de hypothese dat paniekstoornis wordt gekenmerkt door een habituele overactivatie van de rechter hemisfeer.

Hoofdstuk 7 geeft een samenvatting van de belangrijkste bevindingen van de studies van dit proefschrift. Voorts wordt er een poging gedaan om de bevindingen te integreren en worden er aanbevelingen gedaan voor toekomstig onderzoek. Hieruit komt naar voren dat er meer onderzoek nodig is dat inzicht geeft in de uitingsvormen van disfunctionele redeneerstrategieën bij psychopathologic. Meer kennis van redeneerfouten die specifiek bijdragen aan de instandhouding van irrationele angst zou tot een verdere aanscherping van bestaande cognitief-gedragstherapeutische interventies kunnen leiden. Tot slot wordt er geopperd dat een combinatie van neurobiologische en experimenteel psychopathologische onderzoeksmethoden een belangrijke vooruitgang in de wetenschappelijke kennis van emotionele stoornissen zou 
kunnen bewerkstelligen. Dergelijk onderzoek zou meer informatie op kunnen leveren over hoe emoties en informatieverwerking elkaar beĩnvloeden en op welke wijze de cognitieve ontregelingen die kenmerkend zijn voor psychopathologie zich in de hersenen manifesteren. 


\section{DANKWOORD}

Een proefschrift schrijven is onmogelijk zonder de steun van anderen. Ook ik ben veel mensen dank verschuldigd. Mensen zonder wie dit proefschrift er niet was gekomen.

In de eerste plaats gaat mijn dank uit naar mijn eerste promotor, Peter de Jong. Peter, ik heb veel van je geleerd. Als de resultaten van een studie in mijn ogen weer eens tegenvielen, wist je er altijd weer een zinvolle betekenis aan te geven. Hoewel ik je denktempo tijdens onze discussies zelf vaak niet kon bijbenen, kwam ik na enige tijd steeds weer tot de conclusie dat je hypothesen doordrenkt waren van de jou kenmerkende scherpte en visie. Ik zie je als een 'experimentele-psychopathologie-onderzoeker' van ongekend formaat. Jouw niveau zal ik nooit bereiken, daar heb ik me bij neergelegd. Veel dank vooral ook voor je geduld. Als je eerste promovendus was ik zeker niet de makkelijkste. Mijn beslissingen stonden vaak haaks op je advies. Het was geen 'labbekakkerigheid' noch pure stijfkoppigheid van mijn kant. Ik denk dat we gewoon erg verschillen. Je had het zelf zeker anders gedaan, maar je bleef me steunen. Arnoud Arntz, het was goed om relativerende woorden te horen van iemand die ik als een authoriteit op het vakgebied zie. Je ontnam me mijn twijfels over mezelf en over het welslagen van het project door mijn disfunctionele opvattingen hierover ter discussie te stellen. Dat gaf me vetrouwen en de moed om door te gaan. Ondanks het feit dat je het zelf ook vreselijk druk had, kon ik altijd bij je terecht voor advies. Dank daarvoor. Peter Muris, buurvriend en collega. Je hebt me er doorheen gesleept, al was het maar met je supersnelle feedback op vele versies van mijn manuscripten. Onze gesprekken over het onderzoek waren voor mij erg waardevol.Vooral de luchtigheid waarmee je kijkt naar het vak van onderzoeker spreekt me aan. Je 
bent voor mij het bewijs dat een goed onderzoeker ook nog de nodige humor en zelfspot kan hebben. Dat vind ik een benijdenswaardige eigenschap. Marcel van den Hout, de passie waarmee je met onderzoek bezig bent en de inspirerende wijze waarop je erover praat zullen me altijd bijblijven. Je bent een groot voorbeeld voor me. Dank.

Toen ik in 1997 begon als AiO bij DMKEP (toen nog DEP), brak er een fijne tijd voor me aan. Het was een leuke, enthousiaste en jonge club. Mijn dank gaat uit naar al mijn ex-collega's van DMKEP. Een paar van die collega's hebben voor mij een bijzondere bijdrage geleverd aan die fijne tijd en zijn inmiddels goede vrienden. Birgit Mayer, buurvriendin, ik ben blij dat ik je tegengekomen ben. De mailtjes en de soepies in de pauzes waren 'great', de films in Lumière en de wijntjes erna super. Fijn dat je zo vaak naar me wilde luisteren en dat nog steeds doet. Ik ga ook graag gauw weer met je squashen, maar dan moet je me wel een keer laten winnen, 'if not, then not'. Sandra Mulkens, ik ben vaak in de lach geschoten als ik weer een mail van je kreeg. Mijn voormalige kamergenoten, eerst Anja Meijboom, later Anneke van Brakel. Wat hebben we veel gepraat. Over de zin van het leven en wat belangrijk is. Onderzoek kwam voor ons bij lange na niet op de eerste plaats. Anja, de gesprekken met jou waren 'AiO-peners' voor mij. Anja en Anneke, het was erg gezellig om met jullie een kamer te delen. Dank voor de vriendschap en de fijne tijd.

Een aantal mensen dank ik voor de hulp die ik van ze heb gehad bij het onderzoek en de promotie. Om te beginnen de patiënten die hebben deelgenomen aan mijn studies. $Z$ ij hebben mij geholpen op een moment dat ze zelf hulp nodig hadden. I hoop dat ik hun vertrouwen niet heb geschaad. Ook de 'gezonde' proefpersonen ben ik dank verschuldigd. Verder de onderzoeksassistenten van RIAGG-Maastricht voor de vele metingen die ze 
hebben verricht in het kader van één van mijn studies. Marga van den Oever en Herman Snijders voor de dataverzameling bij twee experimenten. Nicole Dormanns, je hebt je weer van je beste kant laten zien door belangenloos al het 'geregel' van de promotie-aanvraag op je te nemen. Mijn dank is groot. Mijn twee paranimfen en vrienden, Peter Verheijen en Marcel Adriaanse. Dank dat jullie bij de plechtigheid achter me willen staan in een toch nietalledaags tenue. Dank ben ik ook verschuldigd aan Chantal van Wunnik, Erik Schouten, Dré Bosma, Henk van der Molen, Angela Verweij en Herbert Hoijtink voor hun morele, organisatorische, statistische en/of inhoudelijke ondersteuning.

Een speciaal woord van dank will ik richten aan mijn ouders. Pap en mam, jullie hebben altijd in me geloofd. Vaak meer dan ik in mezelf. Zonder jullie was ik er niet, dankzij jullie heb ik kunnen studeren en dankzij jullie sta ik nu hier. Als ik nooit arrogant wordt is dat mede dankzij jullie. Ik ben blij dat jullie er zijn.

Tot slot, lieve Ellen, lieve Hidde. Mijn geluk zijn jullie. Ellen, je bent mijn steun en toeverlaat en nog zoveel meer. Hidde, mijn trots. Laten we eindeloos genieten van het leven! 
$\therefore$

a

a $\quad \therefore$ 


\section{CURRICULUM VITAE}

Guus Smeets werd geboren op 5 november 1967 in Sittard. Na zijn Atheneum- $\beta$ aan het Bisschoppelijk College te Sittard, startte hij in 1987 met de opleiding Solozang aan het Maastrichts Conservatorium. In 1990 ontving hij in het kader van het culturele verdrag tussen Nederland en Hongarije een beurs om gedurende 9 maanden onderwijs te volgen aan de Franz Liszt Academie te Boedapest. Bij terugkomst in Nederland in 1991, besloot hij om naast zijn muziekopleiding te beginnen met een studie Gezondheidswetenschappen aan de Universiteit Maastricht. In $\ 995$ behaalde hij zijn doctoraal diploma Gezondheidswetenschappen, met als afstudeerrichting Geestelijke Gezondheidkunde (GGK). Zijn scriptie, getiteld 'Hemisfeer preferentie en paniek' schreef hij onder begeleiding van Prof.dr. Harald Merckelbach en Prof.dr. Eric Griez. Na zijn afstuderen werkte hij korte tijd als wetenschappelijk assistent en junior gedragstherapeut aan het Academisch Angstcentrum te Maastricht, onder supervisie van Prof.dr. Eric Griez.

In april 1996 startte Guus Smeets met een baan als universitair docent aan de Open Universiteit Nederland. Een jaar later besloot hij deze functie te combineren met een parttime functie als assistent in opleiding (AiO) bij het departement Medische, Klinische en Experimentele Psychologie van de Universiteit Maastricht. Tijdens zijn AiO-periode volgde hij de onderzoekersopleiding van de landelijke onderzoeksschool Experimentele Psychopathologie (EPP). In 2001 behaalde hij het 'European Certificate in Anxiety and Mood Disorders'.

In 2002 werd Guus Smeets aangsteld als universitair docent en programmacoördinator van de opleiding Geestelijke Gezondheidkunde (GGK) aan de Universiteit Maastricht, waar hij zich o.a. bezighield met de omvorming van het bestaande doctoraalprogramma GGK naar de Bachelor- 
Master structuur. Daarnaast werd hij in datzelfde jaar als inhoudscoördinator en hoofddocent wetenschappelijk onderzoek van de postdoctorale beroepsopleiding Klinisch Psycholoog-BIG gedetacheerd aan RINO Zuid Nederland.

Sinds juni 2004 is Guus Smeets werkzaam als universitair docent voor de opleiding psychologie van de Erasmus Universiteit Rotterdam. Deze functie combineert hij nog steeds met zijn werkzaamheden voor de opleiding Klinisch Psycholoog-BIG van RINO Zuid Nederland. 


\section{PUBLICATIES}

\section{Wetenschappelijke publicaties}

Adriaanse, M., \& Smeets, G. (1994). Het project 'Begeleid wonen oostelijk Zuid-Limburg': Een onderzoek naar de bekendheid bij verwijzende instanties. Maastricht, Universitaire Pers Maastricht

Smeets, G., Merckelbach, H. \& Griez, E. (1997). Panic Disorder and RightHemisphere Reliance. Anxiety, Stress and Coping, 10, 245-255.

Smeets, G. (1998). Emotions and Deductive Reasoning: Etiological and Maintaining Factor in Psychopathology. Lecture at the Conference of the Dutch Association of Behavioural Therapy, November 1998.

Smeets, G., \& De Jong, P. (1999). Reasoning Strategies and Anxiety. Symposizm at the $29^{\text {th }}$ Anmual Congress of the EABCT. Dresden, Germany, 1999.

Smeets, G., \& De Jong, P. (1999). Belief Bias in Anxiety Disorders: Maintaining Factor in Psychopathology? Lecture at the $29^{\text {th }}$ Annual Congress of the EABCT. Dresden, Germany, 1999.

Smeets, G. (1999). 'Als een moedervlek jeukt, dan is het huidkanker': Doelrationaliteit en de instandhouding van irrationele angst. $D e$ Psycholoog, 12, 554-559.

Smeets, G., De Jong, P.J. (2000). The role of belief-bias in anxiety disorders. Lecture at the $30^{\text {th }}$ annual Congress of the EABCT. Granada, Spain, 2000.

Smeets, G., De Jong, P.J., \& Mayer, B. (2000). If you suffer from a headache, then you have a brain tumour: Domain-specific reasoning "bias" and hypochondriasis. Behaviour Research and Therapy, 38, 763-776. 
Smeets, G. \& De Jong, P.J.; (2001). Deductive Reasoning bias and the persistence of dysfunctional beliefs. Symposium at the World Congress of Behovioural and Cognitive Therapies. Vancouver, Canada 2001.

Smeets, G., De Jong, P.J. (2002) Threat-confirming reasoning 'bias' in panic disorder. Lecture at the $32^{\text {nd }}$ Annual Congress of the EABCT, Maastricht, The Netherlands, 2002.

Smeets, G., De Jong, P.J. (2005). Domain-specific reasoning in hypochondriasis: The effect of perceived threat on confirmation bias. In preparation.

Smeets, G. \& De Jong, P.J. (2005). Belief Bias and Symptoms of Psychopathology in a Non-Clinical Sample. Cognitive Therapy and Research, 29, 377-386

Smeets, G., De Jong, P.J., \& Mayer, B. (2004). Better safe than sorry: Reasoning with conditionals in the context of threat. (Submitted)

\section{Boeken}

Smeets, G., Bögels, S.M., Molen, H.T., van der, \& Arntz, A. (Eds.), (1999). Klinische Psychologie: Diagnostiek en Therapie. Groningen / Heerlen: Wolters Noordhoff / Open Universiteit Nederland

\section{Onderwijs-uitgaven}

Smeets, G. (1997). Intelligentie en Sociale Competentie, Practicumhandleiding. Heerlen, Open Universiteit Nederland Smeets, G., (Red.), (1999). Klinische Psychologie 2: Diagnostiek en behandeling. Cursus / Werkboek. Heerlen: Open Universiteir Nederland Mayer, B. \& Smeets, G. (Red.), (2002). Klinische Psychologie 3: De ambulante praktijk. Cursus / Werkboek. Heerlen: Open Universiteit Nederland. 
